\title{
MULTIPLE RECEIVER WIRELESS POWER CHARGER FOR MOBILE ELECTRONIC DEVICES IN NEAR FIELD
}

by

Khadijat Hassan

A thesis submitted to the Department of Electrical and Computer Engineering In conformity with the requirements for the degree of Masters of Applied Science

\author{
Queen's University \\ Kingston, Ontario, Canada
}

(January, 2017)

Copyright @Khadijat Hassan, 2017 


\begin{abstract}
Portable consumer electronics like mobile phones, laptops, tablets and other devices have flooded the markets these days. While providing the convenience of keeping in touch with friends and family at the touch of a button, or performing complex scientific computations of a physical system, these devices have become an essential part of everyone's day-to-day lives. In order to keep them up and running at all times, they need electrical energy, which in most cases is stored in the batteries of these devices. These batteries have limited storage capacity and life-time. For these reasons, portable device users have to carry wired chargers all the time which can be an inconvenience and limits accessibility. Hence, there is a need for an alternative method of charging these devices.

Wireless power transfer provides a viable solution to the challenges encountered by portable device consumers when using the traditional method of charging batteries.

This thesis presents a multiple receiver wireless power transfer system for charging mobile phone batteries. The circuit consists of a transmitter and two receiver systems. A mathematical analysis of the circuit is carried out and simulated to understand its behavior with variation in coupling coefficient and load. In order to charge the mobile phones without an extra communication module over a wide range of coupling coefficients, a variable frequency control algorithm is used. The transmitter circuit uses the algorithm to track the maximum input power of the system. The output voltage of the receiver circuit is controlled to meet the power requirement of the load as coupling coefficient varies by using a switch capacitor modeled as two back to back connected MOSFETs with their drain-tosource capacitance.
\end{abstract}


The proposed converter circuit topology is simulated and the results are presented. The circuit operates over a wide range of coupling coefficient, with good voltage regulation. Zero voltage switching (ZVS) is achieved at the inverter switches and the power requirement of the mobile phones are met without use of an extra communication module. The resonance frequency of the circuit is $5.7 \mathrm{MHZ}$ and it is design to deliver $10 \mathrm{~W}(5 \mathrm{~V}, 2 \mathrm{~A})$ each to two mobile phones. 


\section{Acknowledgements}

I would like to express my appreciation to my supervisor Dr. Praveen Jain and cosupervisor Dr. Shangzhi Pan, for their patience, encouragement, support and constructive criticism all through my graduate studies. It has been a great privilege working with them.

I would like to thank Snehal Bagawade, Housein Mousavain and all my other colleagues at ePOWER laboratory for their support and encouragement all through my studies. I am glad to have met you all! I would like to thank Jeananne Vickery for her love and encouragement all through my program. I would also like to thank all ECE staff for their relentless assistance.

I would like to thank my friends Fatma, Judith, Harir, Maryam, Habiba, Bashir, Philip, Soliat, Zainab, Ajoke, Hauwa, Tansha, Cong and others to mention a few that always put a smile on my face and encouraged me through my journey to self-discovery.

I would like to appreciate my parents Alh. Abdullateef and Rahmatu Hassan, my siblings Rilwan, Abdulazeez and their spouses for their love, prayers and encouragement. I would like to show my profound gratitude to my loving husband Sheriff and daughter Amal for their unending love, encouragement and most of all their patience all through my studies at Queen's University.

Finally, the financial support received from Natural Science and Engineering Research Council (NSERC), Ontario Research Fund and Queen's University is highly appreciated. 


\section{Table of Contents}

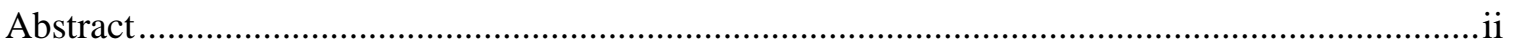

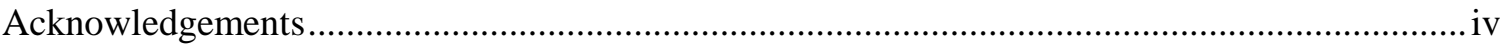

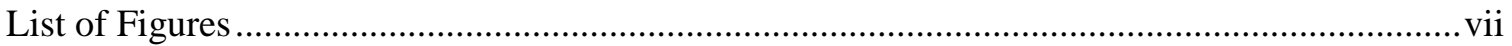

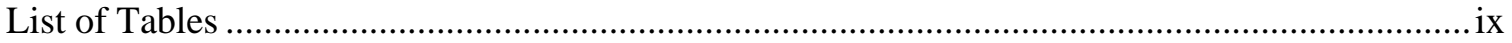

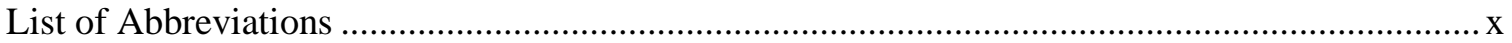

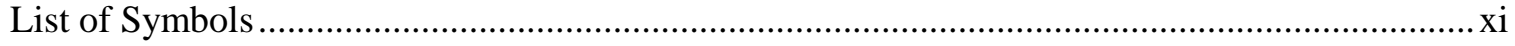

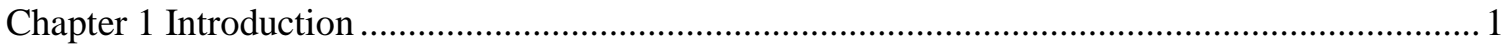

1.0 History of Wireless Power Transfer................................................................................. 1

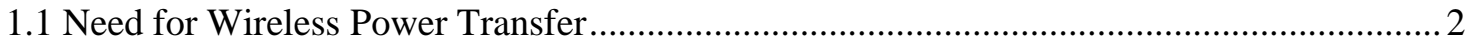

1.2 Basic Structure and Classification of Wireless Power Transfer ........................................... 3

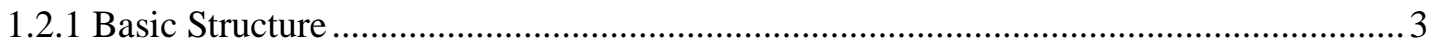

1.2.2 Classification of Wireless Power Transfer.......................................................................... 3

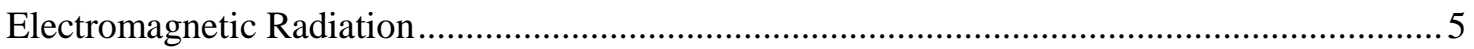

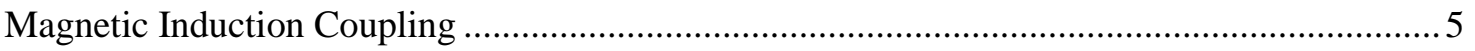

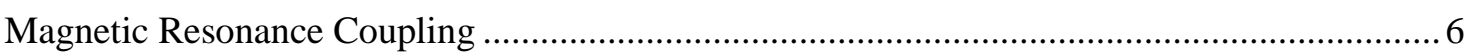

1.4 Benefits, Application and Challenges of Wireless Power Transfer ...................................... 8

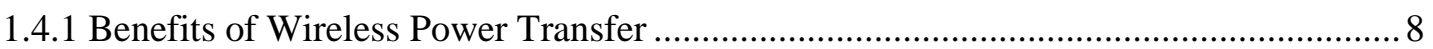

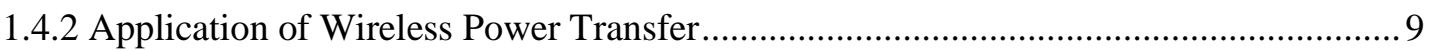

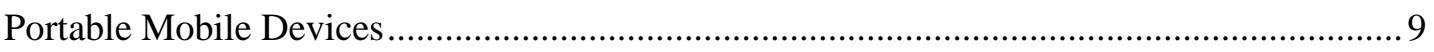

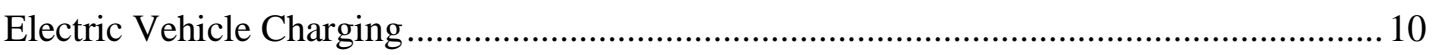

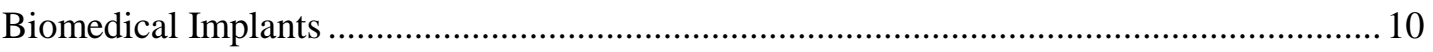

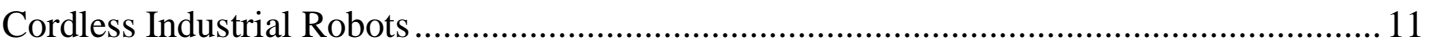

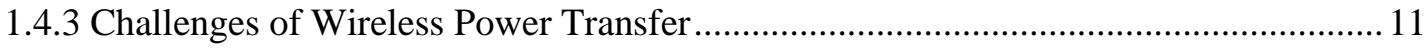

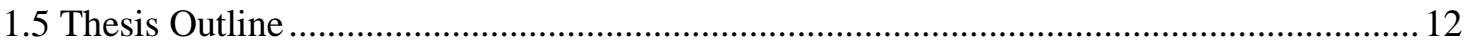

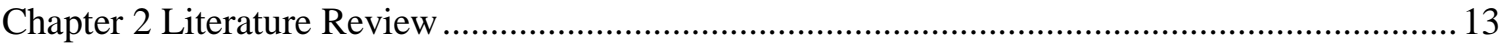

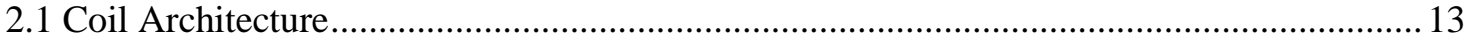

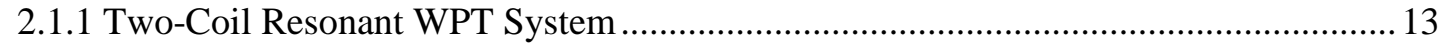

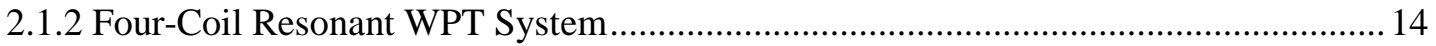

2.2 Methods for Improving WPT System Performance ........................................................ 15

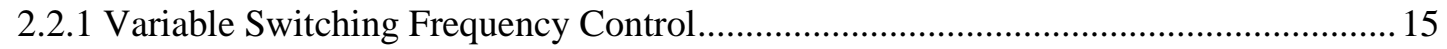

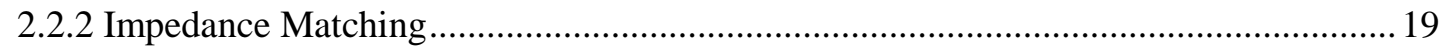

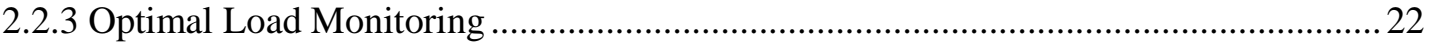




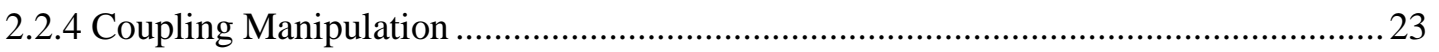

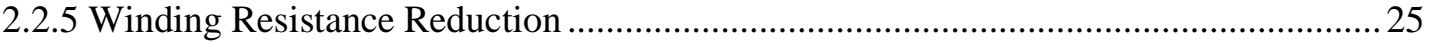

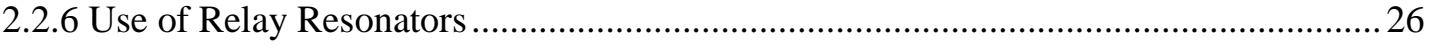

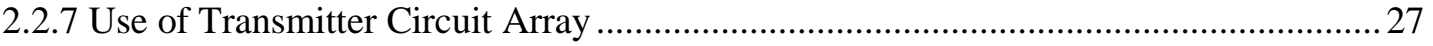

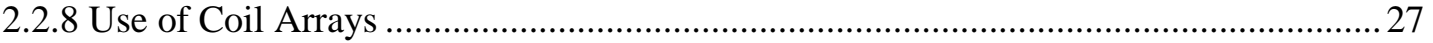

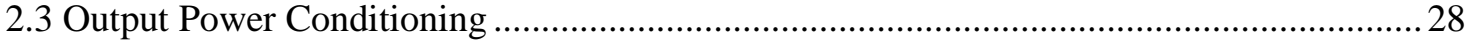

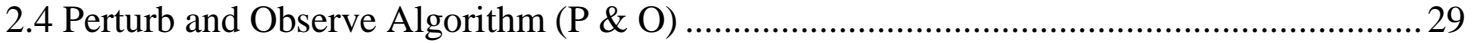

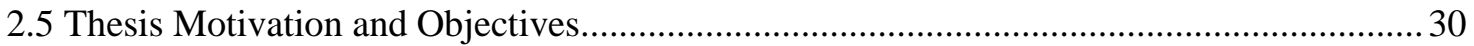

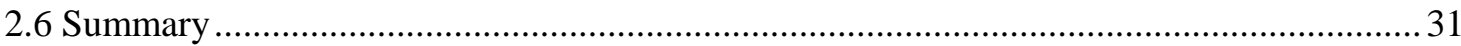

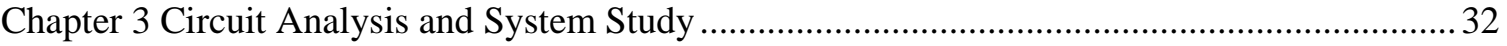

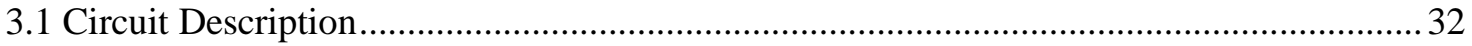

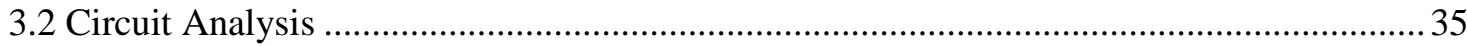

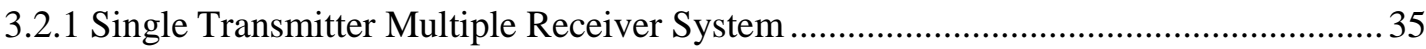

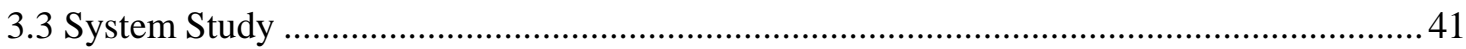

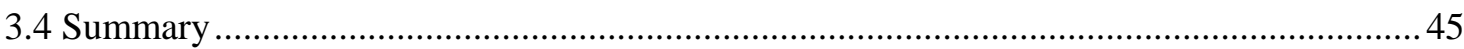

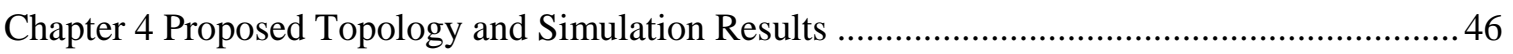

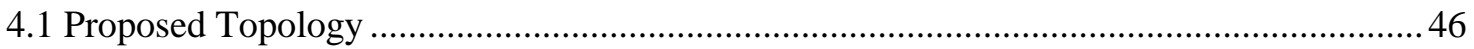

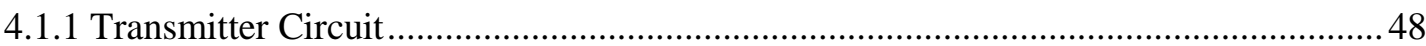

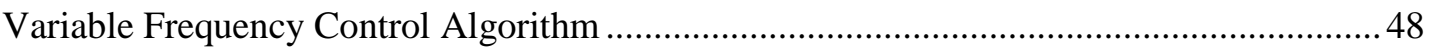

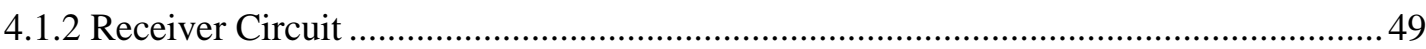

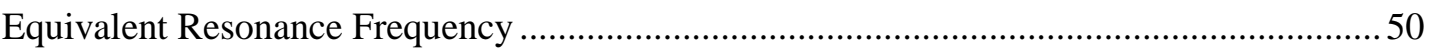

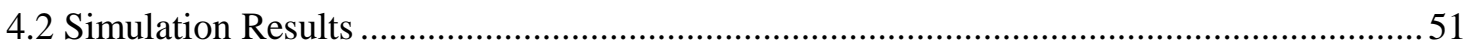

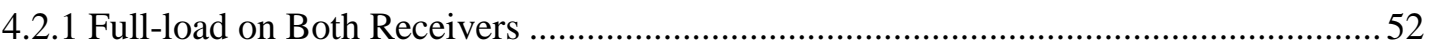

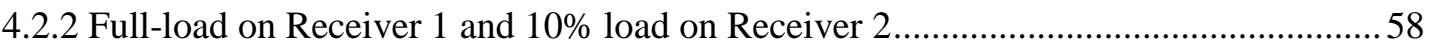

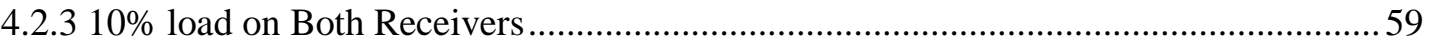

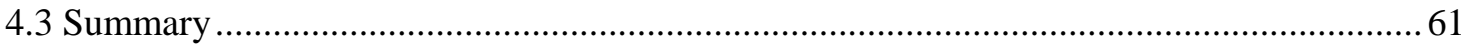

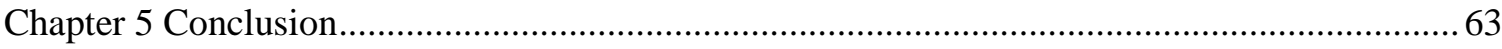

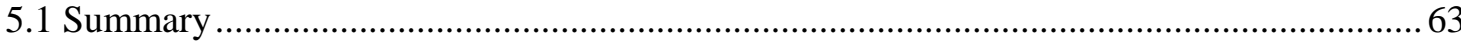

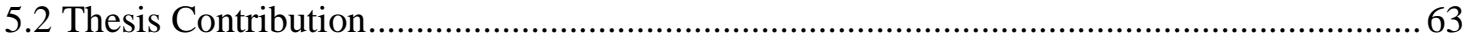

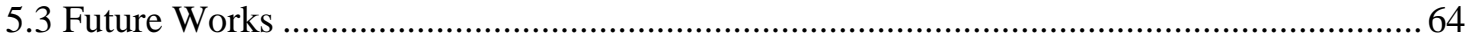

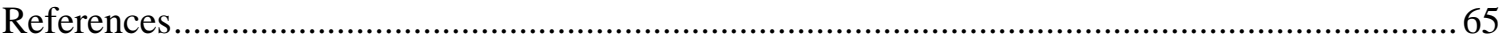




\section{List of Figures}

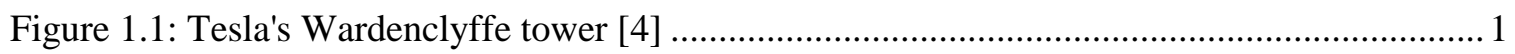

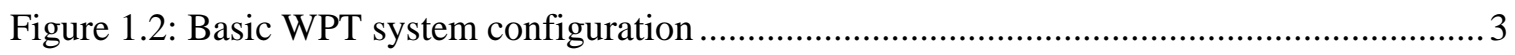

Figure 1.3: Classification of wireless power transfer .................................................................. 4

Figure 1.4: Exponential decay curve of the efficiency as a function of transmission distance for

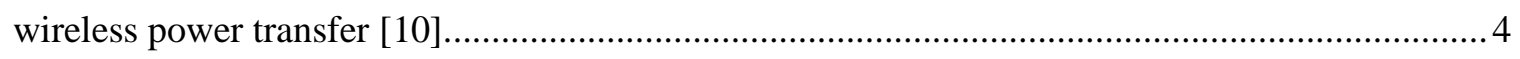

Figure 1.5: Electromagnetic radiation wireless power transfer [16] .......................................

Figure 1.6: Magnetic inductive coupling model [16]............................................................. 6

Figure 1.7: Magnetic resonance wireless power transfer system [16] ........................................ 7

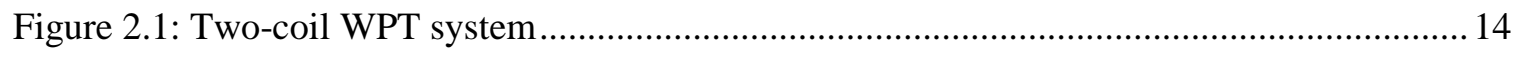

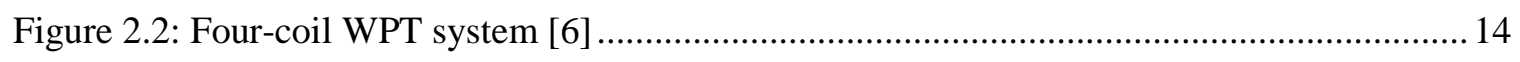

Figure 2.3: Block diagram of WPT with adaptive frequency tracking [23] ............................... 17

Figure 2.4: Block diagram of the wireless power charging pad system for multiple devices [24] 18

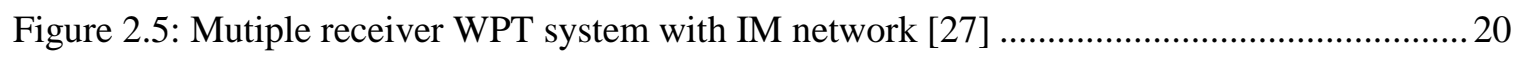

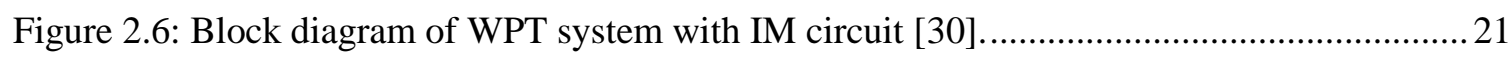

Figure 2.7: Block diagram of system for tracking optimal load [5] ..........................................22

Figure 2.8: Wireless power transfer system for mobile devices using rotating system [35] ........24

Figure 2.9: Loop switching wireless power transfer system[36] .............................................25

Figure 2.10: Magnetic resonance WPT with relay resonators [41] .........................................2

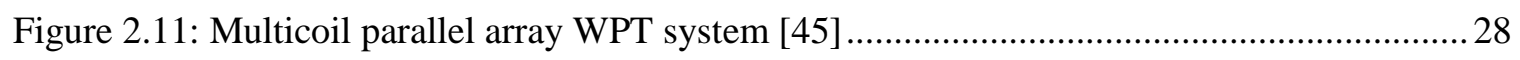

Figure 2.12: Diagram of basic dc-dc converter topologies used in WPT: (a) boost-buck [5], (b)

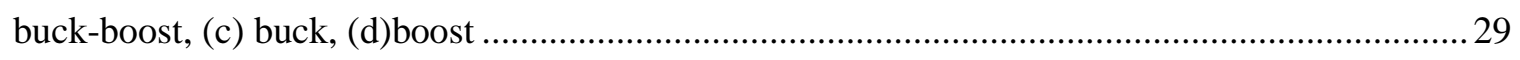

Figure 3.1: Circuit diagram of a multiple receiver WPT system. ............................................. 33

Figure 3.2: Waveforms of the multiple receiver WPT system................................................... 34

Figure 3.3: Equivalent circuit diagram of a multiple receiver WPT system................................. 35

Figure 3.4: Variation in efficiency for different values of coupling coefficient ............................ 41

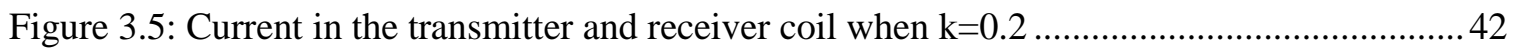

Figure 3.6: Output power against frequency for different values of coupling co-efficient ...........42

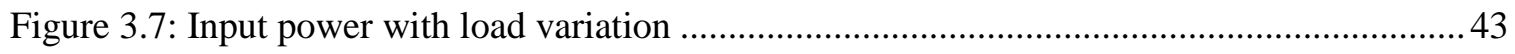

Figure 3.8: Input impedance against the relative operating frequency for different values of coupling coefficient. 
Figure 3.9: Input power against the relative operating frequency for different values of coupling coefficient.

Figure 3.10: Phase angle against the relative operating frequency for different values of coupling

coefficient. .44

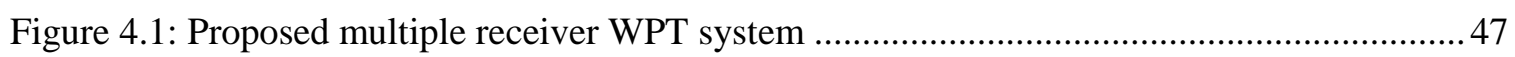

Figure 4.2: Equivalent circuit diagram of proposed WPT system when switch is off.................. 47

Figure 4.3: Flow chart of the proposed variable frequency algorithm......................................49

Figure 4.4: (a) Transmitter resonant tank input voltage and current, (b) dc output voltage and (c)

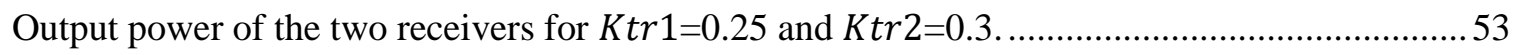

Figure 4.5: (a) Transmitter resonant tank input voltage and current, (b) dc output voltage and (c)

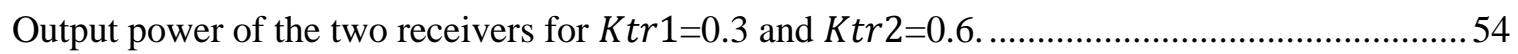

Figure 4.6: (a) Transmitter resonant tank input voltage and current, (b) dc output voltage and (c) Output power of the two receivers for $K \operatorname{tr} 1=0.5$ and $K \operatorname{tr} 2=0.52$. .

Figure 4.7: (a) Transmitter resonant tank input voltage and current, (b) dc output voltage and (c)

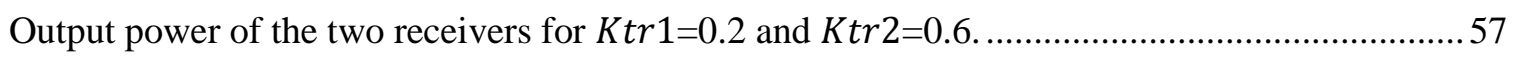

Figure 4.8: Total output power with variation in coupling coefficient .......................................58

Figure 4.9: (a) Transmitter resonant tank input voltage and current, (b) dc output voltage and (c)

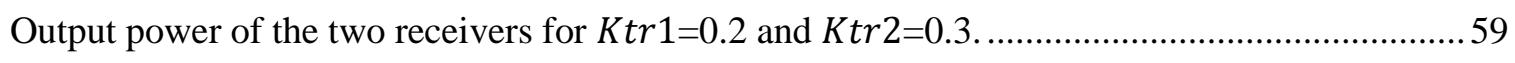

Figure 4.10:(a) Transmitter resonant tank input voltage and current, (b) dc output voltage and (c)

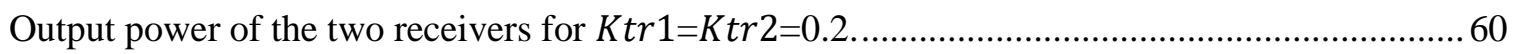




\section{List of Tables}

Table 1.1: Comparison of Different Wireless Power Transfer Modes [14].................................. 7

Table 4.1: Circuit Component Value .......................................................................................51

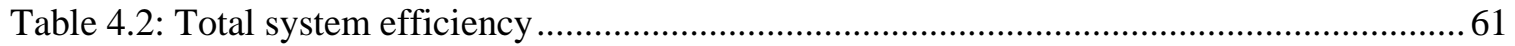




\section{List of Abbreviations}

\begin{tabular}{ll} 
WPT & Wireless Power Transfer \\
SCMR & Strongly Coupled Magnetic Resonance \\
EM & Electro Magnetic \\
RF & Radio Frequency \\
LF & Low Frequency \\
HF & High Frequency \\
LOS & Line-Of-Sight \\
IM & Impedance Matching \\
EV & Electric Vehicle \\
AC & Alternative Current \\
DC & Direct Current \\
MIT & Massachusetts Institute of Technology \\
RMS, rms & Root-Mean-Square \\
PWM & Pulse Width Modulation \\
ZVS & Zero Voltage Switching \\
PA & Power Amplifier \\
MOSFE & Perturb and Observe \\
IEEE & Institute of Electrical and Electronics Engineers \\
PSim & Powide Semiconductor Field Effect Transistor \\
\hline &
\end{tabular}




\section{List of Symbols}

In this thesis, lower case symbols $\mathrm{v}$ and $\mathrm{i}$ represent instantaneous values of voltage and current that are function of time. Upper case symbols $\mathrm{V}$ and $\mathrm{I}$ represent the average values in dc quantities and rms values in ac quantities.

$\begin{array}{ll}\omega_{o} & \text { Operating frequency } \\ \omega_{t o t a l} & \text { Equivalent resonance frequency } \\ \omega_{t x} & \text { Resonance frequency of transmitter } \\ \omega_{r x} & \text { Resonance frequency of receiver } \\ \omega & \text { Relative operating frequency } \\ \Phi & \text { Phase angle of input impedance } \\ E_{i} & \text { DC input voltage of inverter } \\ S_{1}, S_{2} & \text { Switches of the half bridge inverter } \\ C_{t x} & \text { Internal capacitance of the transmitter coil } \\ L_{t x} & \text { Inductance of the transmitter coil } \\ R_{t x} & \text { Parasitic resistance of the transmitter coil } \\ C_{r x} & \text { Internal capacitance of the receiver coil } \\ L_{r x} & \text { Inductance of the receiver coil } \\ R_{p} & \text { Parasitic resistance of the receiver coil } \\ C_{d s} & \text { Drain to source capacitance of the MOSFETS of the switch } \\ M_{t r 1}, M_{t r 2} & \text { capacitor } \\ M_{r 12} & \text { Mutual coupling between the transmitter and receivers } \\ & \end{array}$




\begin{tabular}{|c|c|}
\hline $\mathrm{d}$ & Duty cycle \\
\hline$C_{\text {total }}$ & Equivalent series resonance capacitance of the receiver \\
\hline$v_{\text {in }}$ & Input voltage of series resonant tank \\
\hline$R_{a c}$ & Equivalent ac resistance of the load \\
\hline$R_{L}$ & Load resistance \\
\hline$v_{r x 1}, v_{r x 2}$ & Voltage induced by the receivers of the transmitter \\
\hline$v_{t x}$ & Voltage induced on receivers by the transmitter \\
\hline$v_{r 12}$ & Voltage induced by the receivers on each other \\
\hline$v_{n l}$ & No-load voltage \\
\hline$v_{f l}$ & Full-load voltage \\
\hline$v_{o}$ & Output voltage \\
\hline$K_{t r 1}$ & Coupling coefficient between the transmitter and receiver 1 \\
\hline$K_{t r 2}$ & Coupling coefficient between the transmitter and receiver 2 \\
\hline$Q_{r x}$ & Quality factor of the receiver \\
\hline$Q_{t x}$ & Quality factor of the transmitter \\
\hline$\eta$ & Total system efficiency \\
\hline$P_{\text {out }}$ & Total output power \\
\hline$P_{\text {in }}$ & Input power \\
\hline$P_{\max }$ & Maximum input power \\
\hline$P_{\text {loss }}$ & Total power loss \\
\hline$K_{r 12}$ & Coupling coefficient between receivers \\
\hline$I_{t x}$ & Transmitter coil current \\
\hline$I_{r x}$ & Receiver coil current \\
\hline
\end{tabular}




$\begin{array}{ll}Z_{\text {in }} & \text { Total input impedance } \\ I_{o} & \text { Output dc current } \\ f_{o} & \text { Operating frequency }(\mathrm{MHz}) \\ f_{o_{-} \min } & \text { Minimum operating frequency }(\mathrm{MHz}) \\ f_{o_{-} \max } & \text { Maximum operating frequency }(\mathrm{MHz}) \\ \mathrm{N} & \text { Turns ratio } \\ L_{m} & \text { Magnetizing inductance }\end{array}$




\section{Chapter 1}

\section{Introduction}

\subsection{History of Wireless Power Transfer}

Wireless power transfer started in the early nineteenth century when Nicole Tesla who is referred to as the father of wireless power started the construction of the Wardenclyffe Tower in Shoreham, Long Island as shown in figure 1.1. The tower was intended to be used for broadcast and wireless transmission of power to all parts of the world. Tesla was able to successfully light 200 florescent lamps without the aid of wires at a distance of 25 miles from the source [1]. However, his research was not widely applied due to limitation in radio-wave technology, cost effective power conditioning devices and low demand. Advancement in power electronics in terms development of devices with fast switching speed, high efficiency and high power handling capabilities has rekindled the interest of researchers in wireless power transfer [2].

In 2007 a team of researchers from MIT headed by Professor Marin Soljacic came up with the concept of witricity and were able to transfer $60 \mathrm{~W}$ of power over a distance of 2 meters with $40 \%$ efficiency via strongly coupled magnetic resonance (SCMR) [3]

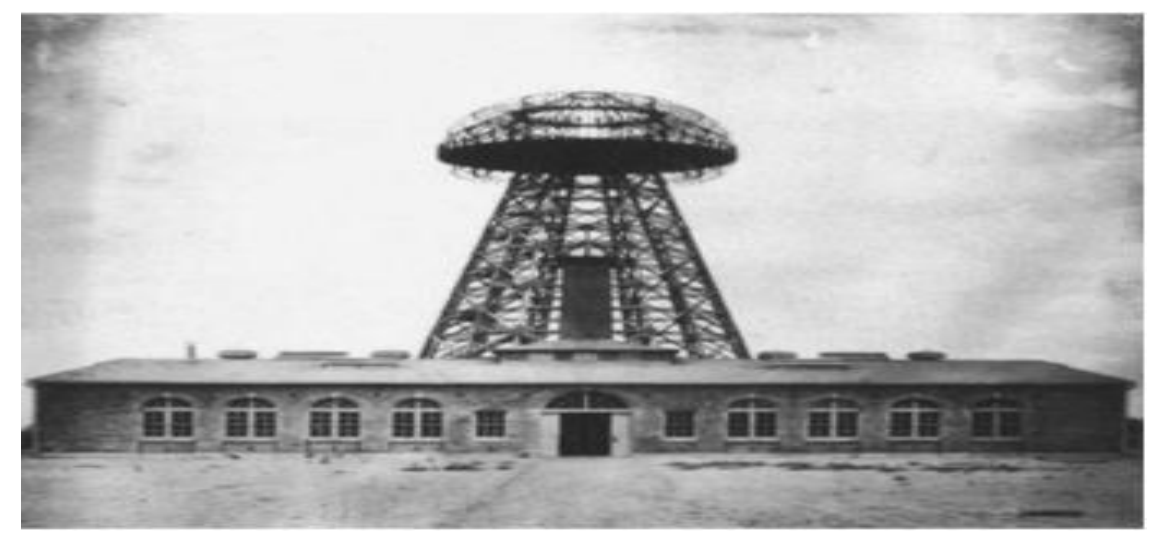

Figure 1.1: Tesla's Wardenclyffe tower [4] 


\subsection{Need for Wireless Power Transfer}

The widely used method of power transfer is conduction through a closed circuit using electrical cables. The major problems faced by this conventional method are accessibility, safety and the rise in electrical power demand due to the unprecedented increase in the production of portable electronic devices such as laptop computers, iPads and mobile phones.

Portable devices use batteries, which are known to have limited storage capacity, slow charge rate, weight, lifetime, power density and cost. Wireless power transfer can serve as a possible solution to these challenges in the absence of improved battery technology [5]. Also, the need for frequent charging of the batteries has led to an increased production of mobile wired chargers with an unattended effect on the environment due to industrial effluents associated with the manufacturing and disposal of the wired chargers. Hence, a need for wireless power transfer which is a more environmentally friendly way to provide the power required by these devices. Also, as consumer electronics manufacturers are trying to make their devices portable, connectors are becoming a large portion of the device. Wireless power transfer provides an opportunity for connector-free devices, which could enhance size, reliability and flexibility [6].

Finally, Advancement in biomedical engineering in terms of development of implanted devices such as pacemakers, neural simulators and endoscopes has prompted the need for wireless power transfer due to the difficulty and danger involved in putting cables through the skin [7], [8]. 


\subsection{Basic Structure and Classification of Wireless Power Transfer}

\subsubsection{Basic Structure}

Wireless power transfer systems have a common configuration regardless of the method of power transfer. The system includes; a power source, power converter, coupling system, rectifier, power regulation circuit and a load as shown in figure 1.2.

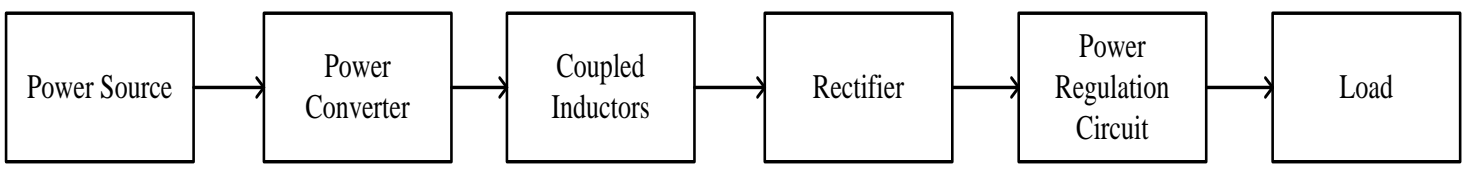

Figure 1.2: Basic WPT system configuration

The power source supplies the converter with the required voltage and a high frequency alternating current is produced by the converter in the transmitter which then flows through the transmitter coil in the coupled system to generate an alternating magnetic field. The time varying magnetic field cuts across the receiver coil to induce a voltage in the coil which is rectified by the rectifier. The power regulation circuit is used to regulate the power according to the needs of the load [9].

\subsubsection{Classification of Wireless Power Transfer}

Wireless power can be broadly classified into two, namely:

- Near-field magnetic coupling: Near field coupling is a non-radiative wireless power transfer which is sub-divided into short range and mid-range applications. In short-range application, the distance between the power source and the load is less than the dimension of the coil resonators while in mid-range application, the transmission distance is greater than the dimension of the coil resonators. 
- Far-field magnetic coupling: Far- field coupling is a radiative wireless power transfer that involves the transmission of microwaves from an antenna via a medium (air or vacuum) over a distance several times the dimension of the antenna [47].

Figure (1.3) and figure (1.4) illustrates the classification of WPT and the effect of transmission distance on the efficiency respectively

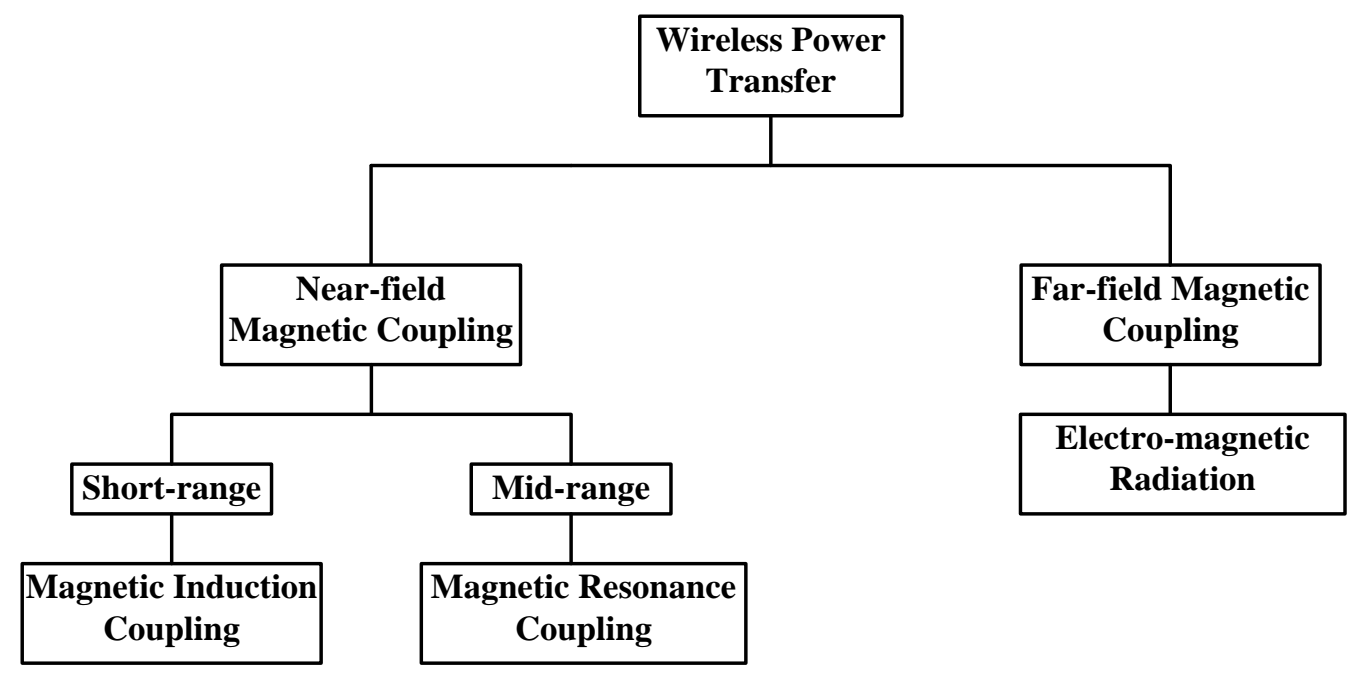

Figure 1.3: Classification of wireless power transfer

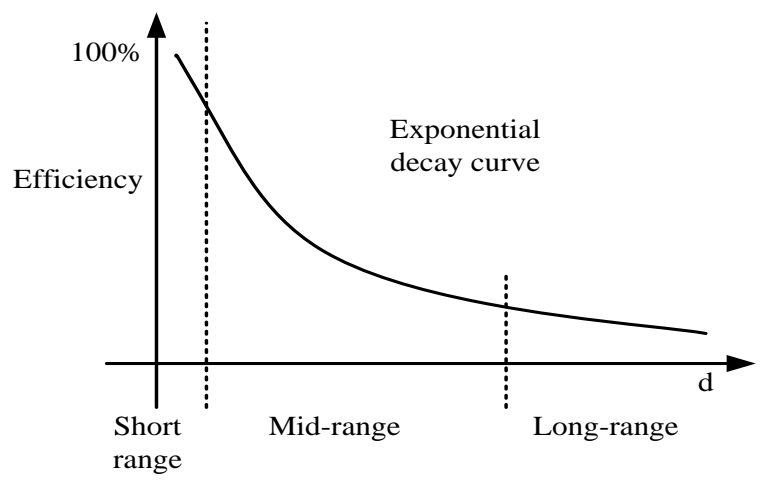

Figure 1.4: Exponential decay curve of the efficiency as a function of transmission distance for wireless power transfer [10]. 


\section{Electromagnetic Radiation}

Electromagnetic radiation is a far-field wireless power transfer method; electrical energy is converted into microwaves which are propagated through vacuum or air to the rectenna (rectifier and antenna) at the receiver. The rectenna receives and convert the microwaves to electrical energy. Electromagnetic radiation is appropriate for transmitting information but it is not suitable for power transfer due to high losses during transmission, sensitivity to obstacles and its effect on biological organisms [11]. It also requires large antennas to concentrate the microwave beams. Figure 1.5 shows how electromagnetic radiation WPT is used.

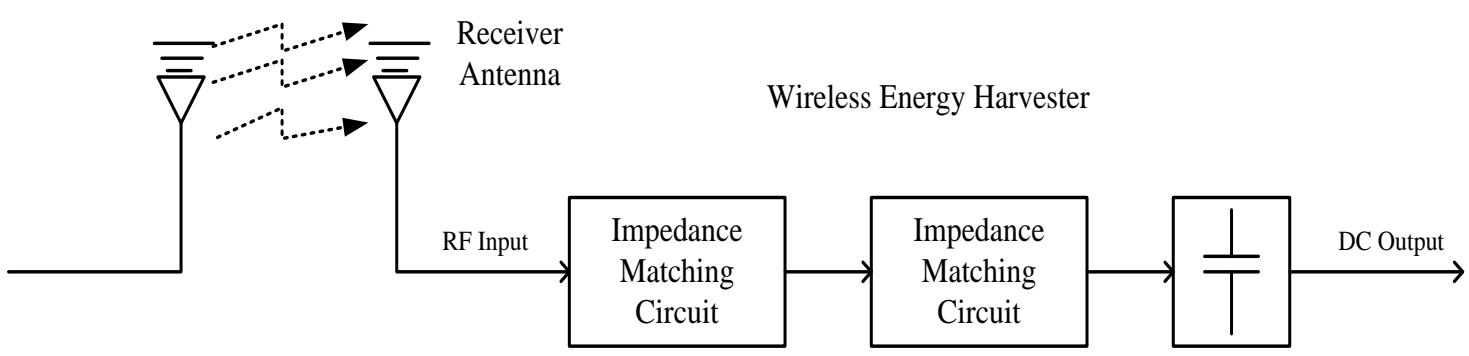

Figure 1.5: Electromagnetic radiation wireless power transfer [16]

\section{Magnetic Induction Coupling}

Magnetic inductive coupling is built on the principle magnetic field induction which is used to transfer electrical energy between a transmitting and receiving coil. It is a non-radiative near-field wireless power transfer method that operates at a distance less than the dimension of the resonators. In this method, a varying magnetic field is created at the source which induces a voltage across the receiving coil and hence, power is delivered to the load [7]. It is used in applications that require short transfer distance (in millimeter range), high efficiency and power [12]. In magnetic inductive coupling the source and the 
receiving devices are tuned to resonate using external capacitors [13]. The efficiency of this method is highly sensitive to coil misalignment and dependent on the strength of coupling between the coils. Figure 1.6 shows a magnetic induction coupling model.

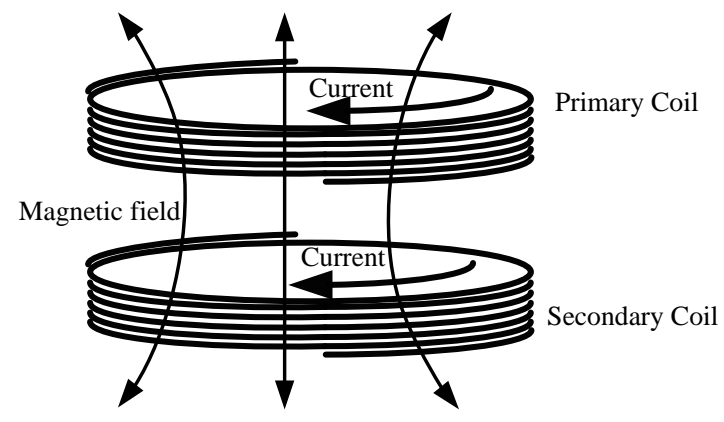

Figure 1.6: Magnetic inductive coupling model [16]

\section{Magnetic Resonance Coupling}

Magnetic resonance coupling is a non-radiative near-field wireless power transfer method that operates at a distance more than the dimension of the resonators. In magnetic resonance coupling, an alternating magnetic flux is created in a transmitter coil which is converted to electrical current at the receiver coil. The source and the receiving devices are tuned to resonate using at the same natural frequency. It is used in applications where transfer distance of a few meters is required. The transferred power and efficiency in this method is lower compared to magnetic inductive coupling [12]. The efficiency is dependent on the strength of coupling between the coils and their quality factor. Major considerations in the design of coils used in magnetic resonance wireless power transfer are power level, the quality factor, coil geometry, including size and weight, the coupling parameters and the operating frequency [14]. Magnetic resonance WPT systems operates in the megahertz frequency range because the parasitic capacitance of the coil is used in 
tuning the circuit. Therefore, the quality factor of the coils is high and it helps to reduce the negative effect of low coupling coefficient on the efficiency of the system. The quality factor in magnetic inductive coupling WPT is usually below 10 and the transfer efficiency plunges with decrease in coupling coefficient [15]. This method has the ability to support multiple receivers, requires no line-of-sight (LOS), less sensitive to surrounding environment, and delivers power with more efficiency than far-field method and longer distance than inductive coupling. Figure 1.7 shows a magnetic resonance coupling model.

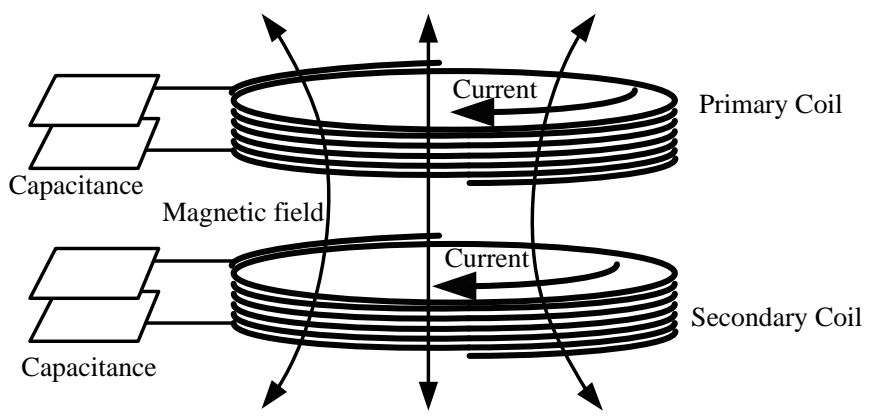

Figure 1.7: Magnetic resonance wireless power transfer system [16]

Table 1.1: Comparison of Different Wireless Power Transfer Modes [14].

\begin{tabular}{l|l|l|l|l}
\hline WPT Method & Operating & Range & Advantages & Disadvantages \\
& frequency & & & \\
Electromagnetic & RF-band (GHZ & Medium and & Long charging & Unsafe for \\
range) & long (Tens of & distance & biological \\
& meters to & several & organisms. \\
& & & & Low efficiency. \\
& & & & Easily affected \\
\end{tabular}




\begin{tabular}{|c|c|c|c|c|}
\hline $\begin{array}{l}\text { Magnetic } \\
\text { Induction }\end{array}$ & $\begin{array}{l}\text { LF-band } \\
\text { (hundreds of } \\
\text { KHZ) }\end{array}$ & $\begin{array}{l}\text { Very short } \\
(\mathrm{mm} \text { to } \mathrm{cm})\end{array}$ & $\begin{array}{l}\text { Safe for } \\
\text { biological } \\
\text { organisms. } \\
\text { Easy to } \\
\text { implement. } \\
\text { High } \\
\text { efficiency. }\end{array}$ & $\begin{array}{l}\text { High sensitivity } \\
\text { to } \\
\text { misalignment. } \\
\text { Short charging } \\
\text { distance. } \\
\text { Heating of } \\
\text { surrounding } \\
\text { materials }\end{array}$ \\
\hline $\begin{array}{l}\text { Magnetic } \\
\text { Resonance } \\
\text { Coupling }\end{array}$ & $\begin{array}{l}\text { HF-band } \\
\text { (MHZ range) }\end{array}$ & $\begin{array}{l}\text { Short }(\mathrm{cm} \text { to } \\
\mathrm{m})\end{array}$ & $\begin{array}{l}\text { Can be used to } \\
\text { charge multiple } \\
\text { devices. } \\
\text { Less sensitive } \\
\text { to } \\
\text { misalignment }\end{array}$ & $\begin{array}{l}\text { Difficult to } \\
\text { implement. } \\
\text { Restricted } \\
\text { charging } \\
\text { distance. }\end{array}$ \\
\hline
\end{tabular}

\subsection{Benefits, Application and Challenges of Wireless Power Transfer}

\subsubsection{Benefits of Wireless Power Transfer}

- Accessibility and Convenience: WPT makes power available to portable electronics users everywhere from coffee shops to libraries. They do not have to carry chargers which makes this technology more convenient.

- Safe: The advent of WPT has helped to improve the safety of mobile device users because they no longer have to come in contact with the electrical mains. This will reduce the risk of electrocution which is a major concern in conventional power supply. 
- Portability: WPT is bringing about the possibility for manufacturers to achieve miniaturization of devices which is normally impossible when a device requires conventional cable connection to charge the battery. This technology also makes the device lighter in weight.

- Cost: If the efficiency and the amount of power that can be obtained from WPT is improved, it will be more economical to install WPT systems in buildings since only a few electrical sockets will be needed on the walls.

- Environmentally Friendly: WPT promises to be environmentally friendly on a logrun because it will significantly reduce the quantity of cables and batteries that are been produced. Hence, the amount of industrial effluents generated from the production and disposal of the batteries and cables will be greatly reduced.

\subsubsection{Application of Wireless Power Transfer}

The emergence of portable electronic devices, mobile robots, biomedical implants and electric vehicles which all use rechargeable batteries has further emphasized the need for alternative methods of replenishing the batteries. Wireless power transfer offers a safe, convenient and accessible alternative to the conventional wired charging of the batteries. Applications of WPT are as follows:

\section{Portable Mobile Devices}

The twenty-first century as experienced a rapid increase in the production of portable consumer electronics such as laptops, iPads, and mobile phones. These devices make use of batteries which have limited charge capacities and hence require frequent 
charging. Therefore, consumers have to move around with their chargers all the time. In most cases this is not convenient as they may not have access to a power source. They are also stand a high risk of electrocution because of their frequent contact with the electrical mains. Wireless power transfer is a viable solution that can provide power to these devices while ensuring user convenience and safety.

\section{Electric Vehicle Charging}

Electric vehicle (EV) charging is one of the most widely researched areas of the application of wireless power transfer because of the rapid growth in the use of eco-friendly hybrid vehicles. Electric vehicles use rechargeable batteries as a means of power supply but the storage capacity, cost and lifetime of the batteries poses a major challenge to this technology. Though, commercialized Lithium-ion batteries are commonly used in electric vehicles nevertheless its energy density is $90-100 \mathrm{Wh} / \mathrm{kg}$ which is low compared to gasoline with energy density of $12000 \mathrm{Wh} / \mathrm{kg}$. Therefore, for an EV to operate like a combustion engine, it will require many batteries which would be heavy and expensive. EVs also require long charging time and risk of electrocution makes it unattractive to drivers [17]. Wireless power transfer offers a possible means of mitigating these challenges as the EVs will no longer need large battery banks because they can recharge their batteries while in motion. WPT also reduces the driver's risk of electrocution.

\section{Biomedical Implants}

Biomedical implants such as pacemakers, neural simulators and endoscopes used to monitor internal organs of the human body are becoming prevalent in the medical field. However, this technology is faced with a major challenge of powering the devices in the body because of limitation in size of the device and risk involved. The batteries account 
for most part of the size. Wireless power transfer can help reduce the size of the batteries since they can be recharged internally as required without putting the patients at risk.

\section{Cordless Industrial Robots}

Recent advancement in robot technology has made the use of industrial robots in manufacturing plants common. Robots are preferred to humans in manufacturing processes because they are said to be cheaper, precise, consistent, safer, faster and can work in hazardous environments. Most industrial robots rely on rechargeable batteries for power as they cannot be conveniently powered from an electrical main. These batteries have limitations in terms of lifetime, size and charge capacity. Wireless power transfer is a possible solution to these challenges as the robots can carry fewer batteries and be charged conveniently as required.

\subsubsection{Challenges of Wireless Power Transfer}

WPT is a relatively, new power transfer technology that is currently facing a lot of challenges ranging from system analysis, through technical implementation to cost. The traditional transformer circuit is easier to analyze compared to WPT circuit due to the loose coupling between the coupling systems. Adequate compensation and control must be considered in the analysis of the circuit. In addition, successful implementation is largely dependent on advancement in power electronics in aspects of development of high speed semi-conductor devices and control.

Finally, WPT is not widely used because the transfer power and efficiency of the system is low considering the fact that the cost of installation, operation and maintenance of a WPT system is much higher than the traditional power supplies [18]. 


\subsection{Thesis Outline}

This thesis is made up of five chapters. Chapter one provides a brief history about WPT. Also, conventional power supply for mobile phone charging, the challenges currently faced and the need for WPT are discussed. In addition, the chapter explains the methods used in WPT, comparison of the methods and the applications of WPT.

Chapter two provides an overview of previous researches that have been done to solve the problems associated with WPT. The motivation and objectives of the thesis is also outlined.

Chapter three provides a mathematical analysis of the WPT system. The analysis is simulated using MATLAB to give a graphical understanding of the circuit behavior in the presence of load and coupling coefficient variation.

Chapter four gives a detailed explanation of the proposed topology. The topology is simulated using PSIM and the results are presented to verify that the thesis objectives are met with the proposed topology.

Finally, Chapter five concludes the thesis by giving the summary of the proposed topology, briefly stating the contributions made and future works that can be done to improve the WPT system are suggested. 


\section{Chapter 2}

\section{Literature Review}

Wireless power transfer systems are expected to provide constant output voltage while maintaining considerable level of efficiency. Nevertheless, change in coupling coefficient and load adversely affects the output voltage and efficiency of the system [19].The coupling coefficient depends on the proximity of the transmitter to the receiving device and the impedance of the load depends on the state of charge of the battery. As a result of the large air gap in WPT systems, they have large leakage inductance, small magnetizing inductance and poor coupling coefficient. Large magnetizing current flows through the transmitter system due to small magnetizing inductance making the overall system efficiency low [20]. The essence of this chapter is to give an overview of the research that has been carried out to improve the operation of wireless power transfer systems in terms of increasing transfer distance, efficiency and delivering the required output voltage to the load in presence of load and coupling variations.

\subsection{Coil Architecture}

The widely used coil structures in WPT are the two and four coil structure. These structures are briefly explained as follows:

\subsubsection{Two-Coil Resonant WPT System}

The two-coil system is made up of the transmitter and receiver coils that resonate at the same frequency to transfer power. The transmitter input is usually a high frequency inverter. Even though the two-coil structure is sensitive to change is distance between the 
coils, it is easier to implement in portable consumer electronic devices [14]. Therefore, in this thesis the two-coil approach will be used. Figure 2.1 show the two-coil system.

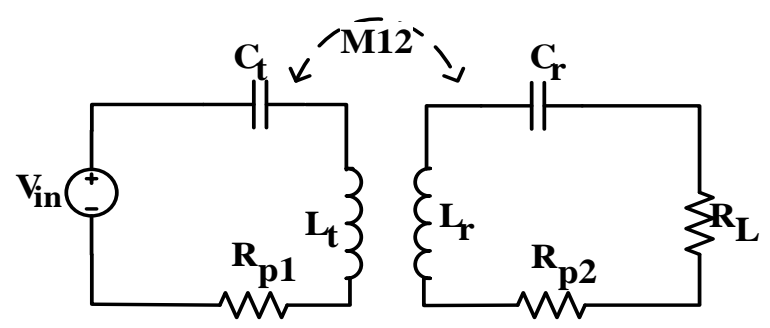

Figure 2.1: Two-coil WPT system

\subsubsection{Four-Coil Resonant WPT System}

The system consists of a power loop, transmitter coil, receiver coil and load loop as shown in figure 2.2. External capacitors are connected to the drive and load loop to make them resonate at same frequency as the transmitter and receiver coils. The coupling coefficient $k_{12}$ (between power loop and transmitter coil) and $k_{34}$ (between receiver coil and load loop) are kept constant. $k_{23}$ (between the transmitter and receiver coil) is varied with change in distance. Although, the four-coil structure is less sensitive to change in distance between the transmitter and receiver circuit, it requires more space, which makes it unsuitable for portable electronic devices [14].

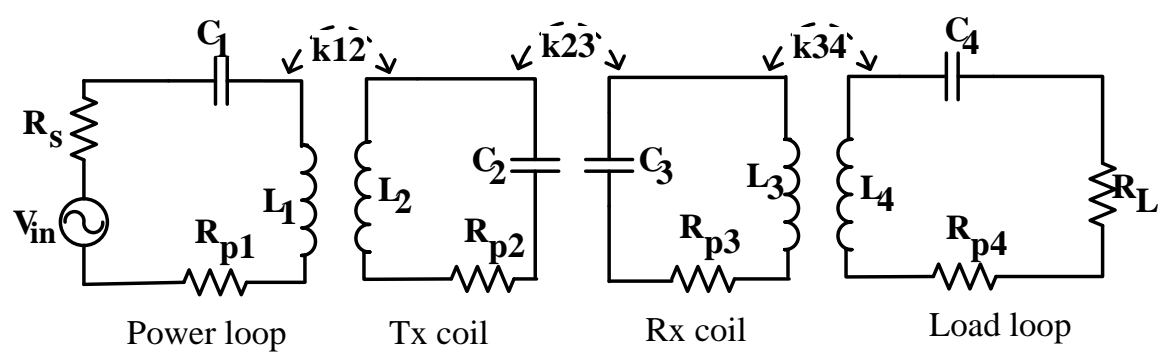

Figure 2.2: Four-coil WPT system [6] 


\subsection{Methods for Improving WPT System Performance}

Change in position of WPT resonant coupled systems is unavoidable in most cases. Therefore, researchers have proposed various methods of improving power transfer and efficiency of WPT systems in the presence of system constraints such as change in coupling coefficient and load. These methods are discussed in this section.

\subsubsection{Variable Switching Frequency Control}

In WPT systems, there is resonant frequency at which maximum power transfer efficiency is achieved. Change in coil position affect the extent of coupling between the coils which results in sub-resonant peaks thereby causing a reduction in the efficiency and power transfer capability. Therefore, there is a need to constantly track the frequency at which the system can work properly.

The concepts of under-coupling, critical coupling and over-coupling need to be explained to understand the need for variable switching frequency control.

- Critical coupling: A system is critically coupled when the coupling coefficient is equal to a value below or above which power cannot be delivered to the load at maximum efficiency.

- Under coupling: A system is under-coupled when the coupling coefficient is below the critical coupling value. The power transfer efficiency drops rapidly with increase in distance.

- Over coupling: A system is over-coupled when the coupling coefficient is above the critical coupling value [6]. In the over-coupled region, the resonant frequency splits into a low and high frequency mode. It is preferable to operate the WPT 
system within the critically coupled to the over-coupled region in order to deliver the required power to the load by selecting the appropriate operating frequency.

In [21], the authors mentioned the possibility of using resonant frequency tracking in multiple receiver wireless power transfer systems but did not implement it. In [22] the authors proposed the use of variable frequency control to provide maximum power to the loads of a universal WPT system for charging multiple electronic devices. The transmitter consists of several parallel connected transmitting coil that independently charge the loads. Communication interfaces were used to enable exchange of information about the status of the system such as frequency. This approach makes the system more complicated because it requires more transmitter coils and an extra communication module to exchange information between the transmitter and the electronic devices. Also, the WPT system is designed to work under a fixed coupling coefficient and so it cannot be used in applications where coupling coefficient variation is needed.

An adaptive frequency and power level tracking system with was proposed in [23] to efficiently deliver the required amount of power to a load on the receiver. The system consists of several functional blocks for frequency tracking, power level tracking and wireless communication as shown in figure 2.4. Magnetic resonance coupling was used to transfer power from the transmitter to the receiver. The frequency tracking block was used to sweep the operating frequency to determine the optimum frequency. A dc-dc converter was used to ensure that the required powers is delivered to the load. A wireless communication link was used to send information on the power delivered at the receiver to the transmitter. In this way, the power transfer efficiency is monitored. A new frequency sweep is carried out to select the optimum operating frequency whenever the power transfer 
efficiency is below the reference value. This idea was applied to a single receiver system only and can be complex for a multiple receiver system since it requires an extra communication module on both the transmitter and receiver circuits.

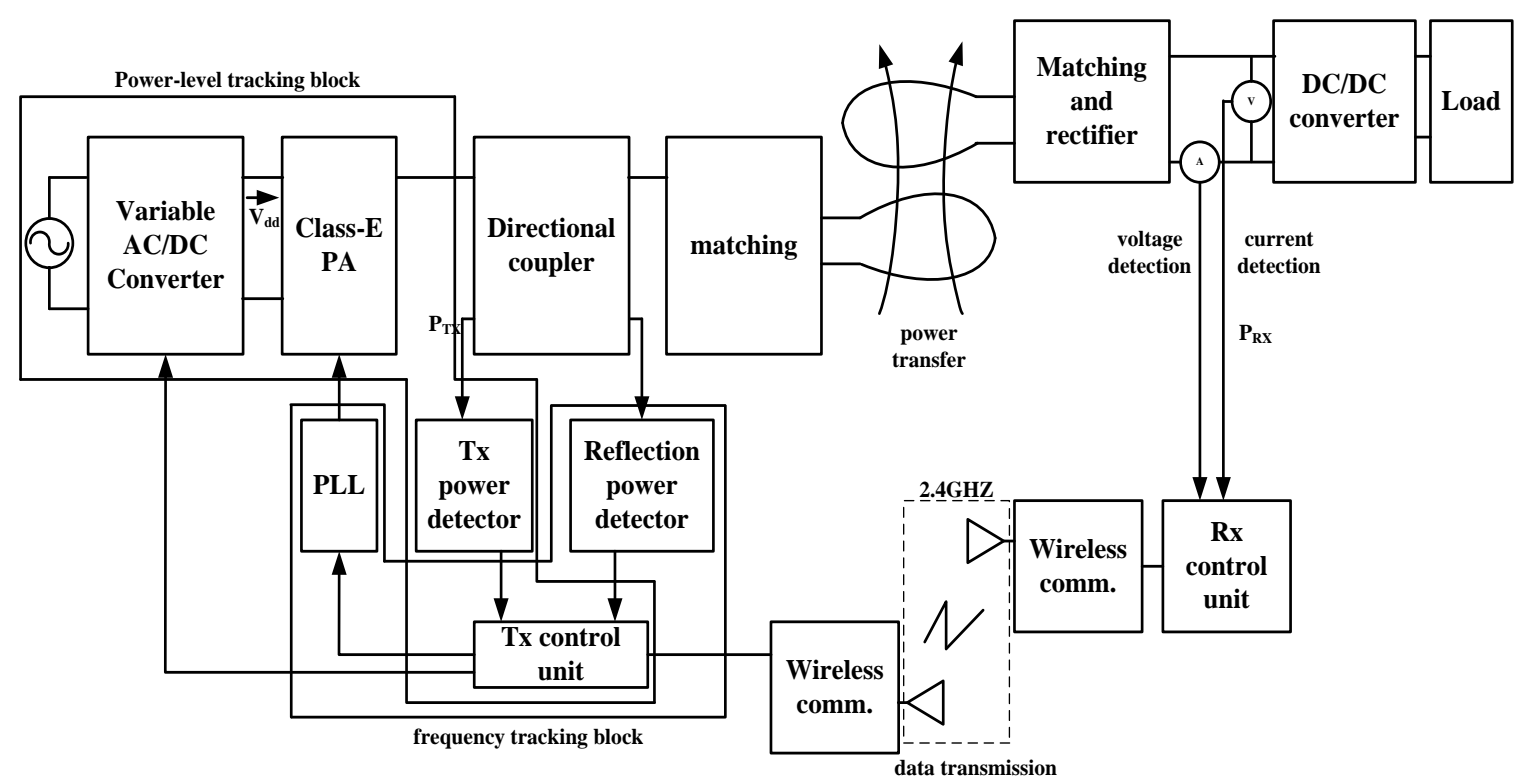

Figure 2.3: Block diagram of WPT with adaptive frequency tracking [23]

In [24] a magnetic resonance based wireless charging pad for multiple mobile devices was proposed. The WPT system consists of a transmitter and several receiver modules as shown in figure 2.4. A power tracking method whose functions are in-built in the ac-dc converter was used to control the input voltage of the RF power amplifier in the transmitter. The supply voltage of the RF power amplifier is controlled according to the information about the load on the receiver by adjusting the operating frequency of the inverter. 


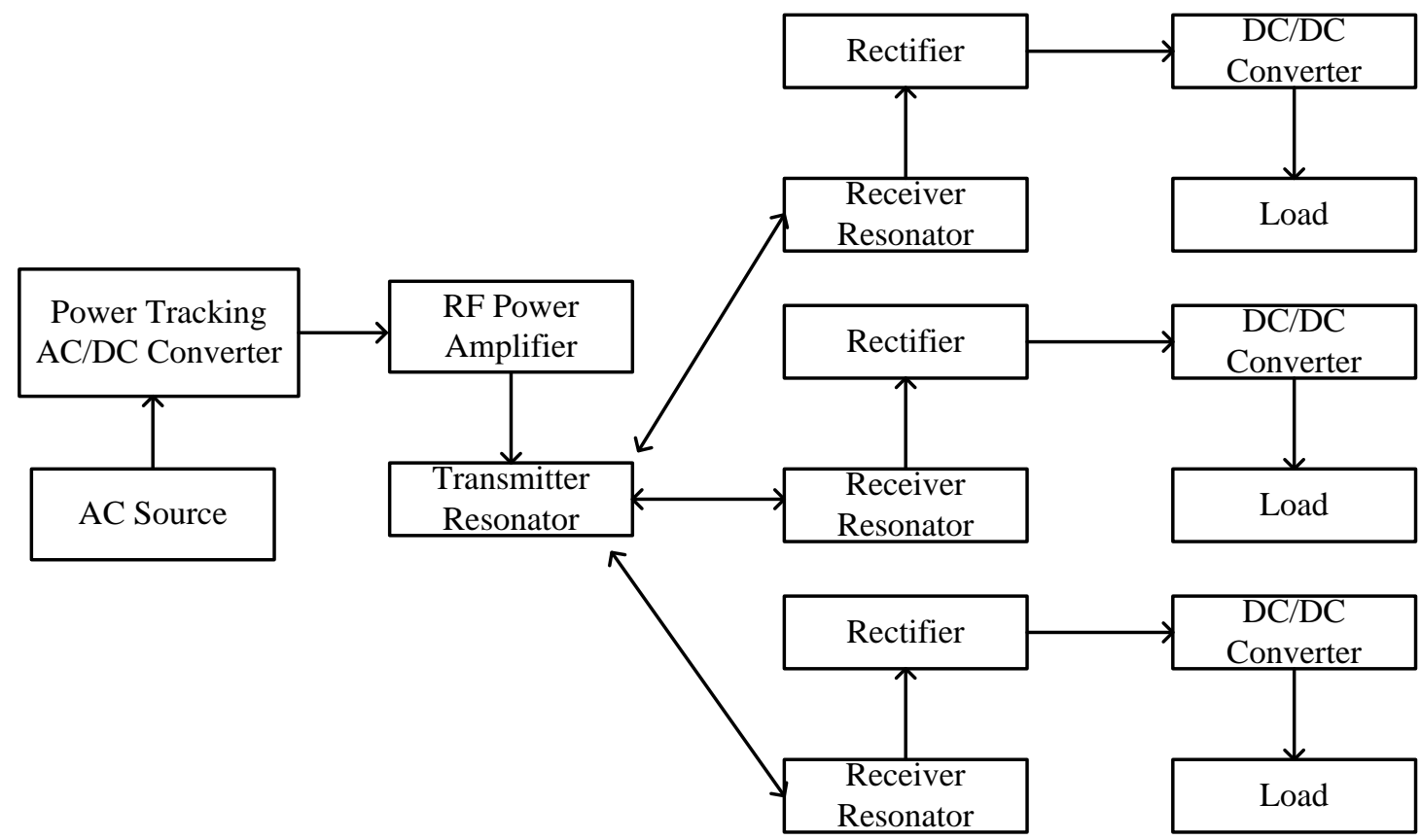

Figure 2.4: Block diagram of the wireless power charging pad system for multiple devices [24]

In this work, fewer functional blocks were used compared to the work done in [23], a fixed coupling coefficient was considered and an additional communication module is required to send information about the load to the transmitter.

Dukju et al [7] proposed the use of frequency tuning in multiple receivers and multiple transmitter WPT systems in presence of cross-coupling between the transmitters or receivers. Since, the resonance frequency of the transmitter or receiver varies with change in coupling, to ensure maximum system efficiency the operating frequency is modified consequently. A mathematical analysis of the system was done to determine the maximum transfer efficiency. In this work the challenge of cross-coupling was addressed as desired but external capacitors were used to resonate the coils and detailed explanation about the complete system operation in terms of how power is delivered to the load was not given. Also, the range of coupling coefficient considered is narrow. 
It can be observed that in the variable frequency control method, extra communication modules were used to send information about the load to the transmitter. This makes the total system more complex.

\subsubsection{Impedance Matching}

Impedance matching (IM) circuits are implemented in magnetic resonance wireless power transfer systems to enhance efficiency with load variation [3], [6]. The coupling coefficient varies with change in distance causing a change in the total impedance of the circuit. These variations affect the resonant frequency and power transfer efficiency [25]. IM circuits help in nullify the reactance in the circuit. Capacitors preferred compare to resistors and inductors in the impedance network due to the fact that resistors dissipate power and low-loss inductors are large in size. Also, tuning inductors can affect the flux linkage between the transmitter and the receiver considering the fact that they are inductively coupled together. Tuning the circuit inductance can also be more challenging in terms of hardware implementation [26].

In [27] an analysis on the use of different topologies of IM networks in multiple receiver WPT circuit was carried out to determine its influence on power transfer efficiency considering load variation. Figure 2.5 show a multiple receiver system with IM network. SP-PS (series-parallel on the transmitter and parallel-series on the receiver), SP-SP, PS-SP and PS-PS topologies were considered. The authors concluded that, WPT systems response to variation in load impedance depending on the IM circuit combination on the receiver. Although this work is based on a multiple receiver system but it does not give detailed explanation on how the complete circuit operates. Also, a fixed distance between the transmitter and the receiver(s) is considered, and external capacitors were used to tune the 
circuit. IM circuits are also implemented in [28], and [25] to achieve maximum power transfer efficiency.

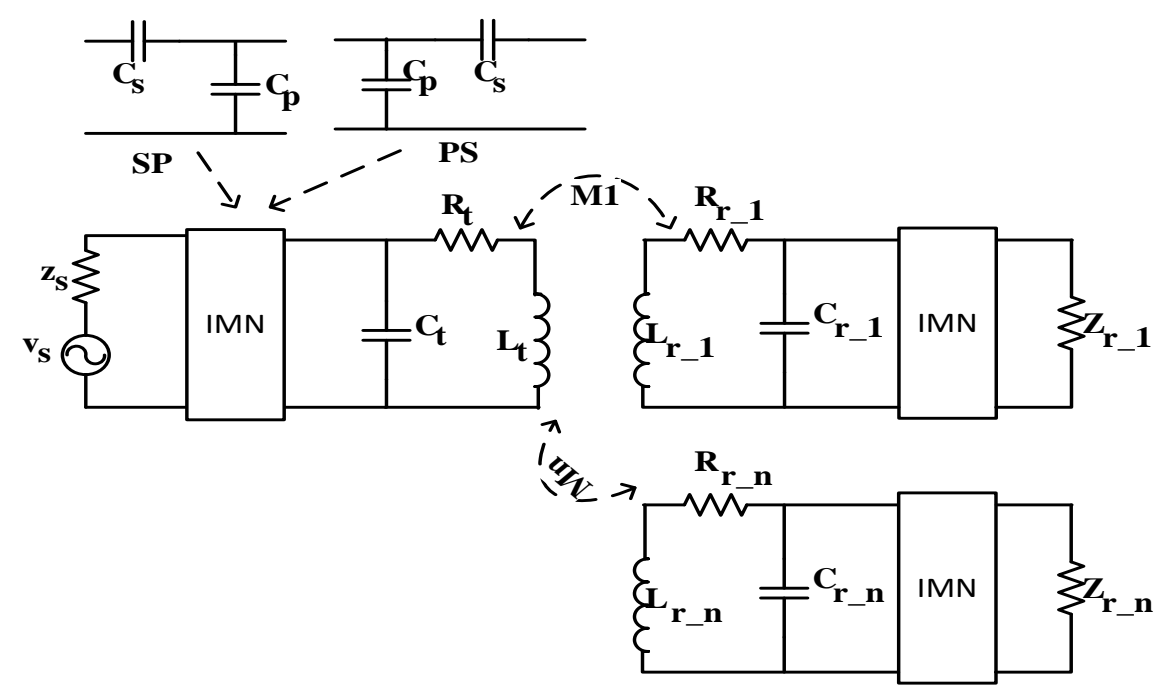

Figure 2.5: Mutiple receiver WPT system with IM network [27]

In [29], the authors proposed the use of IM circuit to improve the power transfer level and efficiency of a WPT system. A parallel resonant IM circuit was added to the series resonant tank to form a LCCL circuit in order to reduce the circuit impedance. A detailed analysis was carried out on both series and impedance matched circuit to observe the circuit behavior. In this work, a narrow range of coupling coefficient was considered, only one receiver was used and detailed information on how the power requirements of the load are met was not given.

Teck et al in [30] proposed the use of IM network to ensure that the resonance frequency of the transmitter and receiver coils corresponds to each other to achieve maximum efficiency. The effect of air-gap variation was analyzed using the equivalent circuit and the tuning parameters of the IM network were calculated. As shown in figure 2.6, the IM network was placed between the power source and the transmitting coil, and then used to tune the resonance characteristics of the coupled coils in order to modify the resonance frequency. 


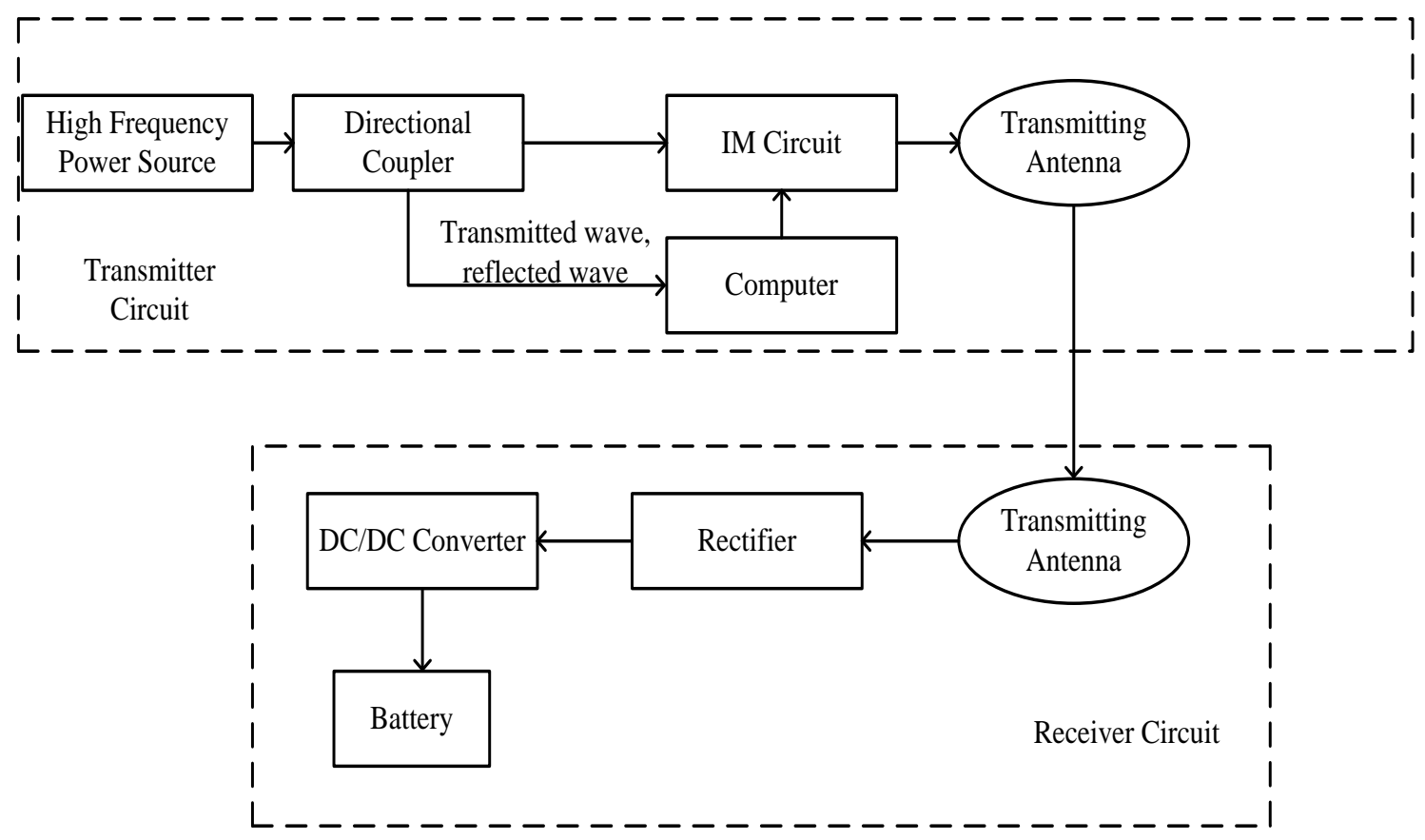

Figure 2.6: Block diagram of WPT system with IM circuit [30].

In this work the IM network was only used on the transmitter side which makes it less bulky compared to the WPT circuit in [29] but only a single receiver system was considered.

In [31], IM circuit was used to improve the efficiency of a multiple receiver WPT system. An equivalent circuit analysis was done to determine the IM circuit parameters. The source impedance was made equal to the complex conjugate of the load impedance using the IM circuit and so the reflected power of the impedance matched circuit is minimal at resonance. In this work the impedance matching circuit is connected on the transmitting coil which makes it less bulky as well but the author did not give a detailed explanation about how the load requirements of the load are met.

Even though IM circuits were used to improve the efficiency of WPT systems, it increases complexity of the overall circuit [5]. 


\subsubsection{Optimal Load Monitoring}

In WPT change in coupling coefficient remains an obstacle in achieving good level of power transfer and as well as total system efficiency. Minfan fu et al [5], proposed the tracking of optimal loads in WPT systems to maintain good efficiency with variation in coupling coefficient. This is based on the fact that every value of coupling coefficient, there is an optimal resistance at which the system operates at maximum efficiency. A detailed analysis of the total system was done and a perturb and observe (P \& O) algorithm was used to control the duty cycle of a boost-buck dc-dc converter. The cascaded boost-buck converter made it possible to achieve an equivalent load resistance variation from $0 \Omega$ to $+\infty$ just like the regular single-switch buck-boost converter but the former is easier to analyze, control and implement. The total system efficiency is measured and the duty cycle of the dc-dc converter is perturbed according to the value of the system efficiency. The WPT system is shown in figure 2.7. Similar concept was reported in [13] and [19] but just like [5] only a single receiver was considered and it requires an additional communication module between the transmitter and receiver circuit.

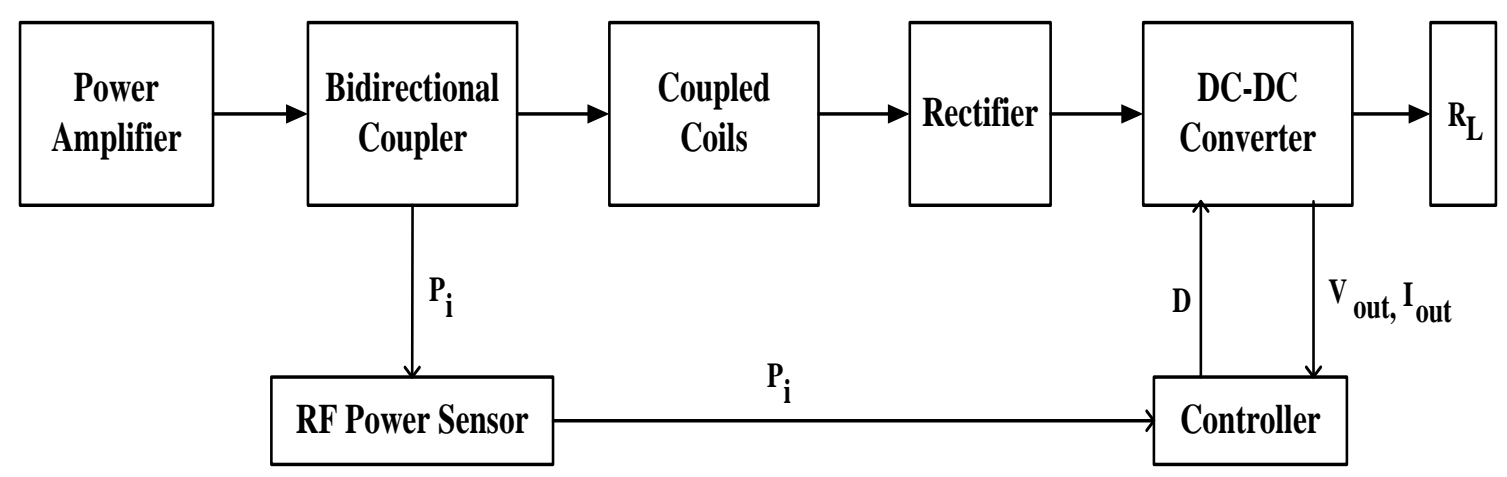

Figure 2.7: Block diagram of system for tracking optimal load [5]. 
In [32], a numerical analysis was carried out on the efficiency and optimal load in multiple receiver WPT systems using the circuit model theory but emphasis was placed on efficiency and no detailed explanation as to how the power delivered to the load was given. It is also essential that the power requirement of the loads is met.

\subsubsection{Coupling Manipulation}

The amount of coupling between the transmitter(s) and receiver(s) circuit plays a pivotal role in the amount of power transferred as well as efficiency. In [33] the authors suggested variation in coupling co-efficient on the transmitter side to improve the efficiency of a 4-coil magnetic resonance wireless power transfer system. The 4-coil system consists of a power loop, transmitter coil, receiver coil and load loop as shown in figure 2.2. Here it is assumed that the cross-coupling between the coils are negligible and that the coupling between the receiver coil and load loop $\left(K_{34}\right)$ is fixed. Although, the authors showed that the efficiency of the system can be improved by optimal variation of the coupling between the power loop and transmitter coil $\left(K_{12}\right)$, this method can only be implemented using electro-mechanical devices which makes it expensive and complex to implement. A similar concept was also proposed in [34] but these works considered only a single receiver system and the method is not a viable solution in a multiple receiver WPT system because each receiver circuit might require a different coil orientation to achieve efficient power transfer.

In [35], the authors proposed the addition of two functional blocks to the basic WPT system for charging mobile devices to enhance the efficiency of the system. A block diagram a basic WPT system with two additional blocks is shown in figure 2.8. The first 
and second block represents the step motor and rotating system, and a maximum flux detector and command pulse generator respectively.
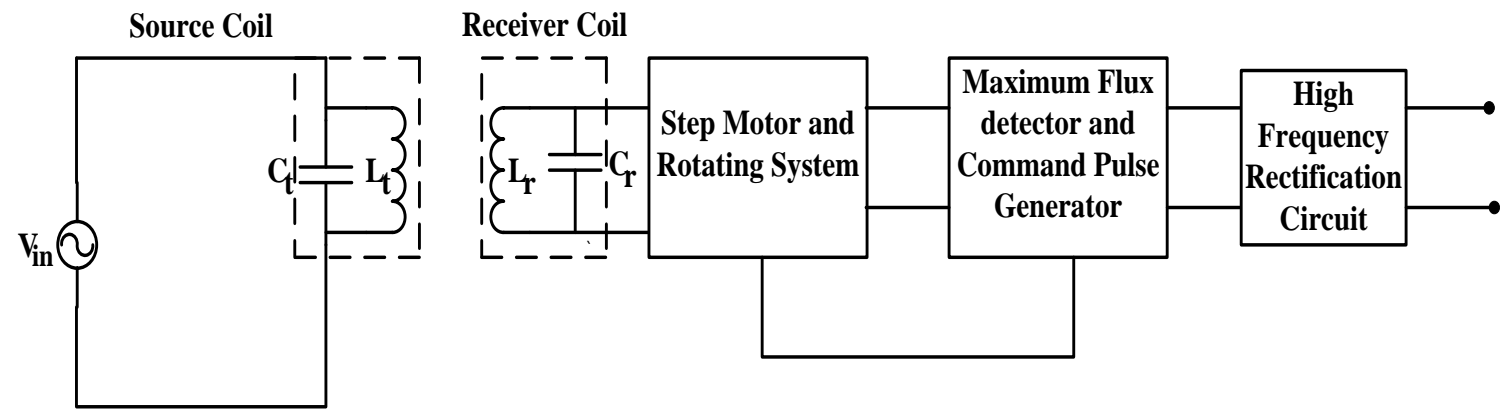

Figure 2.8: Wireless power transfer system for mobile devices using rotating system [35].

The optimum position of the receiver coil is achieved by analyzing the data from the first block using a programmed integrated circuit in the second block. The digital pulses from the second block are converted to mechanical shaft rotations to vary the receiver coil position. In this work, only a single receiver system was considered and detailed explanation about the complete circuit operation was not discussed. This approach will be complex and difficult to implement in a multiple receiver system. It also requires extra mechanical components, which makes it almost impracticable in mobile phone applications considering the size.

In [36], a loop switching technique to improve WPT system efficiency using magnetic resonance coupling was proposed. The system uses several loops of different sizes in which one is connected to the system at various distance between the transmitter and the receiver. This topology allows the coupling coefficient to be manipulated with change in distance thereby enhancing the system efficiency over a wide range of distance. The loop switching technique is illustrated in figure 2.9. The input and output loops are made up of 4 loops of different sizes. The power source and load are switched to one of 
the four loops to adjust the coupling coefficient between the loop and the transmitter, and between the receiver and the load loop denoted by $K_{12}$ and $K_{34}$ respectively to their optimum value as the distance between the transmitter and the receiver coil $\left(d_{23}\right)$ changes. As $d_{23}$ increases the loops are connected in incremental order. This approach requires more coils to implement in a multiple receiver system.

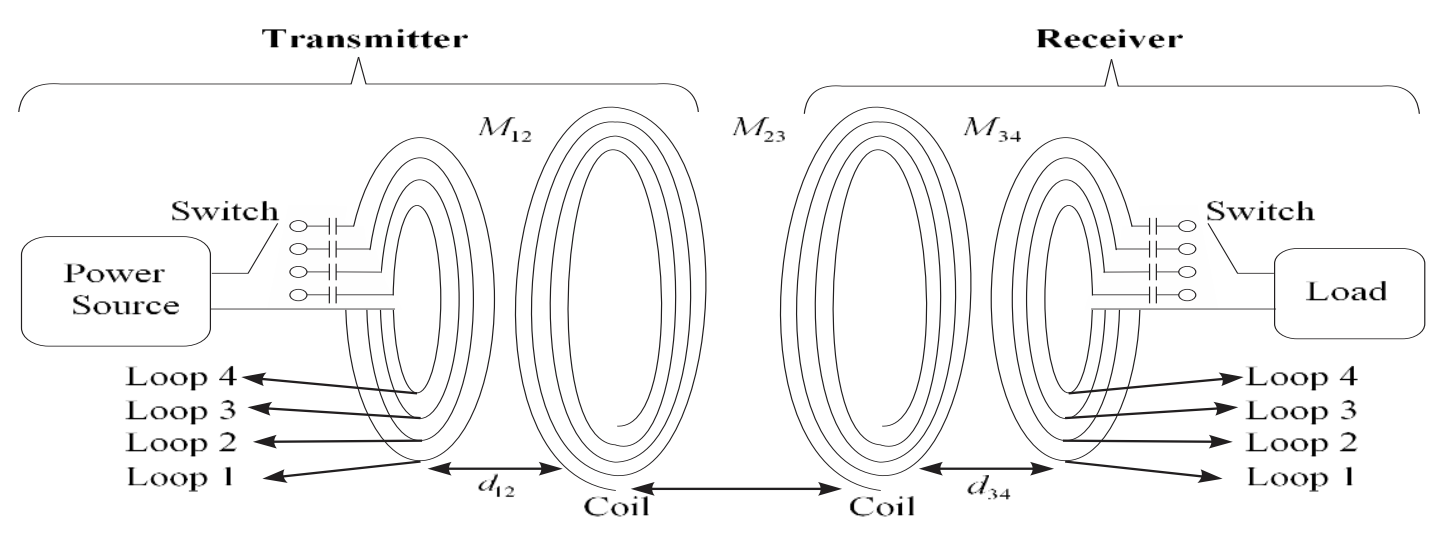

Figure 2.9: Loop switching wireless power transfer system[36]

Although, coupling manipulation is used to improve the efficiency of the system it is not a viable solution for charging mobile phone batteries.

\subsubsection{Winding Resistance Reduction}

In WPT, core losses are not considered in determining the efficiency of the system. The conduction losses in the ac resistance of the coil windings accounts for a major part of the power loss experienced in the system. As a result of the high operating frequency (MHZ range) of WPT, the skin and proximity effects leads to high ac resistance [14]. Consequently, the ac resistance of the coils needs to be reduced to enhance the power transfer efficiency of the system. 
Mizuno et al [37], proposed the use of magnetoplated wires which is made by plating the circumference of a copper wire with a magnetic thin film to improve the transmission efficiency of the WPT system. It was shown that the ac resistance of the magnetoplated copper wire is less than the unplated once. The lower ac resistance makes the magnetoplated copper wire transfer power more efficiently for a low coupling coefficient values. The quality factor of the coil is also improved. Another possible approach for reducing ac resistance of the coil was presented in [38], a loss analysis was done at high frequency in order to design the coil winding. The turns of the coil are arranged in a spiral manner and the thickness of the conducting layer was made equal to the skin depth. In these works, the main focus is on improving the power transfer efficiency of the coils and the entire WPT system operation was not considered.

\subsubsection{Use of Relay Resonators}

The strength of the flux linkage that cuts across the receiver coil in an important consideration in quantifying the amount of power transferred to the load in magnetic resonance coupled WPT systems. When the distance between the transmitter and receiver is much, the magnetic flux linkage is low and as a result, power delivered to the load will be insufficient. The magnetic coupling can be improved by adding relay coils to act as repeaters between the transmitter and receiver coils $[39,40]$.

In [41] and [42] relay resonators were used to increase the power transfer distance and efficiency. Detailed analysis of power transfer efficiency of the system was also given. A diagram of magnetic resonance WPT system with relay resonator coils is shown in figure 2.10. Spiral shaped relay coils were used in order to reduce the size and a capacitors were added to modify the resonance frequency accordingly. 


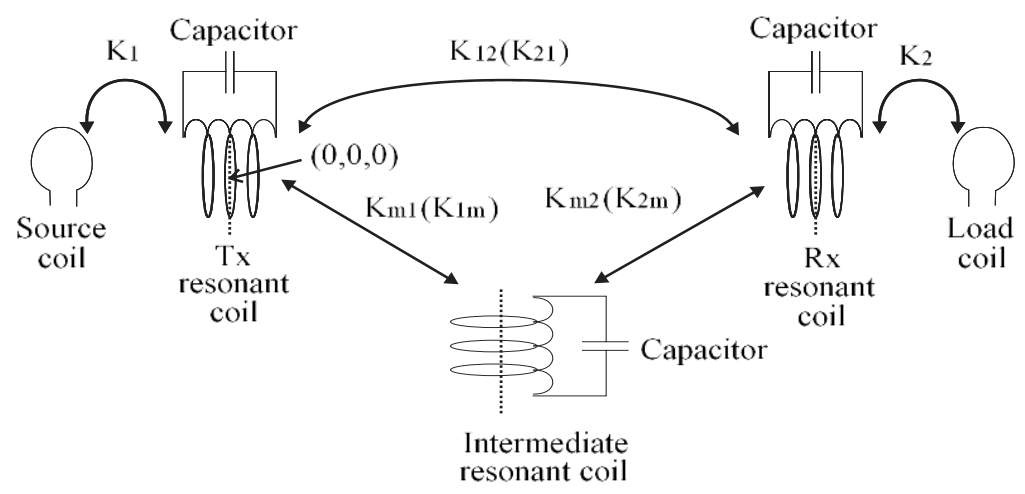

Figure 2.10: Magnetic resonance WPT with relay resonators [41]

The challenge of this method is that the relay coils decrease the power transfer efficiency when they are not optimally placed between the transmitter and receiver [43].

\subsubsection{Use of Transmitter Circuit Array}

Coil orientation in some WPT applications vary and this affects the power transfer efficiency of the system. Coupled coils that are aligned along same axis have good efficiency. In [44], the authors proposed the use of transmitter circuit arrays to improve the efficiency of WPT systems when the coils are misaligned. In this work, even though the authors were able to improve the efficiency of the system, it is not a good solution because it requires several power supplies. Only a single receiver was considered and details about the complete circuit operation was not given.

\subsubsection{Use of Coil Arrays}

The use of coil arrays in the transmitter circuit of a four-coil resonant based WPT system was proposed in [45] and [46] to improve the efficiency of the system. The multicoil structure was built by an array of several parallel-connected transmitter coils with a single power loop as shown in figure 2.11. This approach is a better solution than the use of multiple transmitter circuit proposed in [44]. 


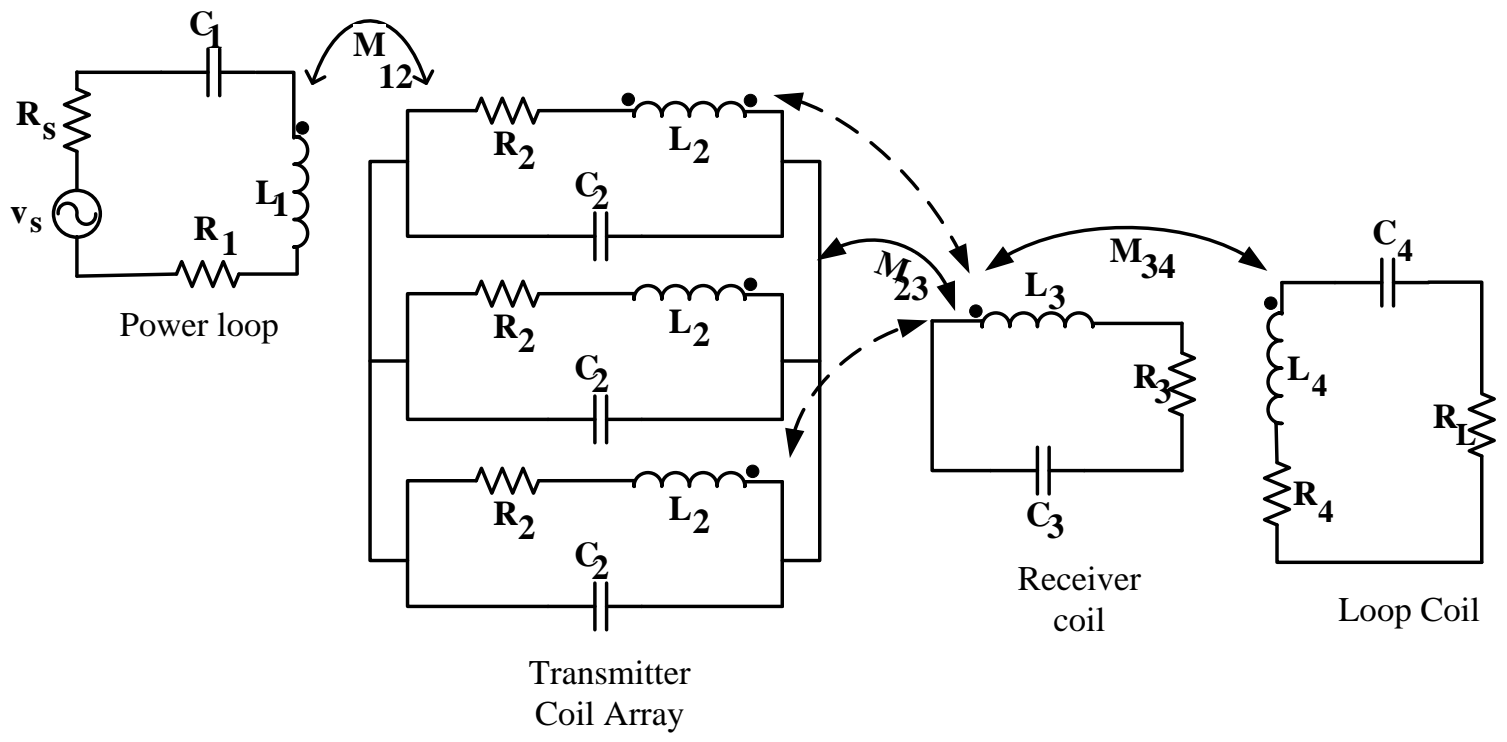

Figure 2.11: Multicoil parallel array WPT system [45]

In these papers the circuits were designed to power only a single receiver, variation in coupling coefficient was not considered and detailed explanation on how the power requirements of the load is fulfilled was not mentioned.

\subsection{Output Power Conditioning}

In WPT, it is important that the power requirements of the load are met to prevent damage. A common approach for output power conditioning in wireless charging is the use of dc-dc converters like the buck, buck-boost and the cascaded boost-buck topologies. In [24], dc-dc converter was used to control the output voltage in a multiple receiver mobile phone charger but the system still requires a communication module to send information about the condition of the loads to the transmitter. Figure 2.12 show different dc-dc converters used in WPT systems. 


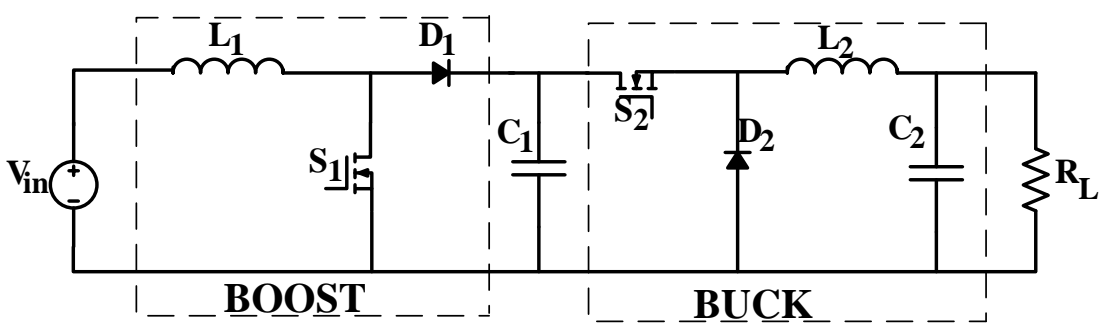

(a)

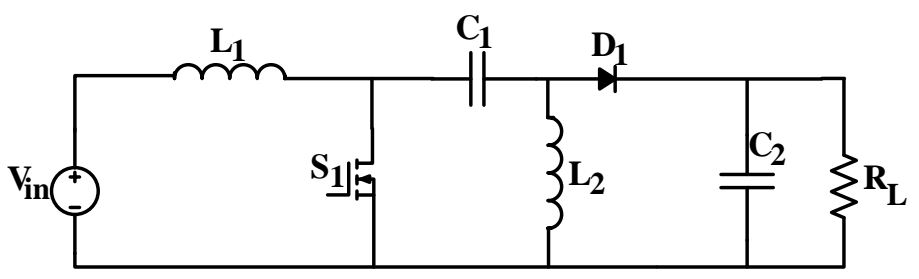

(b)

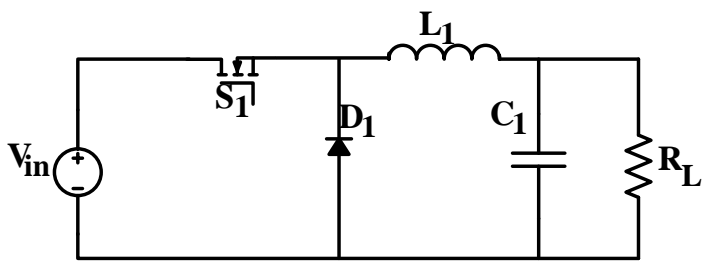

(c)

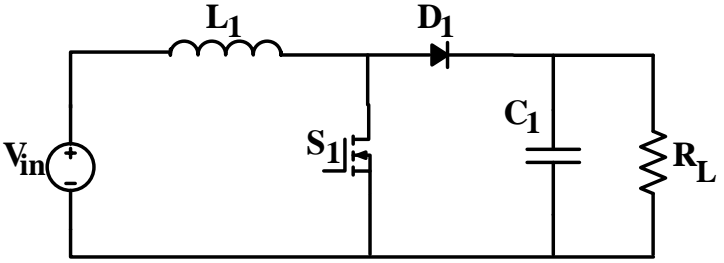

(d)

Figure 2.12: Diagram of basic dc-dc converter topologies used in WPT: (a) boost-buck [5], (b) buck-boost, (c) buck, (d) boost

\subsection{Perturb and Observe Algorithm (P \& O)}

The $\mathrm{P} \& \mathrm{O}$ algorithm is widely used in photovoltaic systems to track the maximum power point. The manipulated variable is modified by an increase or decrease and the controlled variable (output) is measured. If the output increases, the manipulated variable is perturbed in the same direction until no further increment is noticed. Otherwise, the direction of perturbation is reversed. The $\mathrm{P} \& \mathrm{O}$ algorithm is beneficial because of its ease in implementation. 
In [5], [13] and [19] the P \& O algorithm has been used in various WPT systems to track maximum energy efficiency of a WPT system but only single receiver systems were considered.

\subsection{Thesis Motivation and Objectives}

The existing methods of enhancing WPT power transfer capabilities discussed in the review shows that the methods have been used to improve efficiency of the system but extra communication module is still required to transfer information between the transmitter and the receiver(s). It can also be seen that the range of coupling coefficient within which the required power can be delivered to the devices considered in the review is either fixed or narrow. In cases where the coupling coefficient can be adjusted such as the coupling manipulation method, it is not a viable solution for charging the batteries of mobile phones because it requires additional mechanical components. Therefore, there is need to eliminate the communication link in order to reduce the complexity of the entire circuit. It is also important to widen the range of coupling coefficient within which the system can operate while delivering the required power to the device on the receiver(s).

This thesis presents a variable frequency control algorithm and a switch capacitor topology to address the above mentioned problems.

The main objective of this thesis is to develop a topology to achieve the following using magnetic resonance coupling WPT method:

- A variable frequency control algorithm will be used to track the frequency at which the maximum input power occurs. This is to ensure the availability of adequate power at the transmitter for a wide range of coupling coefficient. 
- A switched capacitor will be used in the receiver circuit to control the output voltage to meet the power requirement of the load (mobile phones) without a communication module between the transmitter and receiver circuits.

\subsection{Summary}

In this chapter the two-coil and four-coil structures used in WPT have been explained, methods of improving the level of power transfer and efficiency have been discussed, the dc-dc converter topologies used in regulating the output voltage of the WPT system as well as the $\mathrm{P} \& \mathrm{O}$ algorithm have been discussed. The motivation and objectives of this thesis have also been stated. 


\section{Chapter 3}

\section{Circuit Analysis and System Study}

In chapter two, various methods of improving WPT for powering mobile devices

were discussed alongside the challenges. This chapter a basic WPT system is described in section 3.1. In section 3.2 and 3.3 the system is analyzed and a system study is carried out in order to understand the circuit operation with variation in coupling coefficient and load.

\subsection{Circuit Description}

TRANSMITTER

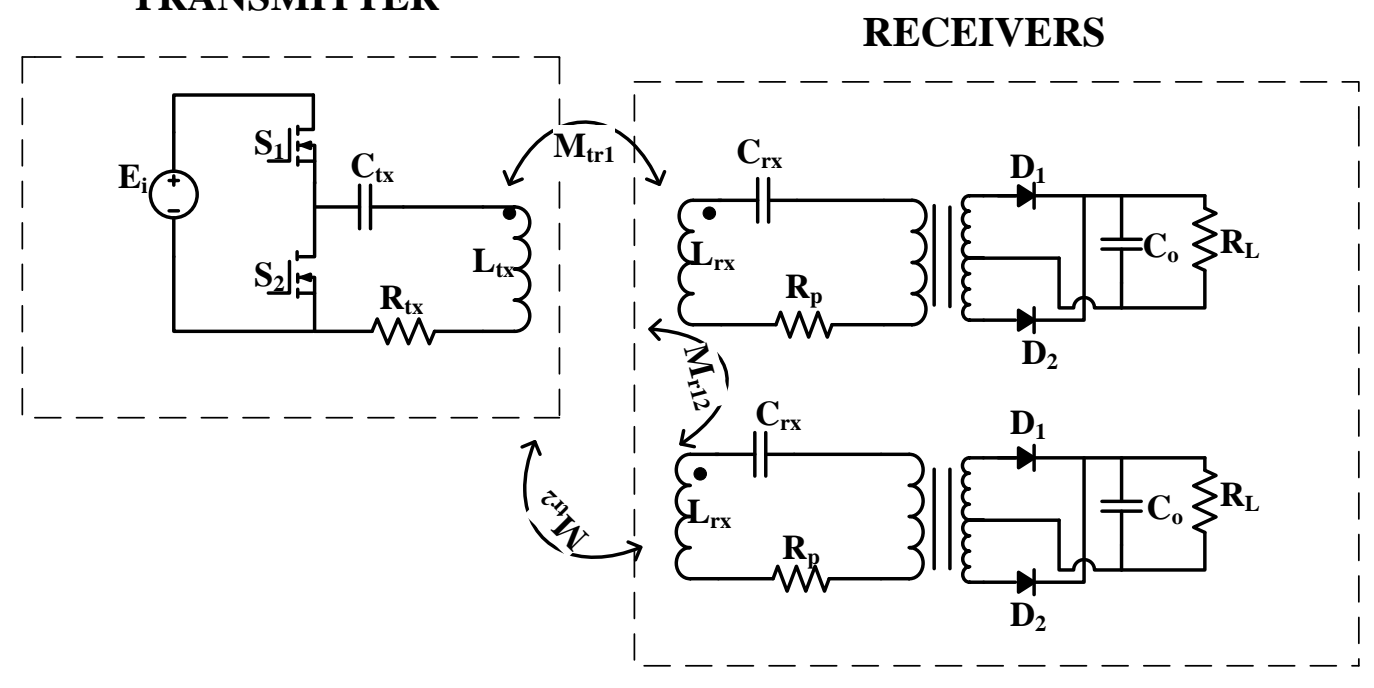

(a) Circuit diagram 

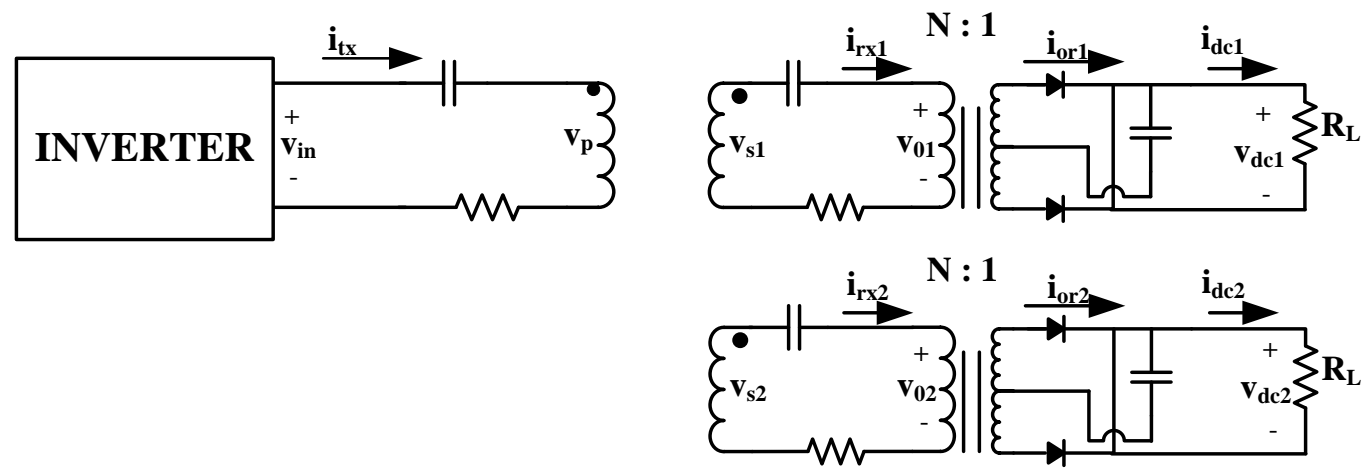

(b) Circuit variable designation

Figure 3.1: Circuit diagram of a multiple receiver WPT system.

In figure 3.1, the multiple receiver WPT system consists of a transmitter and two receivers. The transmitter is made up of a dc source $E_{i}$, a high frequency half-bridge inverter and a self-tuned resonator coil which is modeled as a series resonant tank. The receiver consists of a self-tuned resonator coil modeled as a series resonant tank, a stepdown transformer, a rectifier, an output capacitor filter and a load. The power generated at the transmitter is transferred to the receiver by magnetic resonance coupling using the resonator coils. The voltage is stepped-down by the transformer, rectified and filtered before it is feed to the load. Figure 3.2 show the various waveforms of the WPT system. 


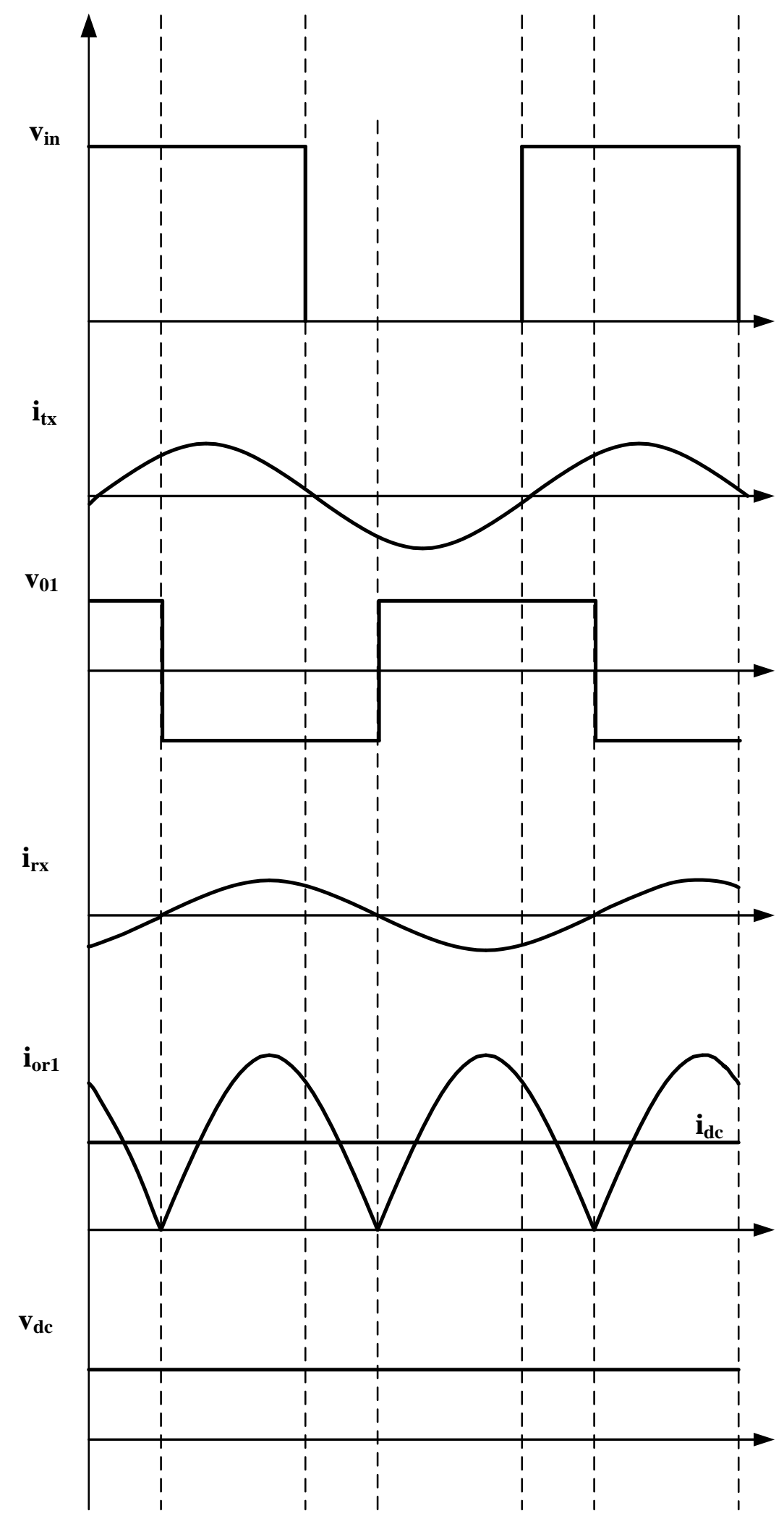

Figure 3.2: Waveforms of the multiple receiver WPT system. 


\subsection{Circuit Analysis}

Wireless power transfer systems have been majorly analyzed using the coupled mode theory and circuit theory. In this thesis the circuit theory analysis will be used because of its simplicity in modeling various system conditions. In order to simplify the analysis of the circuit, the following assumptions were made:

- $\quad$ The input voltage of the series resonant converter is a pure sine wave.

- $\quad$ The output filter capacitor is large and so the dc output voltage is constant.

- The switches of the ac switch have zero or infinite impedance to the current flowing through them

- $\quad$ The load is resistive

- $\quad$ The coupling between receivers is negligible

- $\quad$ Receivers are identical.

\subsubsection{Single Transmitter Multiple Receiver System}

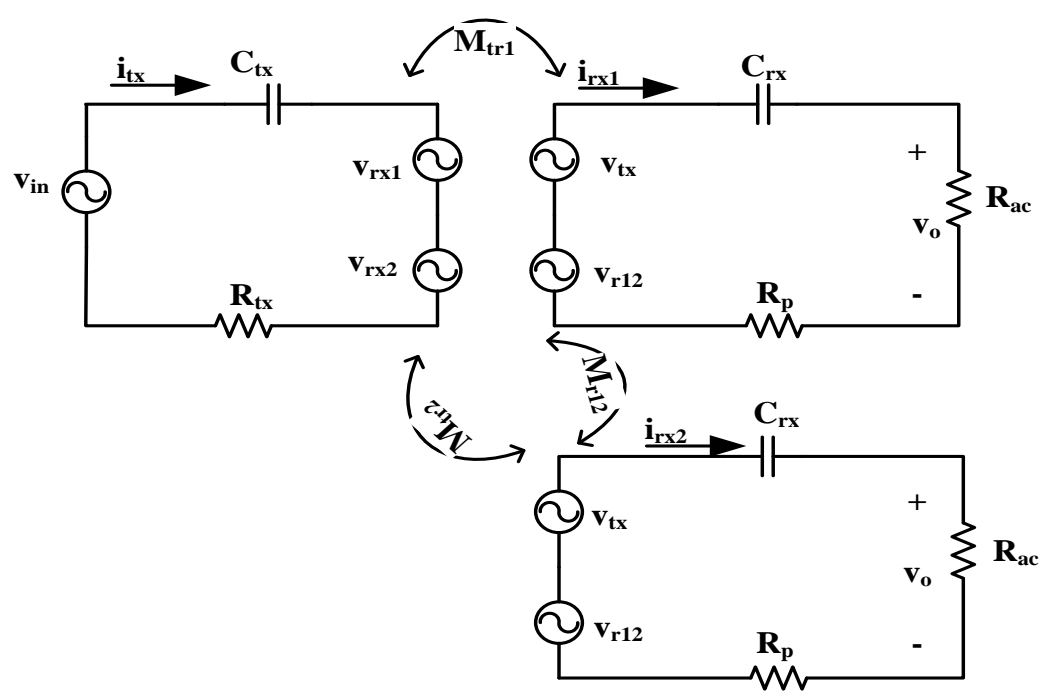

Figure 3.3: Equivalent circuit diagram of a multiple receiver WPT system. 
In figure 3.3, $M_{t r}$ represents the mutual coupling between the transmitter and receiver, $M_{r 12}$ is the mutual coupling between the receivers. The transmitter has an ac voltage source, $v_{\text {in }}$ which is the output of a high frequency half-bridge inverter. The transmitter and receiver coils can be modeled as an inductor $L_{i}$, with an internal capacitance, $C_{i}$. The subscript (i) denotes either the transmitter (tx) or receiver (rx) coils. The parasitic resistances of the transmitter and receiver coils are $R_{t x}$ and $R_{p}$ respectively. $R_{a c}$ is the equivalent ac resistance of the load and $\omega_{o}$ is the operating frequency of the circuit. The voltage induced by the two receivers on the transmitter due to their current $i_{r x}$ is $v_{r x}$, the voltage induced by the transmitter on the receivers due to the transmitter current $i_{t x}$ is $v_{t x}$ and $v_{r 12}$ is the voltage induced by the receivers on each other. $v_{o}$ represents the output voltage. Theoretically, the coupling coefficient (K) ranges from 0 to 1 and it can be calculated using the given formula

$$
\begin{aligned}
& K=\frac{M_{t r}}{\sqrt{L_{t x} L_{r x}}} \\
& V_{t x}=j \omega_{o} M_{t r} I_{t x} \\
& V_{r x}=j \omega_{o} M_{t r} I_{r x} \\
& V_{12}=j \omega_{o} M_{r 12} I_{r x}
\end{aligned}
$$

The resonance frequencies of the transmitter $\omega_{t x}$ and receiver $\omega_{r x}$ when the coupling coefficient between the transmitter and the receivers is zero is given by:

$$
\omega_{t x}=\frac{1}{\sqrt{L_{t x} C_{t x}}}
$$




$$
\begin{gathered}
\omega_{r x}=\frac{1}{\sqrt{L_{r x} C_{r x}}} \\
R_{a c}=\frac{8 N^{2} R_{L}}{\Pi^{2}}
\end{gathered}
$$

Where $\mathrm{N}$ is the turn ratio of the transformer in the receiver circuit

The total resistance of the receiver coil can be expressed as

$$
R_{r x}=R_{p}+R_{a c}
$$

Where $R_{L}$ is the load resistance.

$$
V_{i n}=\frac{2 E_{i}}{\Pi}
$$

Where $E_{i}$ is the dc voltage applied to the inverter. The quality factor of the transmitter $Q_{t x}$ and receiver $Q_{r x}$ can be expressed as

$$
\begin{aligned}
& Q_{t x}=\frac{\omega_{t x} L_{t x}}{R_{t x}}=\frac{1}{\omega_{t x} C_{t x} R_{t x}} \\
& Q_{r x}=\frac{\omega_{r x} L_{r x}}{R_{r x}}=\frac{1}{\omega_{r x} C_{r x} R_{r x}}
\end{aligned}
$$

Relative operating frequency can be expressed as

$$
\omega=\frac{\omega_{o}}{\omega_{i}}
$$

$\omega_{i}$ is the resonance frequency of the transmitter or receiver coils when $\mathrm{K}=0$.

Using the Kirchhoff's voltage law, the equations of the circuit can be expressed as follows:

$$
\begin{aligned}
& V_{i n}=I_{t x}\left(R_{t x}-\frac{j}{\omega_{o} C_{t x}}+j \omega_{o} L_{t x}\right)-I_{r x 1} j \omega_{o} M_{t r 1}-I_{r x 2} j \omega_{o} M_{t r 2} \\
& V_{1}=-I_{t x} j \omega_{o} M_{t r 1}+I_{r x 1}\left(R_{r x 1}-\frac{j}{\omega_{o} C_{r x 1}}+j \omega_{o} L_{r x 1}\right)+I_{r x 2} j \omega_{o} M_{r 12}
\end{aligned}
$$




$$
\begin{aligned}
& V_{2}=-I_{t x} j \omega_{o} M_{t r 2}+I_{r x 1} j \omega_{o} M_{r 12}+I_{r x 2}\left(R_{r x 2}-\frac{j}{\omega_{o} C_{r x 2}}+j \omega_{o} L_{r x 2}\right)
\end{aligned}
$$

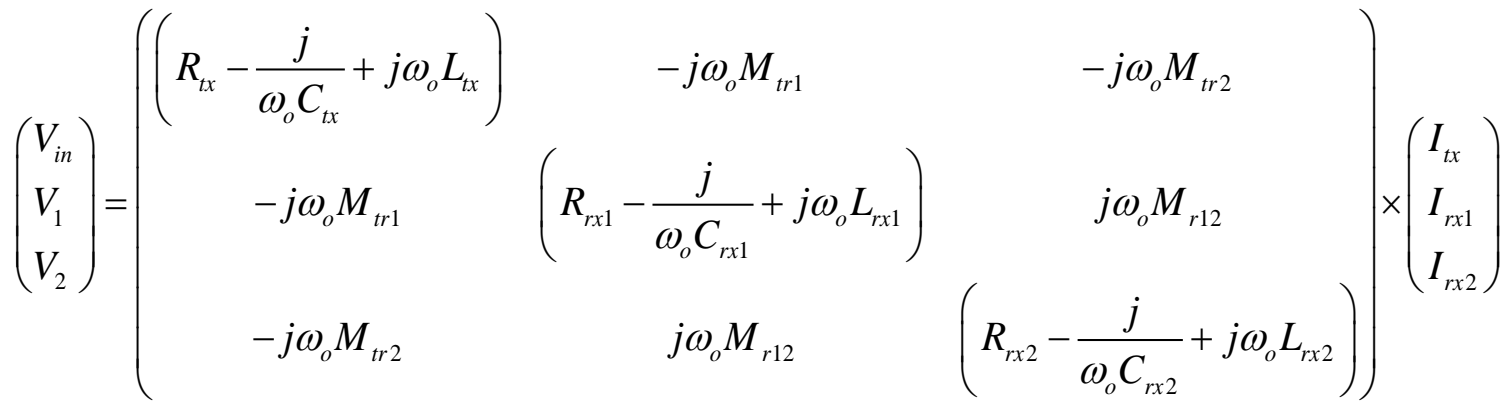

Where $V_{1}=V_{2}=0$ and $I_{r x 1}=I_{r x 2}=I_{r x}$

Efficiency $\eta$ is defined as the ratio between the total power dissipated in the load and the total power supplied by the sources [3]. It can be expressed as follows:

$$
\begin{aligned}
& \eta=\frac{P_{o u t}}{P_{i n}} \\
& P_{o u t}=\left|I_{r x 1}\right|^{2} R_{a c}+\left|I_{r x 2}\right|^{2} R_{a c} \\
& P_{\text {loss }}=R_{t x}\left|I_{t x}\right|^{2}+R_{p}\left|I_{r x 1}\right|^{2}+R_{p}\left|I_{r x 2}\right|^{2} \\
& P_{i n}=P_{o u t}+P_{l o s s} \\
& \eta=\frac{\left|I_{r x 1}\right|^{2} R_{a c}+\left|I_{r x 2}\right|^{2} R_{a c}}{R_{t x}\left|I_{t x}\right|^{2}+\left(R_{p}+R_{a c}\right)\left|I_{r x 1}\right|^{2}+\left(R_{p}+R_{a c}\right)\left|I_{r x 2}\right|^{2}}
\end{aligned}
$$

Where $I_{t x}$ and $I_{r x}$ represent the rms currents in the transmitter and receiver respectively.

From $(3.13 \mathrm{c})$ the ratio of the receiver current to that of the transmitter is given by

$$
\frac{I_{r x}}{I_{t x}}=\frac{K \sqrt{L_{t x} / L_{r x}}}{\frac{R_{r x}}{j \omega_{o} L_{r x}}+\left(1+K_{12}-\left(\frac{\omega_{r x}}{\omega_{o}}\right)^{2}\right)}
$$


In terms of quality factor Q, equation (3.20) becomes

$$
\frac{I_{r x}}{I_{t x}}=\frac{j Q_{r x} K \sqrt{L_{t x} / L_{r x}}}{1+j Q_{r x}\left(1+K_{12}-\frac{1}{\omega^{2}}\right)}
$$

From (3.13a) the transmitter current $I_{t x}$ and receiver current $I_{r x}$ can be expressed as follows,

$$
\begin{aligned}
& V_{i n}\left(\frac{R_{r x}}{j \omega_{o} L_{r x}}+1+K_{12}-\left(\frac{\omega_{r x}}{\omega_{o}}\right)^{2}\right) \\
& I_{t x}=\frac{\left.\left(R_{t x}+j \omega_{o} L_{t x}\left(1-\left(\frac{\omega_{t x}}{\omega_{o}}\right)^{2}\right)\right)\left(\frac{R_{r x}}{j \omega_{o} L_{r x}}+1+K_{12}-\left(\frac{\omega_{r x}}{\omega_{o}}\right)^{2}\right)\right]-2 j \omega_{o} L_{t x} K^{2}}{\left[\left(\omega_{o} L_{r x}\right.\right.} \\
& I_{r x}=\frac{V_{i n} K \sqrt{L_{t x} / L_{r x}}}{\left[\left(R_{t x}+j \omega_{o} L_{t x}\left(1-\left(\frac{\omega_{t x}}{\omega_{o}}\right)^{2}\right)\right)\left(\frac{R_{r x}}{j \omega_{o} L_{r x}}+1+K_{12}-\left(\frac{\omega_{r x}}{\omega_{o}}\right)^{2}\right)\right]-2 j \omega_{o} L_{t x} K^{2}}
\end{aligned}
$$

The total input impedance of the circuit $Z_{\text {in }}$ can be expressed as

$$
\begin{aligned}
& Z_{i n}=\frac{V_{i n}}{I_{t x}} \\
& Z_{i n}=R_{t x}-\frac{j 2 \omega_{o} L_{t x} K^{2}}{1+K_{12}-\left(\frac{\omega_{r x}}{\omega_{o}}\right)^{2}+\frac{R_{r x}}{j \omega_{o} L_{r x}}}+j \omega_{o} L_{t x}\left(1-\left(\frac{\omega_{t x}}{\omega_{o}}\right)^{2}\right)
\end{aligned}
$$

The phase angle of the input impedance is given by

$$
\Phi=\angle Z_{\text {in }}
$$

From equation (3.23) the output voltage can be expressed as 


$$
V_{o}=\frac{V_{i n} R_{a c} K \sqrt{L_{t x} / L_{r x}}}{\left[\left(R_{t x}+j \omega_{o} L_{t x}\left(1-\left(\frac{\omega_{t x}}{\omega_{o}}\right)^{2}\right)\right)\left(\frac{R_{r x}}{j \omega_{o} L_{r x}}+1+K_{12}-\left(\frac{\omega_{r x}}{\omega_{o}}\right)^{2}\right)\right]-2 j \omega_{o} L_{t x} K^{2}}
$$

The voltage across the transmitter coil is given by

$$
\begin{aligned}
V_{p} & =V_{i n}-I_{t x}\left(R_{t x}-\frac{j}{\omega_{o} C_{t x}}\right) \\
& =V_{i n}\left[1-\frac{\left(\frac{R_{r x}}{j \omega_{o} L_{r x}}+1+K_{12}-\left(\frac{\omega_{r x}}{\omega_{o}}\right)^{2}\right)\left(R_{t x}-\frac{j}{\omega_{o} C_{t x}}\right)}{\left[\left(R_{t x}+j \omega_{o} L_{t x}\left(1-\left(\frac{\omega_{t x}}{\omega_{o}}\right)^{2}\right)\right)\left(\frac{R_{r x}}{j \omega_{o} L_{r x}}+1+K_{12}-\left(\frac{\omega_{r x}}{\omega_{o}}\right)^{2}\right)\right]-2 j \omega_{o} L_{t x} K^{2}}\right]
\end{aligned}
$$

The voltage across each receiver coil is given by

$$
\begin{aligned}
V_{s} & =I_{r x}\left(R_{r x}-\frac{j}{\omega_{o} C_{t x}}\right) \\
& =\left[\frac{V_{i n} K \sqrt{L_{t x} / L_{r x}}\left(R_{r x}-\frac{j}{\omega_{o} C_{r x}}\right)}{\left.\left[\left(R_{t x}+j \omega_{o} L_{t x}\left(1-\left(\frac{\omega_{t x}}{\omega_{o}}\right)^{2}\right)\right)\left(\frac{R_{r x}}{j \omega_{o} L_{r x}}+1+K_{12}-\left(\frac{\omega_{r x}}{\omega_{o}}\right)^{2}\right)\right]-2 j \omega_{o} L_{t x} K^{2}\right]}\right]
\end{aligned}
$$

The dc current delivered to the load is given by

$$
I_{o}=\frac{2 \sqrt{2}}{\Pi} N I_{r x}
$$

The output voltage regulation of the circuit can be expressed as

$$
V_{\text {reg }}=\frac{\left|V_{n l}\right|-\left|V_{f l}\right|}{\left|V_{f l}\right|}
$$

Where $V_{n l}$ and $V_{f l}$ represent the no-load voltage and full-load voltage respectively 


\subsection{System Study}

The resonance frequency point of WPT systems is usually affected by variation in coupling coefficient and load. The coupling co-efficient varies with change in distance causing a change in the total impedance of the circuit. It is important to note that maximum system efficiency does not necessarily mean maximum power is transferred in the circuit [7]. The transfer efficiency is dependent on the ohmic losses in the circuit while maximum power is a measure of how much power is transferred to the receiver from the transmitter. Figure 3.4 shows the WPT system efficiency variation with frequency for different values of coupling coefficient. It can be observed that maximum efficiency occurs at $\omega=1$ for all values of coupling coefficient $(\mathrm{K})$. Efficiency also rises with increase in $\mathrm{K}$. The peak efficiency frequency does not change with variation in the amount of coupling because the ohmic losses in the transmitter and receiver are low. This can be verified in figure 3.5, the current in both resonant coils in minimum when the relative operating frequency is unity. Therefore, even though the output power in high at the peak points, the efficiency of the system is lower compared to the system efficiency at unity relative operating frequency.

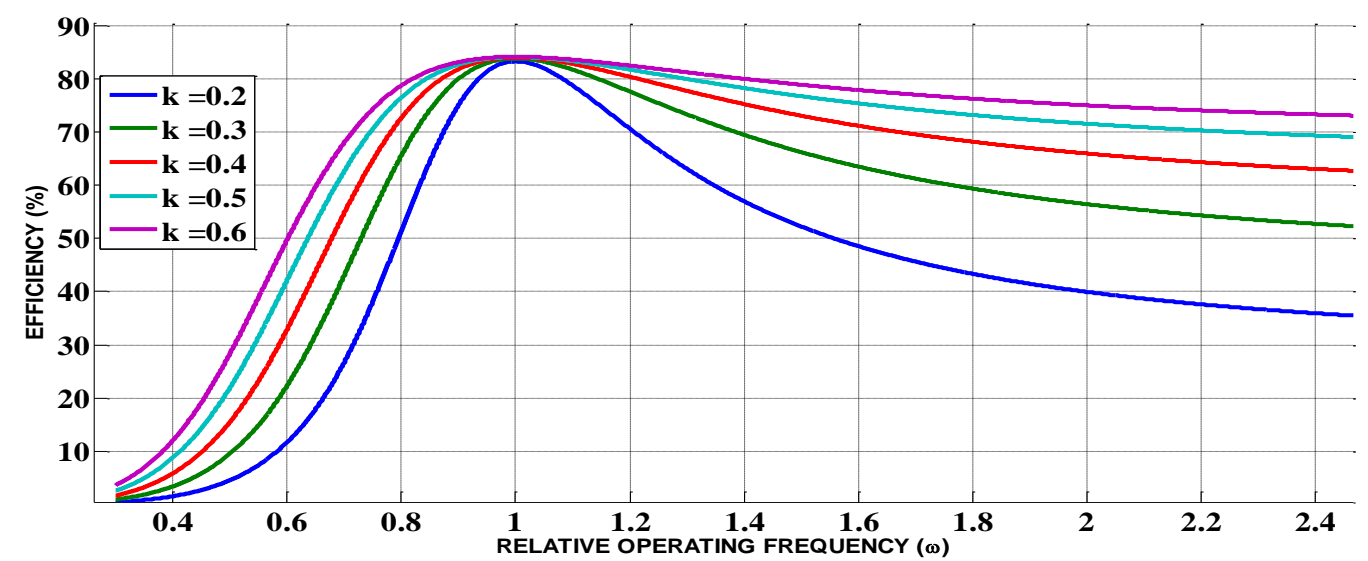

Figure 3.4: Variation in efficiency for different values of coupling coefficient 


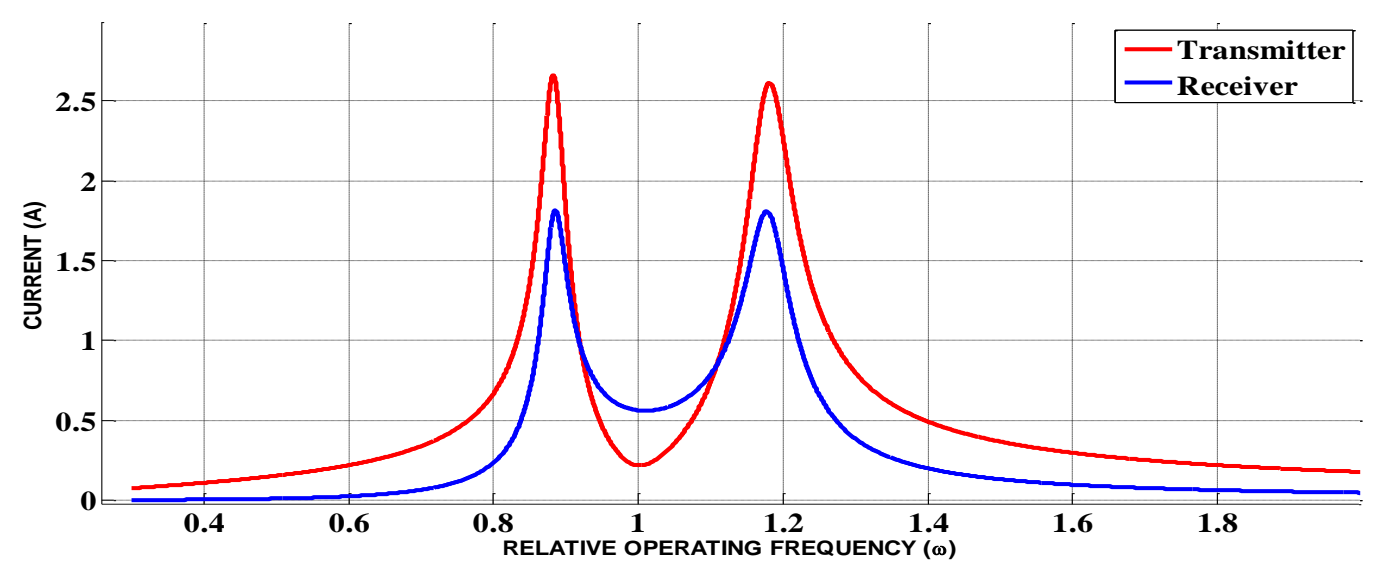

Figure 3.5: Current in the transmitter and receiver coil when $\mathrm{K}=0.2$

Figure 3.6 shows a graphical representation of the power output of the WPT system against frequency with variation in coupling. The power output curve splits into two subresonant peaks due to the frequency splitting phenomenon which occurs when maximum power transfer does not occur at unity relative operating frequency [47]. Here, the output power is low at unity relative operating frequency.

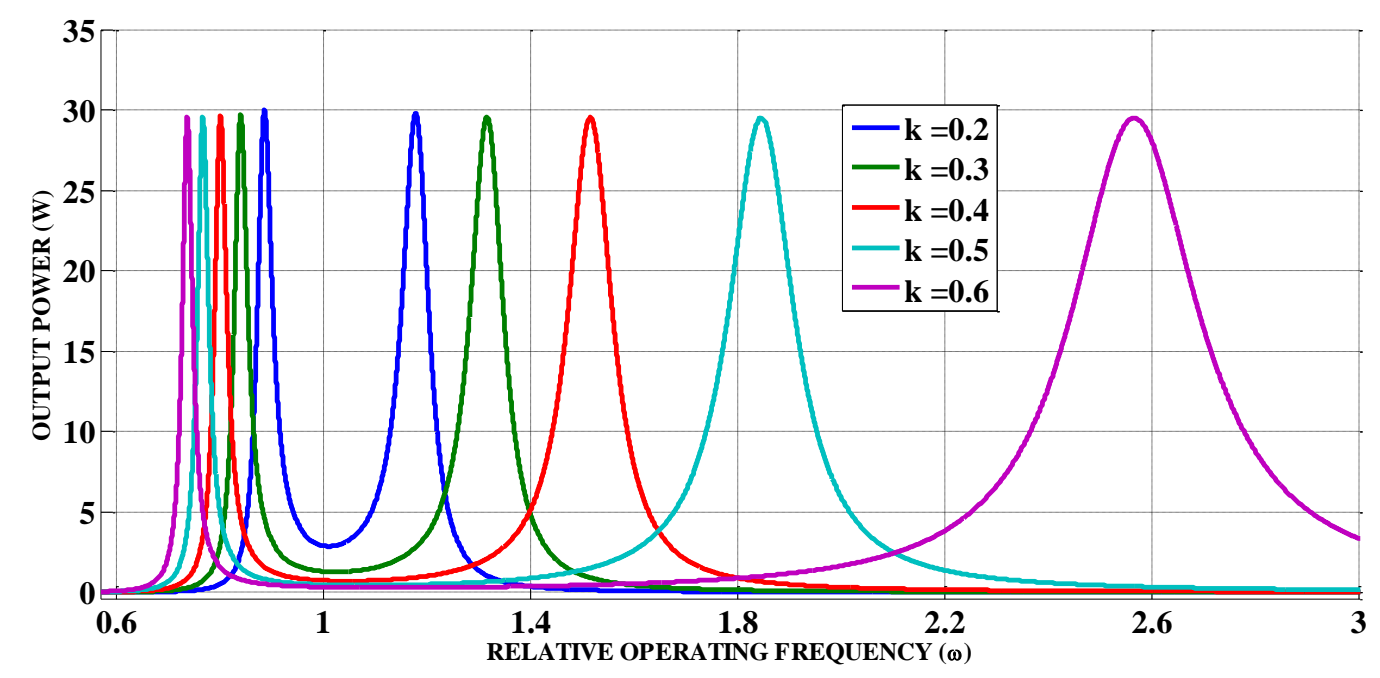

Figure 3.6: Output power against frequency for different values of coupling co-efficient

The effect of load variation on the resonance frequency of the WPT system can be seen in figure 3.7. It can be observed that as the load varies from full-load to $10 \%$ load the 
resonance frequency point changes. This further confirms that the WPT system cannot deliver the required power to the load when operating at a fixed frequency in the presence of coupling coefficient and load variation.

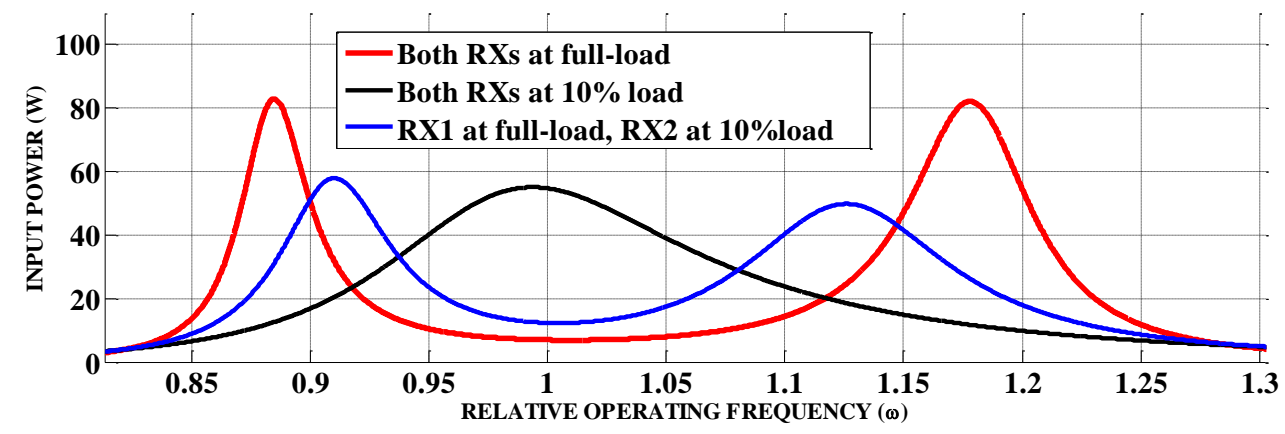

Figure 3.7: Input power with load variation

Equation 3.25 show that the input impedance of the system can be controlled by varying the operating frequency. When frequency is reduced, the impedance decreases and consequently the maximum power can be supplied. Figure 3.8 shows a graphical representation of the WPT systems input impedance against the relative operating frequency for different values of coupling coefficient. The change in input power with frequency variation for different values of coupling is also shown in figure 3.9. The system can be made to operate at the maximum input power frequency by varying the operating frequency as the coupling coefficient and load changes.

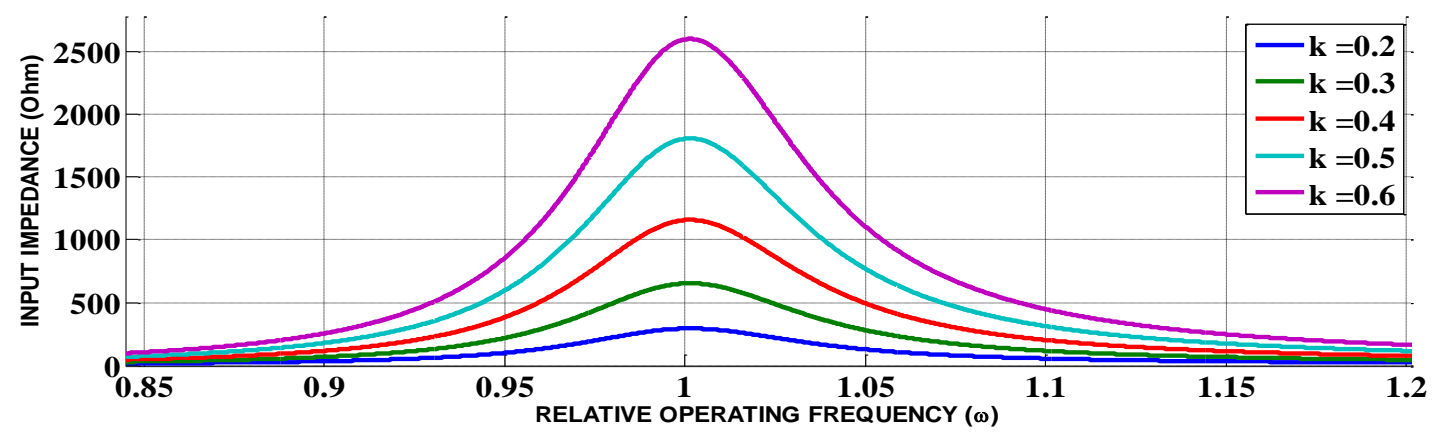

Figure 3.8: Input impedance against the relative operating frequency for different values of coupling coefficient. 


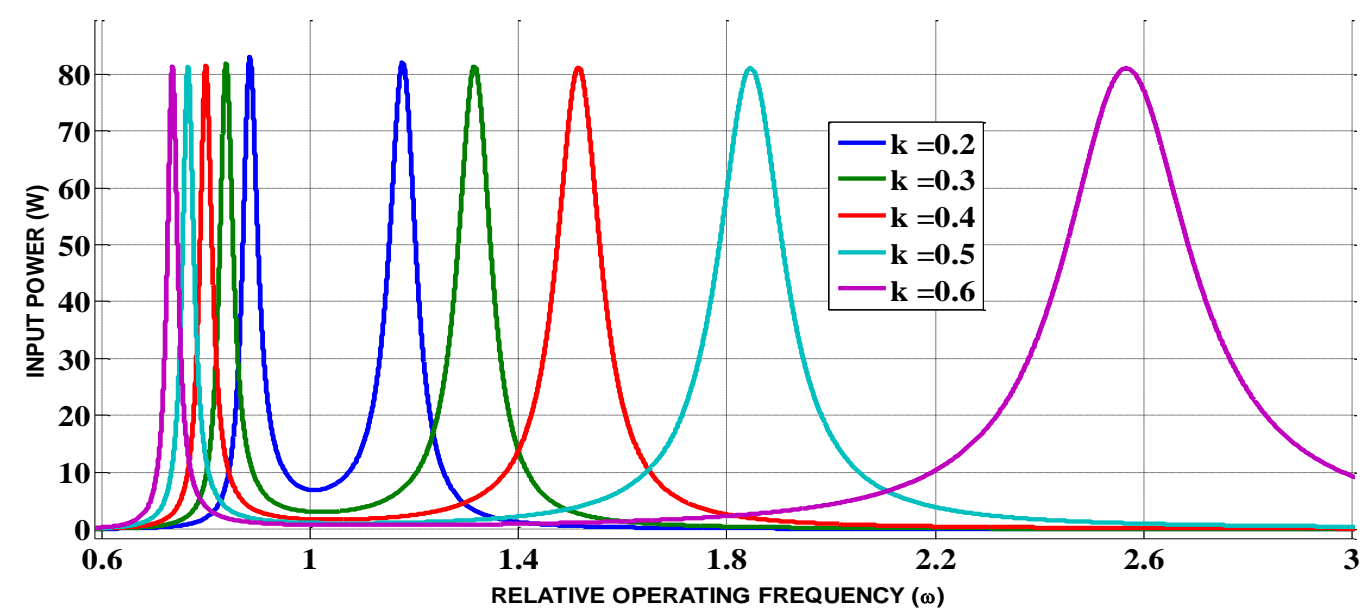

Figure 3.9: Input power against the relative operating frequency for different values of coupling coefficient.

In order to achieve ZVS (Zero Voltage Switching), the operating frequency is varied in the region where the phase angle of the input impedance is positive (inductive) below $\omega=1$. The region above unity relative operating frequency is not used because it requires a wider frequency variation for the system to operate under the range of coupling coefficient considered in this thesis. A graph of the phase angle against relative operating frequency with variation in coupling coefficient is shown in figure 3.10 .

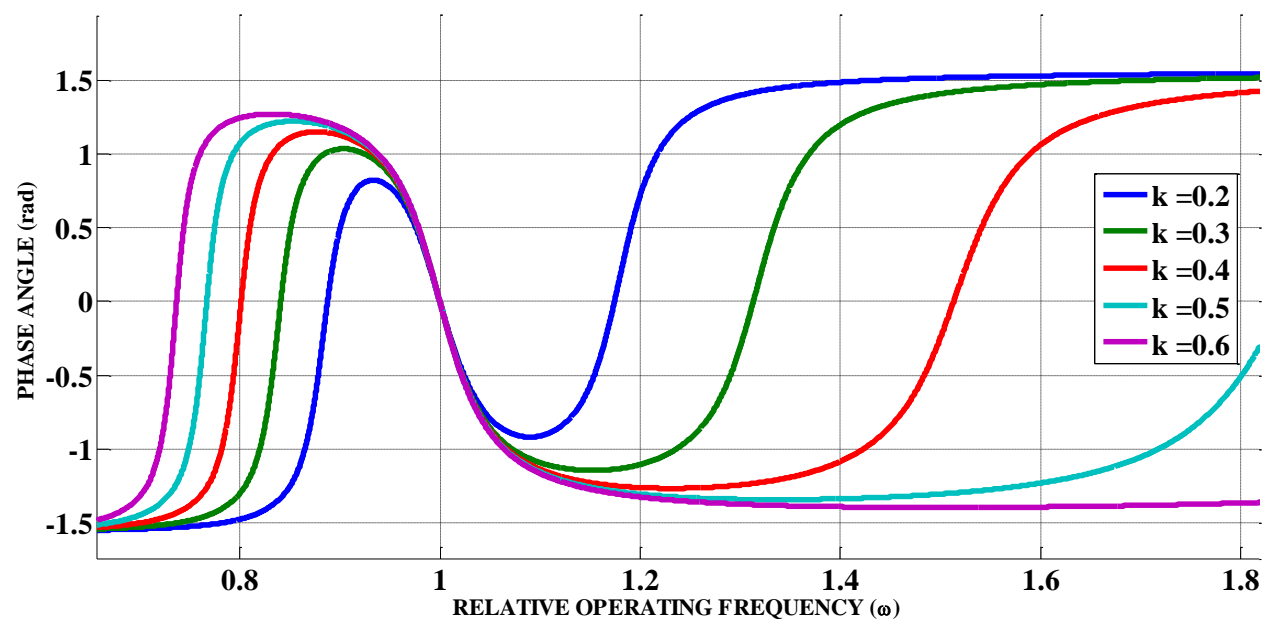

Figure 3.10: Phase angle against the relative operating frequency for different values of coupling coefficient. 


\subsection{Summary}

In this chapter, The WPT system has been described and a mathematical analysis carried out. The effect of variation in coupling coefficient and load on the circuit have been represented graphically and discussed. The following drawbacks have been observed from the system study carried out in this chapter:

- The resonance frequency point of the WPT system changes with variation in load and coupling coefficient. Therefore, the use of a fixed operating frequency is not viable.

- In order to achieve ZVS, operating at frequencies above $\omega=1$ will result is a wide variation in operating frequency.

The above mentioned drawbacks are overcome in the next chapter by using a variable frequency control algorithm. 


\section{Chapter 4}

\section{Proposed Topology and Simulation Results}

A variable frequency control algorithm is used in the transmitter circuit to track the frequency at which the maximum input power of the WPT system occurs to ensure adequate power supply whenever there is a variation in load and coupling coefficient. In addition, a new topology which consist of two switch capacitors is used in the receiver circuits to regulate the power delivered to the load. This topology enables power transfer without the use of a communication link and increase the range of coupling co-efficient within which the WPT system operates. The resonance frequency of the circuit is $5.7 \mathrm{MHZ}$ and it is design to deliver $10 \mathrm{~W}(5 \mathrm{~V}, 2 \mathrm{~A})$ each to two mobile phones. The idea of this work is to enable the mobile phone users to charge their phone using magnetic resonance coupling on a desk or even table at a coffee shop at a distance of $10 \mathrm{~cm}$ from the transmitter without a conventional wired charger. Even though lithium batteries work on $3.6 \mathrm{~V}$, a typical USB cables deliver $5 \mathrm{~V}$ to mobile phones. This is possible because the phones have internal power conditioning circuit to control the charging process of the battery [48].

\subsection{Proposed Topology}

A block diagram of the proposed multiple-receiver wireless power charger for mobile devices is shown in figure 4.1. 
TRANSMITTER

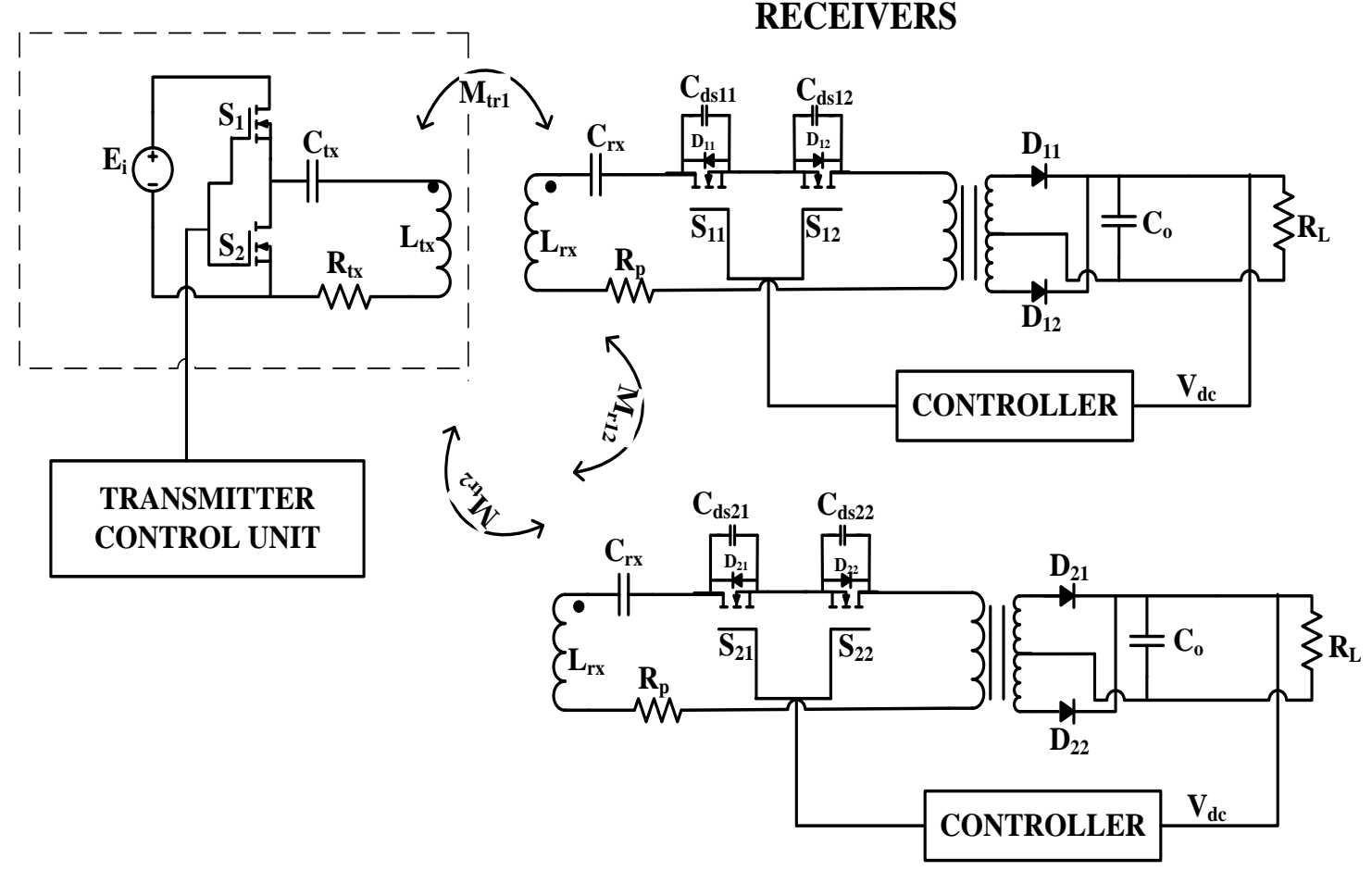

Figure 4.1: Proposed multiple receiver WPT system

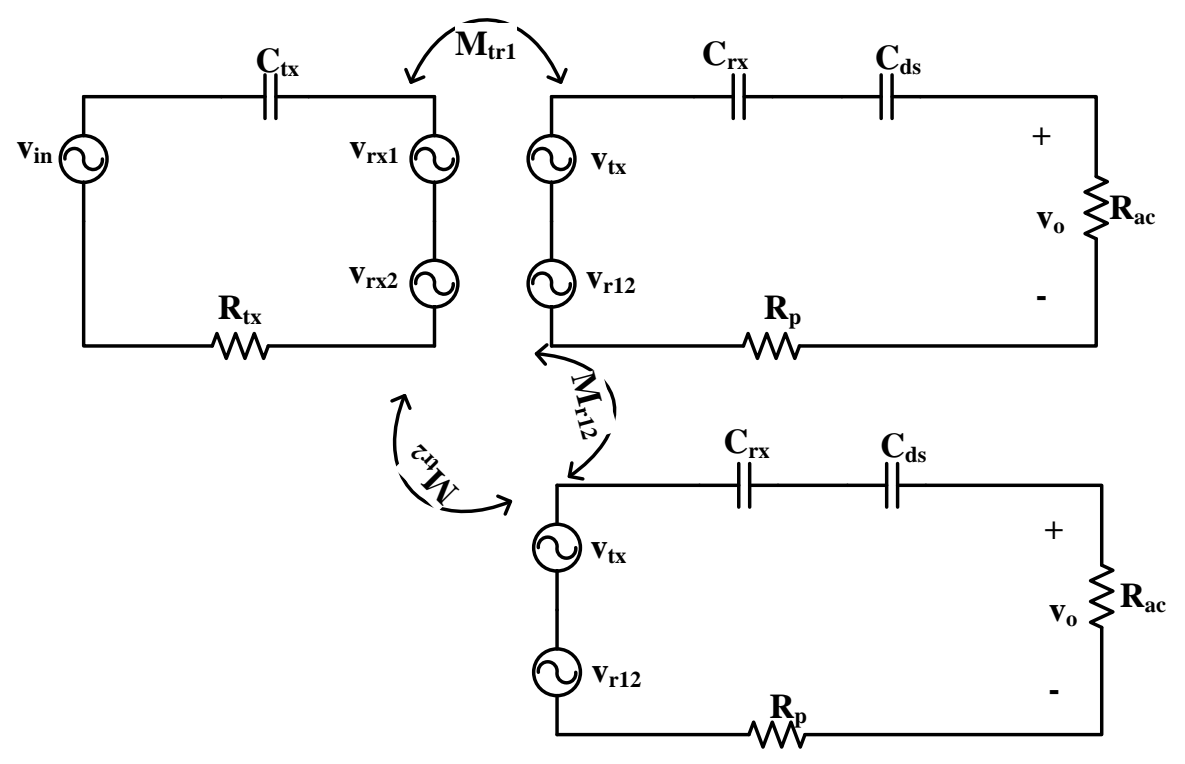

Figure 4.2: Equivalent circuit diagram of proposed WPT system when switch is off. 


\subsubsection{Transmitter Circuit}

The proposed WPT circuit diagram is shown in figure 4.1. The circuit description of the transmitter is same as described in section 3.1 of chapter three. It is necessary to continuously control the input power of the transmitter so that the WPT system can deliver the required power to the load when variation in coupling co-efficient occurs. In this thesis the variable frequency control method is applied at the transmitter based on the Perturb and Observe ( $\mathrm{P} \& \mathrm{O})$ algorithm. The algorithm is used to track the frequency at which the maximum input power occurs and then the selected frequency is applied to the inverter. The operating frequency is adjusted from $4.27 \mathrm{MHZ}$ to $5.11 \mathrm{MHZ}$ and the coupling coefficient is varied from 0.2 to 0.6 . The transmitter circuit to be embedded in a desk or table.

\section{Variable Frequency Control Algorithm}

The algorithm works in two modes; namely, the start-up mode and the MPPT mode. The system remains in the start-up mode for a predefined number of scan cycles. The system operating frequency $f_{o}$ is swept over a range of frequency $f_{o_{-} \min }$ to $f_{o_{-} \max }$ in order to search for the frequency at which the maximum input power occurs. This process is repeated multiple times to determine the initial frequency at which the converter operation should commence. This process helps to start the system at a frequency close to the one that provides maximum power input. Once this frequency is determined to a fair degree of confidence, the controller switches the mode of operation from the start process to MPPT mode.

In the MPPT mode of operation, the perturb and observe algorithm's direction of the next perturbation is determined based on the direction of the previous perturbation of the operating frequency and the direction of the previous increment in the power input 
$\left(P_{\text {in }}\right)$ of the WPT system. If the power input increases, the perturbation should be maintained in the same direction but if the power decreases, then the next perturbation should be in the reverse direction. This process is replicated until the maximum input power is detected. The flow chart of the algorithm is shown in figure 4.3

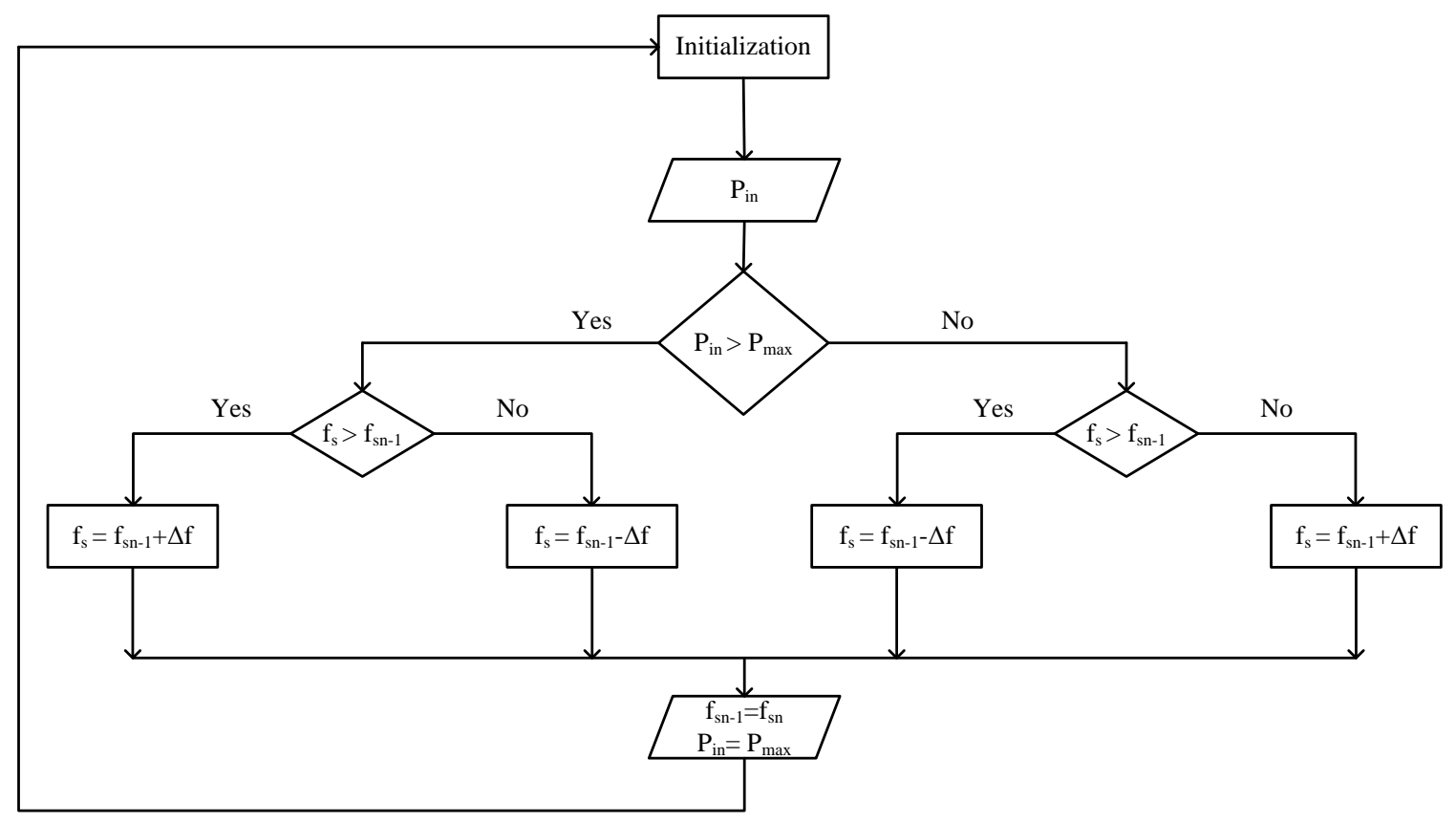

Figure 4.3: Flow chart of the proposed variable frequency algorithm

\subsubsection{Receiver Circuit}

In wireless power charging of mobile devices, it is required that the power requirements of the device are met in order to prevent damage. To satisfy this need a switch capacitor topology is proposed to regulate the output voltage of the WPT system. As shown in figure 4.1 the ac switch in the receivers consists of two back to back connected MOSFETs. The drain-source capacitance of the switch $C_{d s}$ serves as a switch-controlled capacitor. Hence, the ac switch shifts the resonant point in order to control the output 
voltage to meet the power requirements of the load. The switches are controlled using Pulse Width Modulation (PWM) technique.

In a bid to simplify the analysis of the circuit, the following assumption is made in addition to the assumptions made in section 3.2 of chapter 3 :

- The built-in drain-source capacitance of the switch is seen as a constant external capacitor across the ideal switch.

\section{Equivalent Resonance Frequency}

The equivalent circuit of the proposed topology can be developed by replacing the back to back connected MOSFETs and resonant capacitor with an equivalent capacitance depending on the state of the switches. When the switch is on, the equivalent circuit is same as figure 3.3 and the capacitance of the series resonant tank is $C_{r x}$. When the switch is off the equivalent circuit is shown in figure 4.2, the equivalent capacitance of the series resonant tank is a series combination of $C_{r x}$ and $C_{d s}$. Consequently, the ac switch adjusts the value of the series resonant capacitance over a switching cycle. The equivalent resonance capacitance is given by,

$C_{\text {total }}=C_{r x} \cdot d+\frac{C_{r x} \cdot C_{d s}}{C_{r x}+C_{d s}}(1-d)$

The steady state analysis of the circuit is same as the analysis in section 3.2 of chapter three. The only difference is that the resonance frequency of the receiver is given by,

$\omega_{\text {total }}=\frac{1}{\sqrt{L_{r x} C_{\text {total }}}}$ 
By switching the capacitors of the ac switch in and out of the receiver circuit, the equivalent capacitance of the receiver changes and consequently it's resonance frequency is adjusted to ensure that the voltage of the mobile device is keep constant. Equation (3.27) represents the output voltage of the WPT system.

Table 4.1: Circuit Component Value

\begin{tabular}{|c|c|c|c|}
\hline \multicolumn{2}{|c|}{ TRANSMITTER } & \multicolumn{2}{c|}{ RECEIVER(S) } \\
\hline COMPONENTS & VALUE & COMPONENTS & VALUE \\
\hline$L_{t x}$ & $7.8 \mu H$ & $\mathrm{~L}_{\mathrm{rx}}$ & $7.8 \mu \mathrm{H}$ \\
\hline$C_{t x}$ & $100 P F$ & $\mathrm{C}_{\mathrm{rx}}$ & $100 P F$ \\
\hline$R_{t x}$ & $3.4 \Omega$ & $f_{r}$ & $5.7 M H Z$ \\
\hline$f_{r}$ & $5.7 M H Z$ & $K_{12}$ & 0.0001 \\
\hline$K$ & $0.2-0.6$ & $R_{p}$ & $3.4 \Omega$ \\
\hline$V_{i n}$ & $100 V$ & $R_{L}$ & $2.5 \Omega$ \\
\hline & & $C_{o}$ & $50 \mu F$ \\
\hline & & $C_{d s}$ & $70 p F$ \\
\hline & & Transformer & $85 \mu H$ \\
\hline
\end{tabular}

\subsection{Simulation Results}

The proposed WPT system is simulated in PSIM based on the topology and control algorithm explained in section 4.1. The component values were selected based on previous work done in [49] and simulations carried out on MATLAB. The circuit parameters are shown in table 4.1. The circuit is simulated for coupling coefficients of 0.2 to 0.6 and the parameters are observed. As the coupling changes the algorithm automatically tracks the maximum input power. The circuit is simulated at full-load to $10 \%$ load conditions. 


\subsubsection{Full-load on Both Receivers}

The circuit was simulated at full-load condition for different values of coupling coefficient and the following simulation results were obtained.

Figure 4.4(a) shows the transmitter input current and voltage, it can be seen that ZVS is achieved. Figure 4.4 (b) and (c) show that the required dc output voltage of $5 \mathrm{~V}$ and output power of $10 \mathrm{~W}$ is achieved for $K_{t r 1}=0.25$ and $K_{t r 2}=0.3$. In this case the two receivers are far from the transmitter with almost similar coupling coefficients.

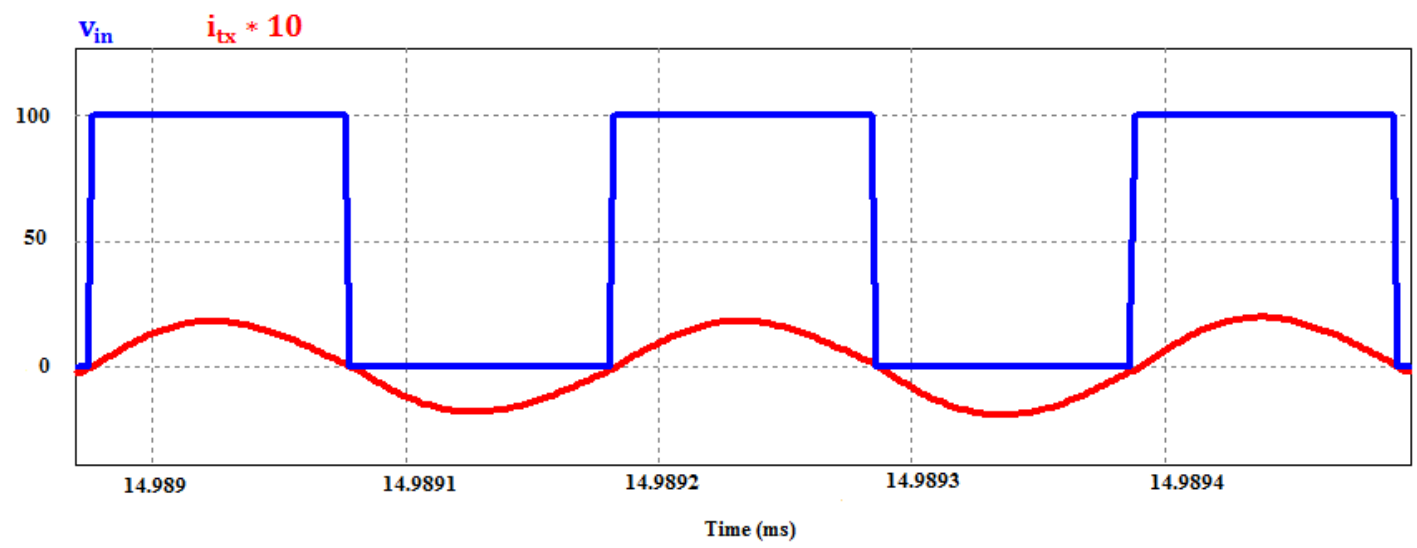

(a)

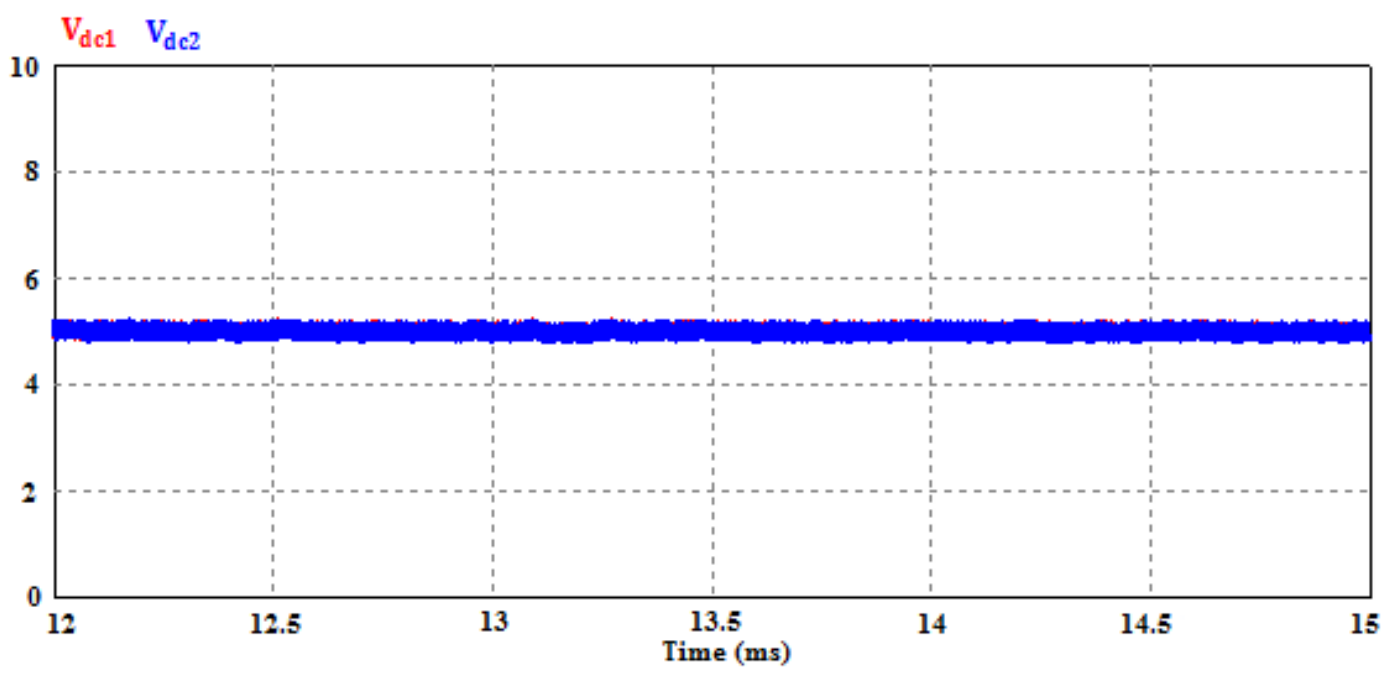

(b) 
OUTPUT POWER OF RX1 OUTPUT POWER OF RX2

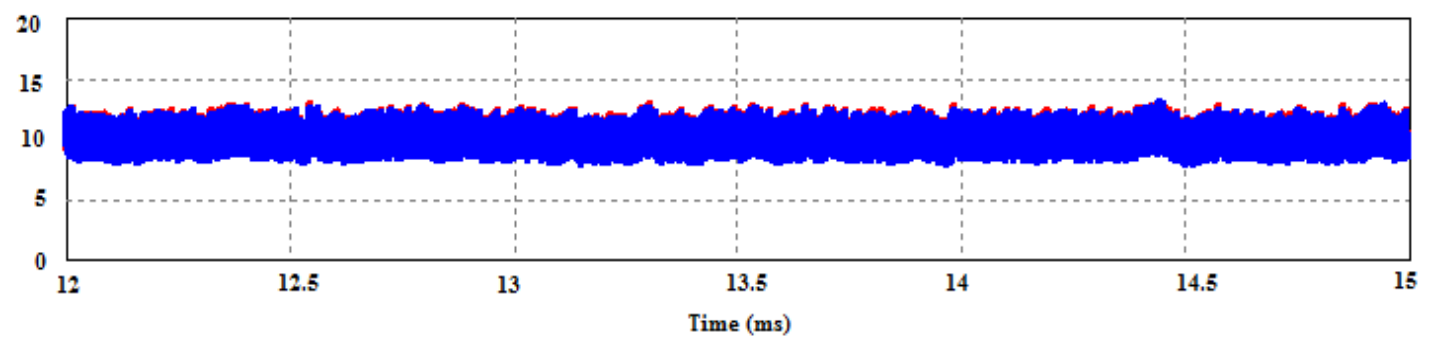

(c)

Figure 4.4: (a) Transmitter resonant tank input voltage and current, (b) dc output voltage and (c) Output power of the two receivers for $\mathbf{K}_{\operatorname{tr} 1}=0.25$ and $\mathbf{K}_{\mathbf{t r 2}}=0.3$.

In figure 4.5 the coupling coefficient between second receiver and the transmitter is twice the coupling coefficient between the first receiver and the transmitter. Figure 4.5(a) shows the transmitter input current and voltage, it can be seen that ZVS is achieved. The output power of receiver one is $9.4 \mathrm{~W}$, which is slightly less than the required output power of $10 \mathrm{~W}$ as shown in figure $4.5(\mathrm{c})$. This is as a result of the different coupling coefficients of the two receivers from the transmitter.

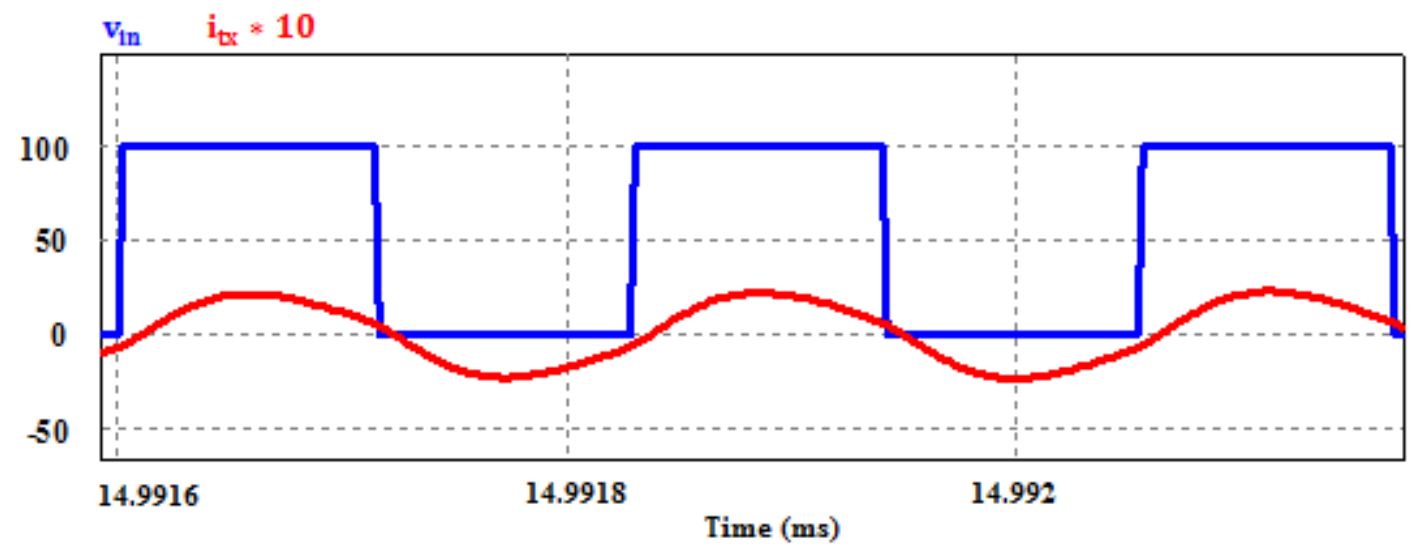

(a) 


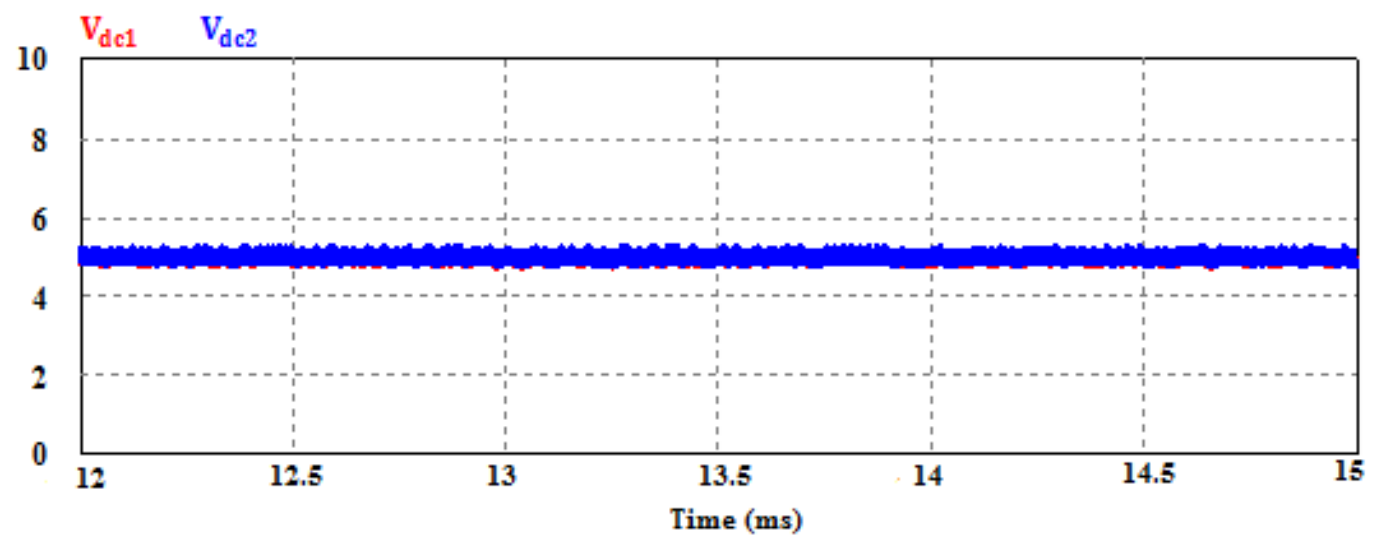

(b)

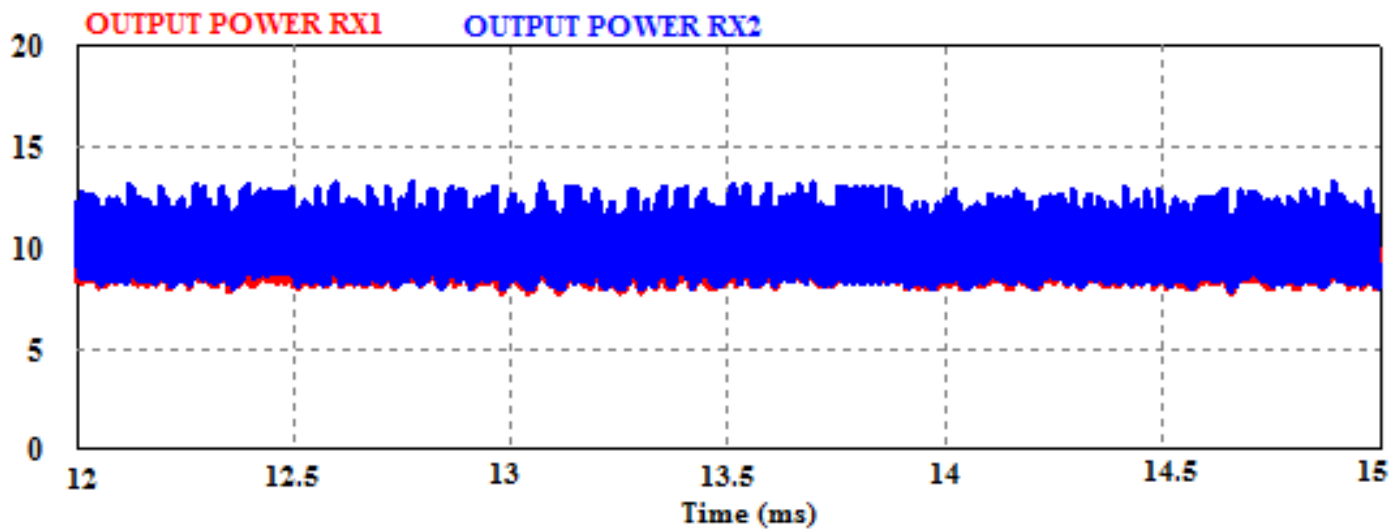

(c)

Figure 4.5: (a) Transmitter resonant tank input voltage and current, (b) dc output voltage and (c) Output power of the two receivers for $\mathbf{K}_{\operatorname{tr} 1}=0.3$ and $\mathbf{K}_{\operatorname{tr} 2}=0.6$.

Figure 4.6(a) shows the transmitter input current and voltage, it can be seen that ZVS is achieved. Figure 4.6(b) and (c) show that the required dc output voltage of 5V output power of $10 \mathrm{~W}$ is achieved for $K_{t r 1}=0.5$ and $K_{t r 2}=0.52$. In this case the two receivers are close to the transmitter with slightly different coupling coefficients. 


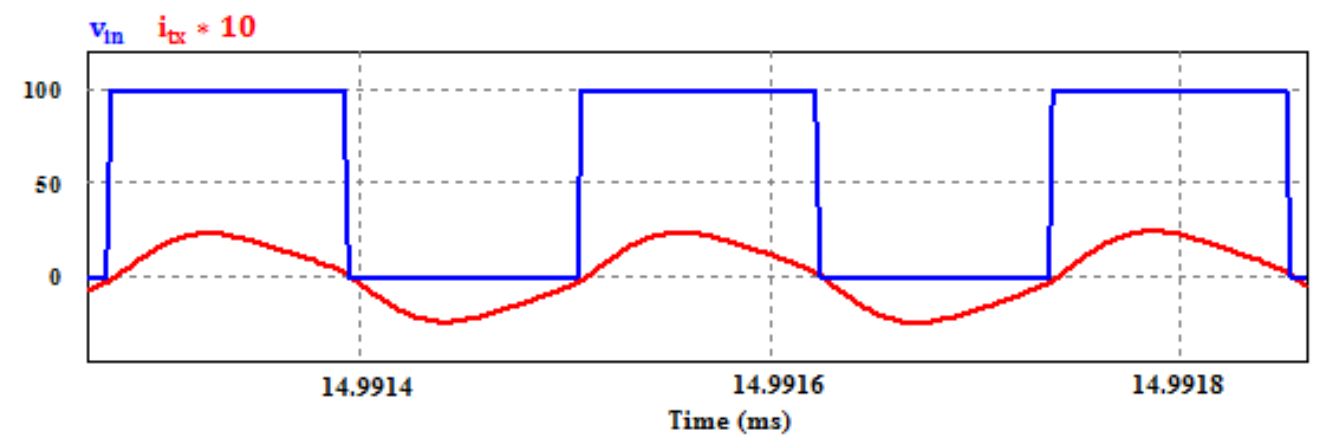

(a)

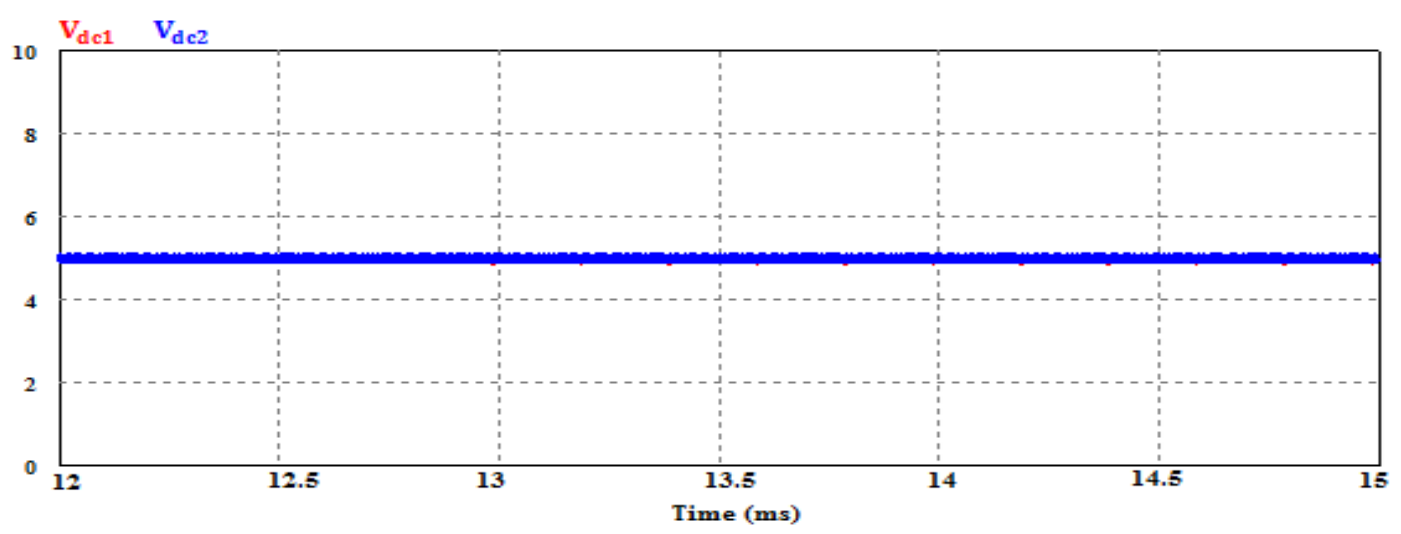

(b)

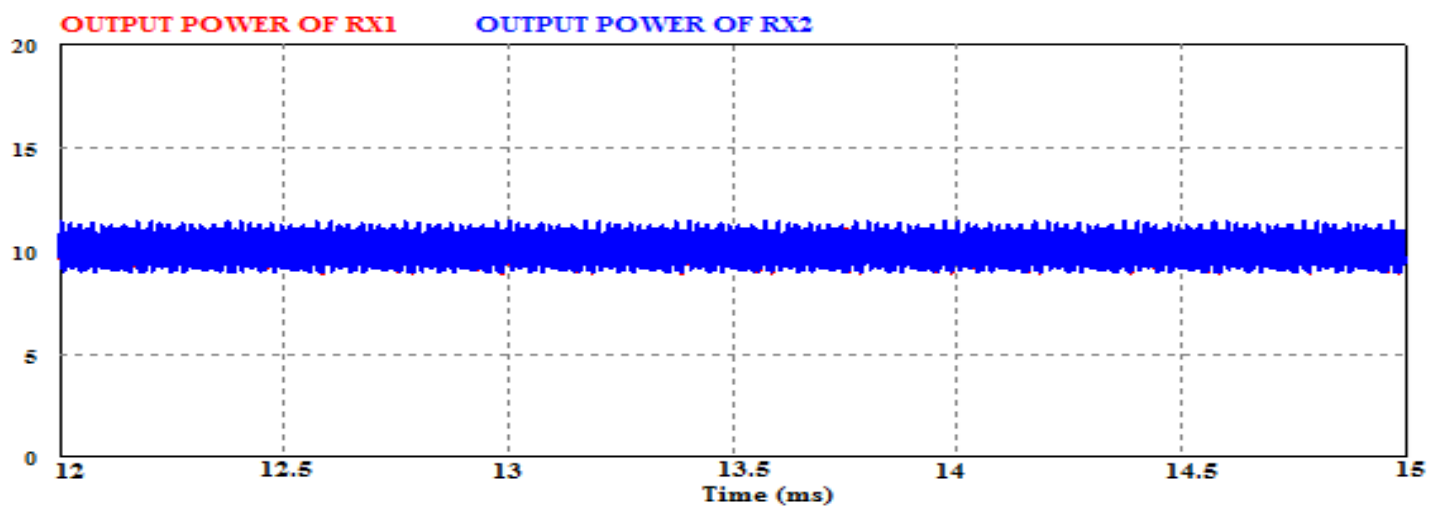

(c)

Figure 4.6: (a) Transmitter resonant tank input voltage and current, (b) dc output voltage and (c) Output power of the two receivers for $\mathbf{K}_{\operatorname{tr} 1}=0.5$ and $\mathbf{K}_{\mathbf{t r 2}}=0.52$.

Figure 4.7(a) shows the transmitter input current and voltage, it can be seen that ZVS is achieved in this case as well. Figure 4.7 (b) show that the dc output of $5 \mathrm{~V}$ was only 
maintained in the second receiver. The first receiver has a dc output voltage of $4.8 \mathrm{~V}$. The WPT system in this case can only deliver $83 \%$ of the required total output power as shown in figure $4.7(\mathrm{c})$. This is as a result of the significant difference in coupling coefficients of the two receivers from the transmitter. The coupling coefficient between second receiver and the transmitter is thrice the coupling coefficient between the first receiver and the transmitter.

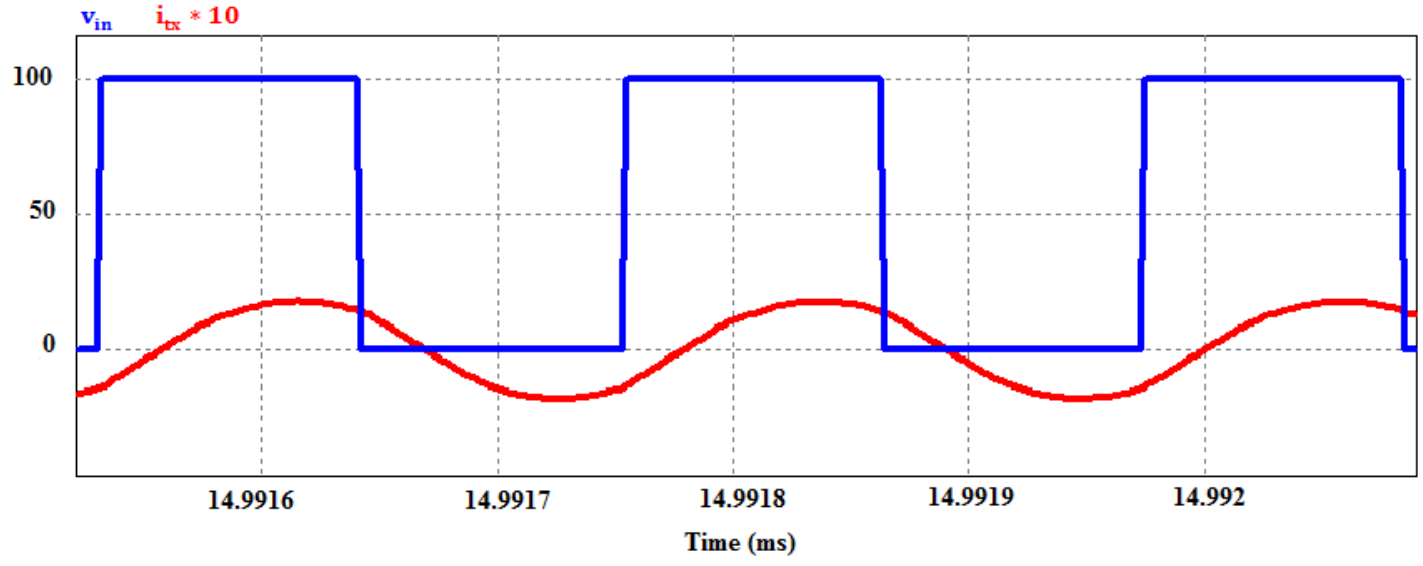

(a)

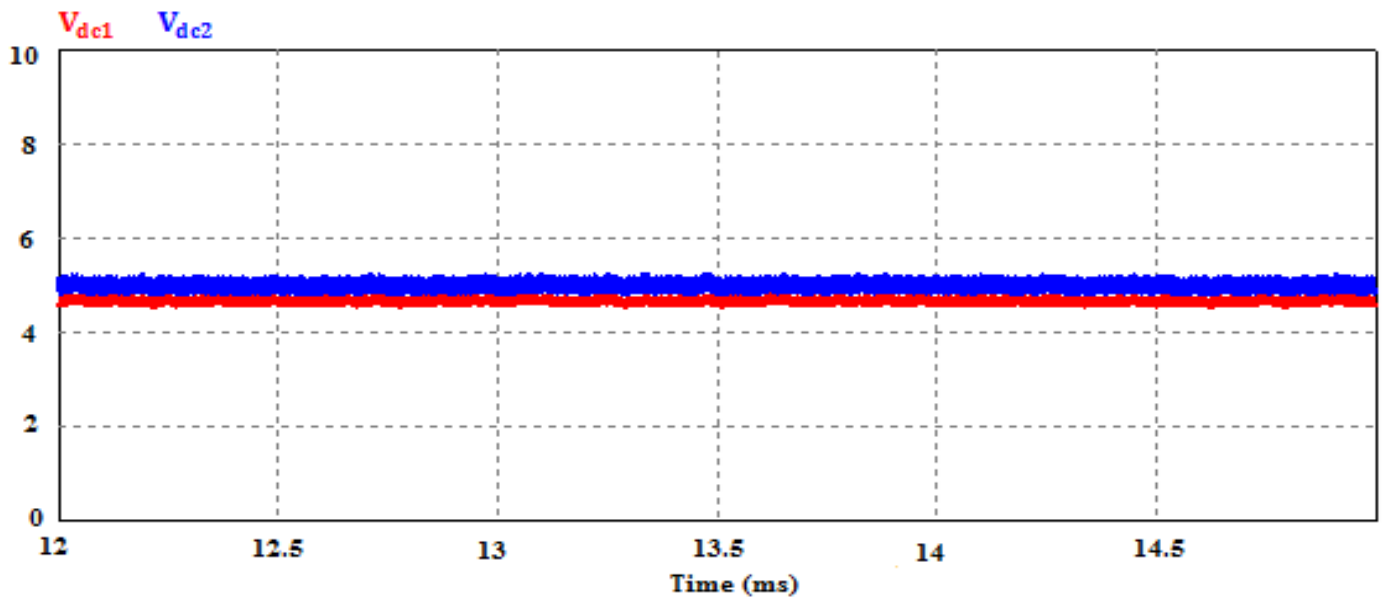

(b) 


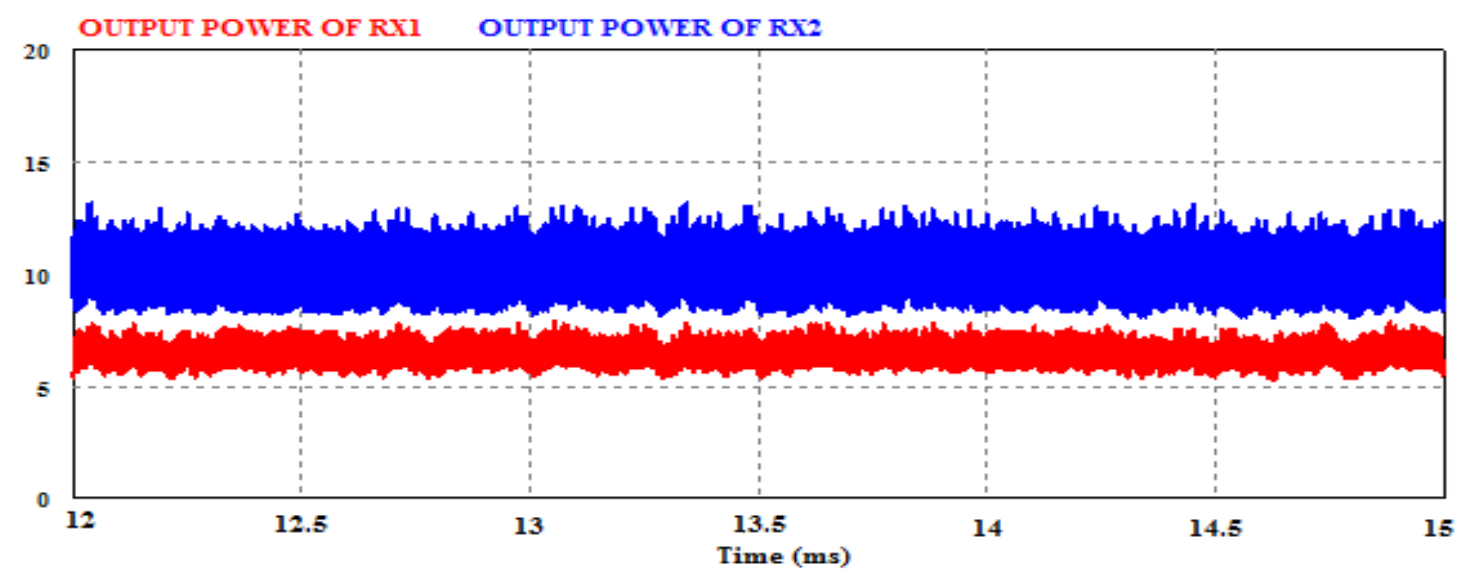

(c)

Figure 4.7: (a) Transmitter resonant tank input voltage and current, (b) dc output voltage and (c) Output power of the two receivers for $\mathbf{K}_{\mathbf{t r} \mathbf{1}}=0.2$ and $\mathbf{K}_{\mathbf{t r} 2}=0.6$.

Figure 4.8 shows a graphical representation of the output power variation for different combinations of coupling coefficients between the transmitter and the receivers. It can be observed that the two receiver WPT system is capable of delivering full power when the coupling coefficients of the transmitter to the receivers are similar but in cases where the coupling coefficients of the individual receivers to the transmitter differ significantly $\left(K_{t r 1}=0.2\right.$ and $\left.K_{t r 2}=0.6\right)$, the system is able to deliver only $83 \%$ of the required total output power. 


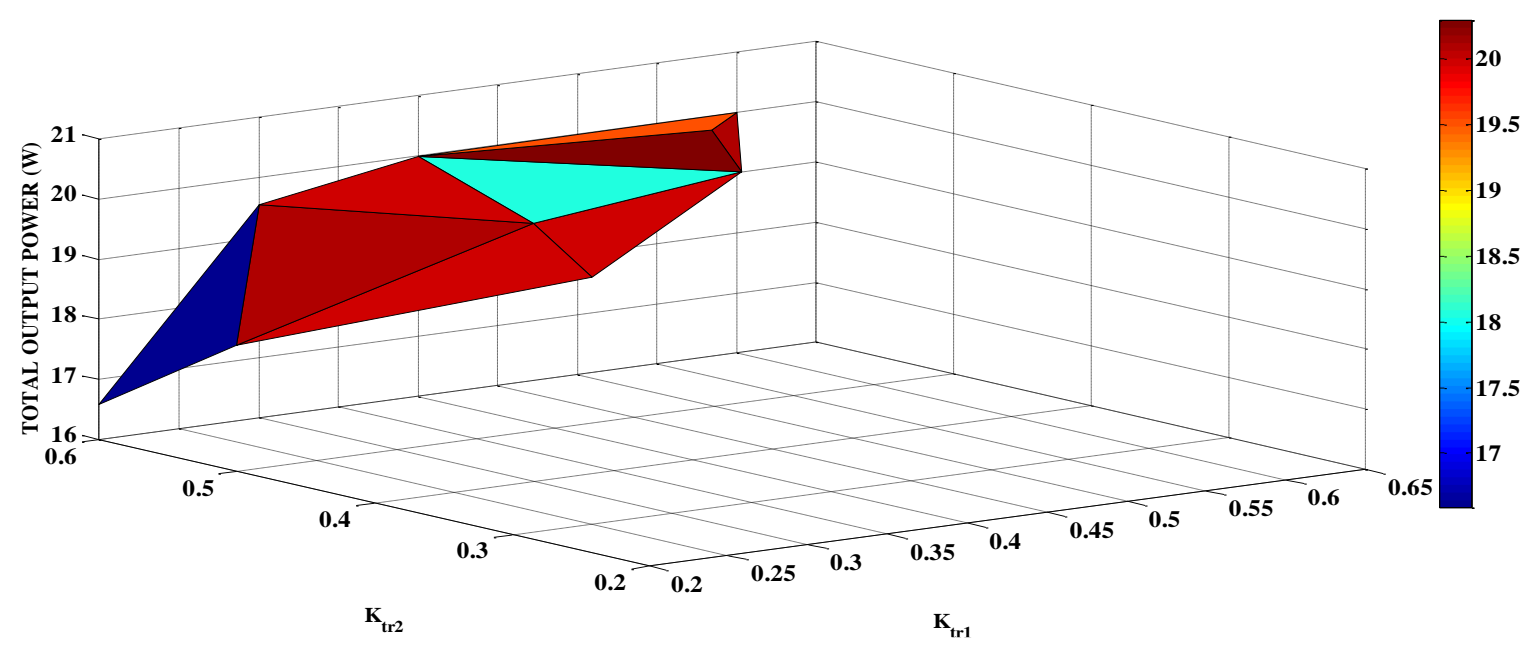

Figure 4.8: Total output power with variation in coupling coefficient

\subsubsection{Full-load on Receiver 1 and $10 \%$ load on Receiver 2}

The receiver WPT system is studied when the first receiver has full-load and the second receiver has $10 \%$ load. In this case, ZVS is lost as shown in figure 4.9(a). This is as a result of the load variation which changes the frequency characteristic of the system. The WPT system is able to maintain a $5 \mathrm{~V}$ dc output voltage and deliver $10 \mathrm{~W}$ to the first receiver as shown in figure $4.9(\mathrm{~b})$ and (c).

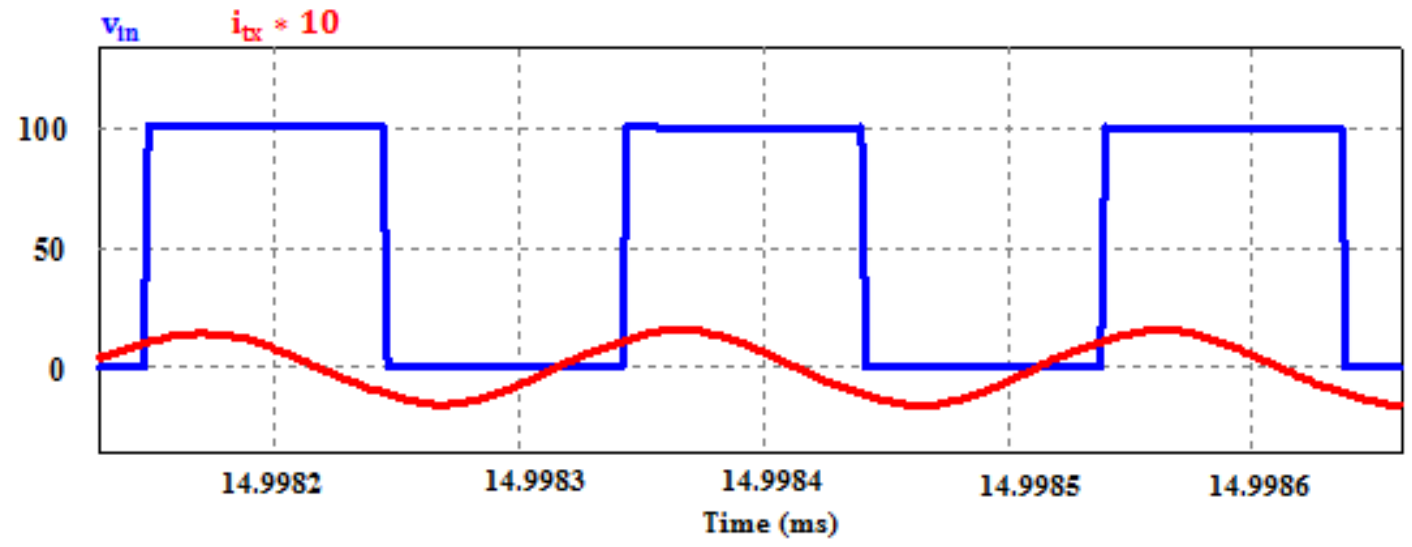

(a) 


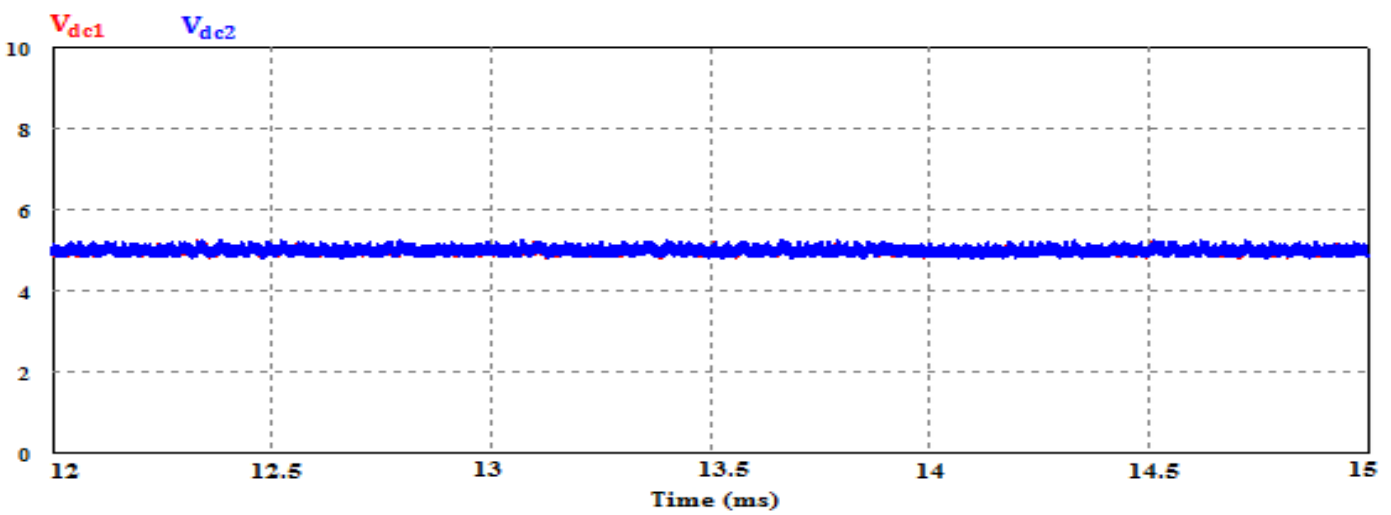

(b)

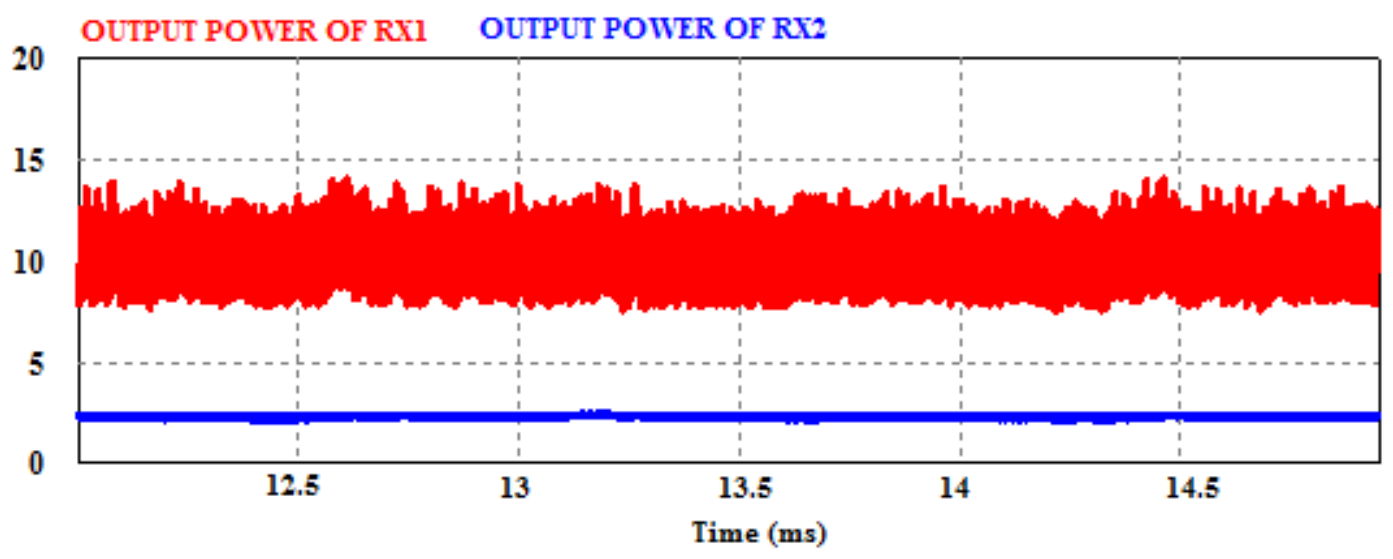

(c)

Figure 4.9: (a) Transmitter resonant tank input voltage and current, (b) dc output voltage and (c) Output power of the two receivers for $\boldsymbol{K}_{\boldsymbol{t r} \mathbf{1}}=0.2$ and $\boldsymbol{K}_{\boldsymbol{t r} \mathbf{2}}=0.3$.

\subsubsection{0\% load on Both Receivers}

Under $10 \%$ load condition, ZVS is lost as shown in figure 4.9 (a) as a result of the load variation but a constant dc output voltage of $5 \mathrm{~V}$ is maintained as shown in figure 4.9(b). 


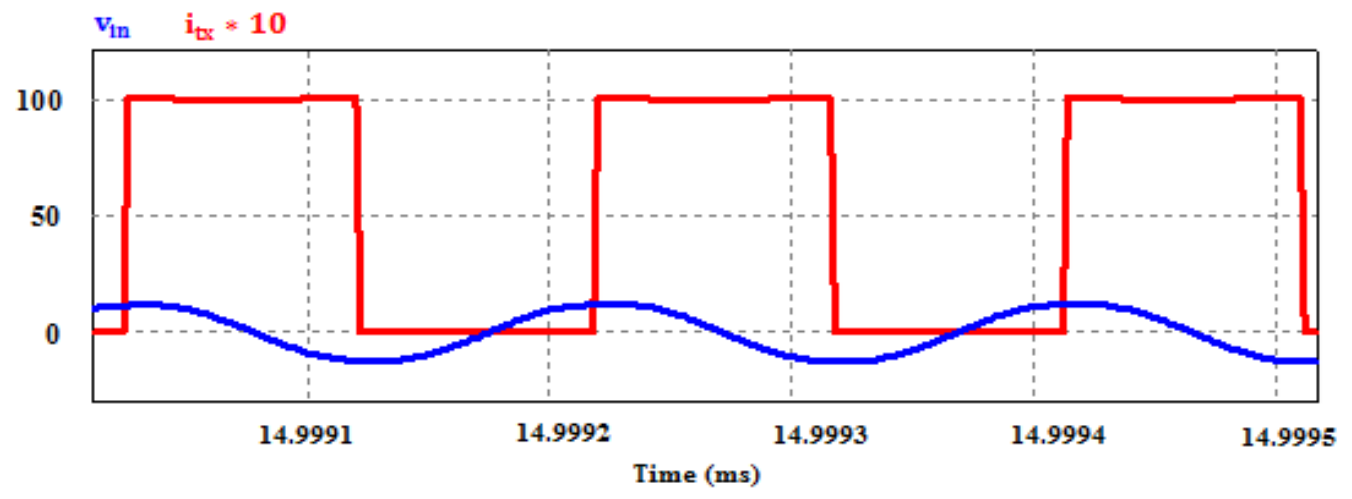

(a)

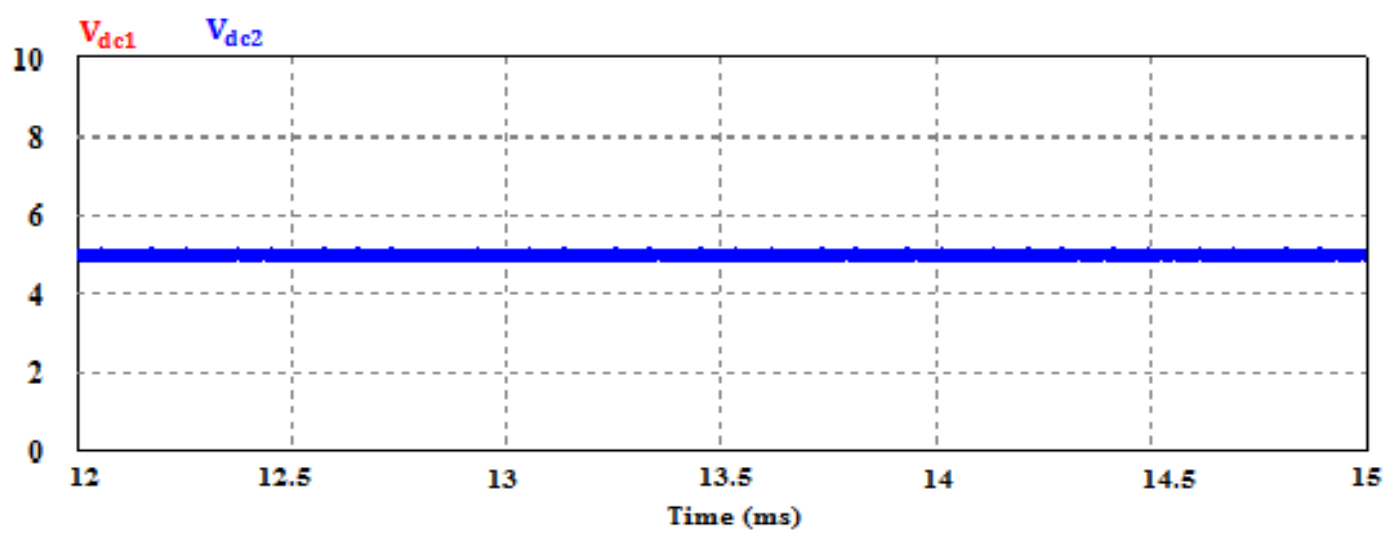

(b)

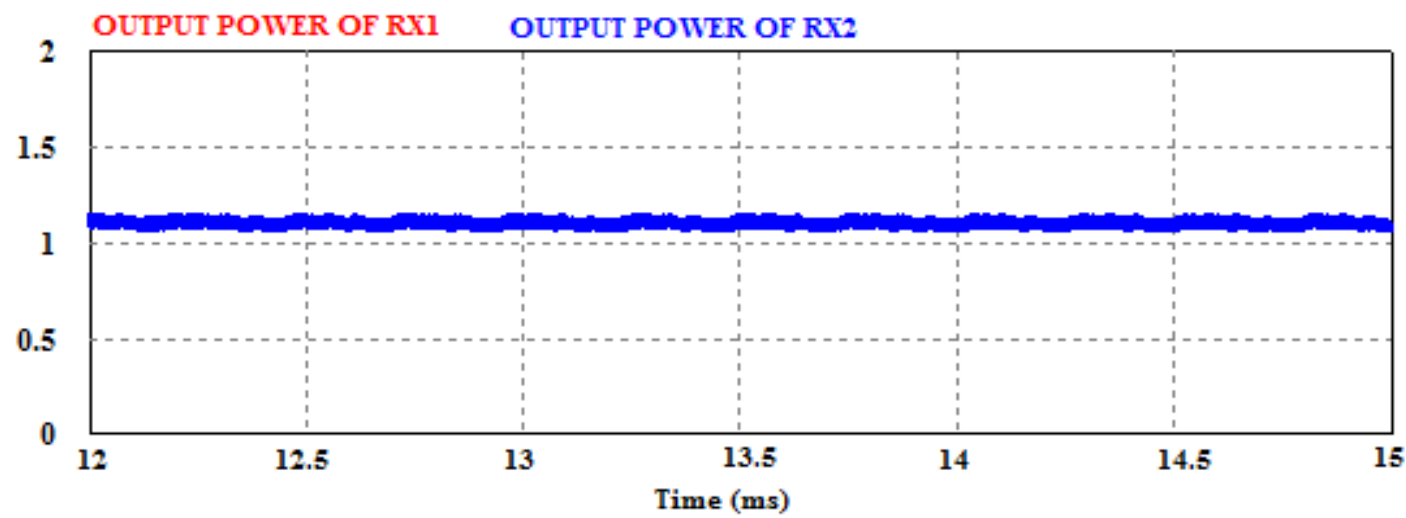

(c)

Figure 4.10:(a) Transmitter resonant tank input voltage and current, (b) dc output voltage and (c) Output power of the two receivers for $\mathbf{K}_{\operatorname{tr} \mathbf{1}}=\mathbf{K}_{\mathbf{t r 2}}=0.2$. 
Table 4.2 shows the total system efficiency of the multiple receiver WPT system with variation of load and coupling coefficient. It can be deduced that the total system efficiency is higher when the receivers have full-load and have almost equal coupling coefficient from the transmitter

Table 4.2: Total system efficiency

\begin{tabular}{|c|c|c|}
\hline \multicolumn{2}{|c|}{ System condition } & Total System Efficiency (\%) \\
\hline Load & Coupling coefficient & \\
\hline $\begin{array}{c}\text { Full-load on both } \\
\text { receivers }\end{array}$ & $\mathrm{K}_{\mathrm{tr} 1}=0.25, \mathrm{~K}_{\mathrm{tr} 2}=0.3$ & 79.4 \\
\cline { 2 - 2 } & $\mathrm{K}_{\mathrm{tr} 1}=0.3, \mathrm{~K}_{\mathrm{tr} 2}=0.6$ & 68.0 \\
\cline { 2 - 2 } & $\mathrm{K}_{\mathrm{tr} 1}=0.5, \mathrm{~K}_{\mathrm{tr} 2}=0.52$ & 84.0 \\
\cline { 2 - 2 } & $\mathrm{K}_{\mathrm{tr} 1}=0.2, \mathrm{~K}_{\mathrm{tr} 2}=0.6$ & 67.0 \\
\hline $\begin{array}{c}\text { Full-load on } \mathrm{Rx} 1 \text { and } \\
10 \% \text { load on } \mathrm{Rx} 2\end{array}$ & $\mathrm{~K}_{\mathrm{tr} 1}=0.2, \mathrm{~K}_{\mathrm{tr} 2}=0.3$ & 51.0 \\
\hline $\begin{array}{c}10 \% \text { load on both } \\
\text { receivers }\end{array}$ & $\mathrm{K}_{\mathrm{tr} 1}=0.2, \mathrm{~K}_{\mathrm{tr} 2}=0.2$ & 40.0 \\
\hline
\end{tabular}

In all the cases examined above it can be seen that despite the use of the variable frequency control algorithm and the switched capacitor topology in the multiple receiver WPT system, extreme variations in the coupling coefficient and load of the two receivers affects the total output power and efficiency of the system. This is because the variable frequency control algorithm tracks the maximum input power of the two receiver system and not the individual maximum input power for each receiver.

\subsection{Summary}

In this chapter the proposed WPT system is verified using the PSIM software and simulation results presented. The circuit was simulated for different combinations of coupling coefficient for both receivers as well as load variations from full-load to $10 \%$ load 
conditions. The circuit is able to deliver $100 \%$ of the required output power when the coupling coefficient between the transmitter and the receivers are similar and $83 \%$ of the required total output power when the coupling coefficient vary significantly with good voltage regulation. ZVS is achieved in all conditions except when one or both receivers are at $10 \%$ load. 


\section{Chapter 5}

\section{Conclusion}

\subsection{Summary}

Recently, research in WPT has been carried out as a result of the recent growth in the production of portable mobile devices, the inconvenience associated with the need to frequently charge the devices due to the limited storage capacity of the batteries and the quest for a greener earth. The performance of WPT systems can be adversely affected by change in coupling coefficient and load.

This thesis has presented the use of switch capacitors and variable frequency control algorithm to ensure that the power requirements of the mobile phones in a multiple receiver WPT system are met without a need for extra communication module between the transmitter and the mobile phones. A mathematical analysis of the WPT system is carried out and simulated using MATLAB and PSIM. The variable frequency control algorithm is used because the resonant frequency of the circuit changes with variation coupling coefficient. Also, ac switch capacitors are used to regulate the voltage delivered to the load.

The proposed system is simulated using PSIM and the results are presented for different values of coupling coefficient and load conditions. The simulation results confirm that the proposed topology is able to deliver the required power to multiple mobile phones in presence of system constraints with a good voltage regulation without any communication module.

\subsection{Thesis Contribution}

The main contributions of this thesis are as follows: 
- A new topology is developed to control the output voltage of the multiple receiver WPT system to meet the power requirements of the load without any communication link between the transmitter and the receivers.

- A WPT system is able to operate over a wide range of coupling coefficient using a variable frequency control algorithm to track the maximum input power.

\subsection{Future Works}

WPT is an emerging aspect of power electronics and so there are opportunities for improving the performance of the system. The following are possible areas for future work:

- The power transfer distance can be increased by modifying the transmitter circuit using a single power loop to drive an array of transmitter coils. This approach will help improve the magnetic field strength which will consequently increase the coverage area of the WPT system.

- A more robust control can be designed to cater for extreme load and coupling coefficient conditions.

- The transfer distance can be improved by optimal placement of relay resonators between the transmitter and receivers.

- Practical implementation of the proposed system could be done to validate the simulation results presented in this thesis. 


\section{References}

[1] “Tesla Biography, Tesla Memorial society New York,” [Online]. Available: http://www.teslasociety.com/biography.htm. [Accessed 16 November, 2016.]

[2] Wenxing Zhong, S.Y.R. Hui. "Maximum Energy Efficiency Tracking for Wireless Power Transfer System”. IEEE Trans. on Power Electron., vol. 30, no. 7, pp. 40254034, Jul. 2015.

[3] A. Kurs, A. Karalis, R. Moffatt, J. D. Joannopoulos, P. Fisher, and M. Soljacic, "Wireless power transfer via strongly coupled magnetic resonances," Science, vol. 317, no. 5834, pp. 83-86, Jul. 2007.

[4] J. Garnica, R. A. Chinga, and J. Lin, "Wireless power transmission: From far field to near field,” Proc. IEEE, vol. 101, no. 6, pp. 1321-1331, Jun. 2013.

[5] Minfan Fu, He Yin, Xinen Zhu. "Analysis and Tracking of Optimal Load in Wireless Power Transfer Systems”. IEEE Trans. on Power Electron., vol. 30, no. 7, pp.3952-3963, Jul. 2015.

[6] Alanson P. Sample, David A. Meyer and Joshua R. Smith. "Analysis, experimental results and range adaptation of magnetically coupled resonators for wireless power transfer". IEEE Trans. on Ind. Electron., vol. 58, no. 2, pp.544-554, Feb. 2011.

[7] Dukju Ahn and Songcheol Hong. "Effect of coupling between multiple transmitter and multiple receiver". IEEE Trans. on Ind. Electron., vol. 60, no. 7, pp.2602-2613 Jul. 2013. 
[8] W. Zhong, C. K. Lee, and S. Y. R. Hui, “'General analysis on the use of Tesla's resonators in domino forms for wireless power transfer," IEEE Trans. Ind. Electron., vol. 60, no. 1, pp. 261-270, Jan. 2013

[9] P. Si, A. P. Hu, S. Malpas, and D. Budgett, "A frequency control method for regulating wireless power to implantable devices," IEEE Trans. Biomed. Circuits Syst., vol. 2, no. 1, pp. 22-29, Mar. 2008.

[10] C. K. Lee, W. X. Zhong, and S. Y. R. Hui, "Effects of magnetic coupling of nonadjacent resonators on wireless power domino-resonator systems," IEEE Trans. Power Electron., vol. 27, no. 4, pp.1905-1916, Apr. 2012.

[11] A. Kurs, "Power transfer through strongly coupled resonance", MSC thesis, Massachusetts Institute of Technology, 2007.

[12] X. Wei, Z. Wang, and H. Dai, "A critical review of wireless power transfer via strongly coupled magnetic resonances," Energies, vol. 7, no. 7, pp. 4316-4341, Jul. 2014.

[13] M. Fu, C. Ma, and X. Zhu, “A cascaded boost-buck converter for high efficiency wireless power transfer systems," IEEE Trans. Ind. Informat., vol. 10, no. 3, pp. 1972-1980, Aug. 2014.

[14] S. D. Barman , A. W. Reza , N. Kumar , M. E. Karim and A. B. Munir. "Wireless powering by magnetic resonant coupling: Recent $t$ rends in wireless power transfer system and its applications," Renewable and Sustainable Energy Reviews, vol. 51, pp. 1525-1552, Jul. 2015. 
[15] C. S. Wang, G. A. Covic, and O. H. Stielau, "Power transfer capability and bifurcation phenomena of loosely coupled inductive power transfer systems," IEEE Trans. Ind. Electron., Vol. 51, No. 1, pp. 148-157, Feb. 2004.

[16] Xiao L., Ping W., Dusit N., Dong K., and Zhu H., "Wireless charging technologies: fundamentals, standards, and network applications" IEEE Communications Surveys \& Tutorials, vol. 18, no. 2, pp. 1413-52, Second Quarter 2016.

[17] S. Li and C. Mi, "Wireless power transfer for electric vehicle applications," IEEE J. Emerg. Sel. Topics Power Electron., vol. 3, no. 1, pp. 4-17, Mar. 2015.

[18] Aiguo P., "Selected resonant converters for IPT power supplies", Ph.d thesis, University of Auckland, 2001.

[19] Hongchang Li, Jie Li, Kangping Wang, Wenjie Chen, and Xu Yang. "A maximum efficiency point tracking control scheme for wireless power transfer systems using magnetic resonant coupling”. IEEE Transactions on Power Electron., vol. 30, no. 7, pp.3998-4008, Jul. 2015.

[20] M. H. Ryu, H. Cha, Y. H. Park, and J. W. Back, "Analysis of the contactless power transfer system using modeling and analysis of the former," Proc. IEEE Ind. Electron. Soc., pp. 1036-1042, 2005.

[21] B. L. Cannon, J. F. Hoburg, D. D. Stancil, and S. C. Goldstein, "Magnetic resonant coupling as a potential means for wireless power transfer to multiple small receivers," IEEE Trans. on Power Electron., vol. 24, no. 7, pp.1819-1825, July 2009. 
[22] L. Nan and W. Bingnan, "An LLC-based planar wireless power transfer system for multiple devices," in Proc. IEEE 29th Annu. Appl. Power Electron. Conf. Expo., 2014, pp. 3411-3417.

[23] N. Kim, K. Kim, J. Choi, and C.-W. Kim, "Adaptive frequency with power-level tracking system for efficient magnetic resonance wireless power transfer," Electron. Lett., vol. 48, no. 8, pp. 452-454, Apr. 2012.

[24] J.Choi, Y. Ryu, D. Kim, N. Kim, C. Yoon, Y. Park, S. Kwon, and Y. Yang, "Design of high efficiency wireless charging pad based on magnetic resonance coupling," in Proc. 42nd European Microwave Conference, pp.916-919, Nov. 2012.

[25] Teck Chuan Beh, Masaki Kato, Takehiro Imura, Sehoon Oh, and Yoichi Hori. “Automated Impedance Matching System for Robust Wireless Power Transfer via Magnetic Resonance Coupling”. IEEE Transactions on Industrial Electronics, vol. 60, no. 9, pp.3689-3698, September 2013.

[26] S. Rajagopal, F. Khan, "Multiple receiver support for magnetic resonance based wireless charging,” IEEE Int. Conf. on Communications Workshops (ICC), pp. 15, Jun. 2011.

[27] Jinwook Kim, Do-Hyeon Kim, and Young-Jin Park. "Analysis of capacitive impedance matching networks for simultaneous wireless power transfer to multiple devices" IEEE Transactions on Ind. Electron., vol. 62, no. 5, pp.2807-2813, May 2015.

[28] Zhen Ning Low, Raul Andres Chinga, Ryan Tseng, and Jenshan Lin, "Design and test of a high-power high-efficiency loosely coupled planar wireless power Transfer system”. IEEE Trans. on Ind. Electron., vol. 56, no. 5, pp.1801-1812, May 2009. 
[29] A. Ong et al., "Analysis of impedance matched circuit for wireless power transfer," in Proc. IEEE 40th Ind. Electron. Conf. (IECON'14), Dallas, TX, USA, Oct./Nov. 2014, pp. 2965-2970.

[30] T. C. Beh, T. Imura, M. Kato, and Y. Hori, "Basic study of improving efficiency of wireless power transfer via magnetic resonance coupling based on impedance matching,” in Proc. IEEE ISIE, Jul. 4-7, 2010, pp. 2011-2016.

[31] T. Imura and H. Yoichi, "Optimization using transmitting circuit of multiple receiving antennas for wireless power transfer via magnetic resonance coupling," in Proc. 33rd IEEE INTELEC, 2011, pp. 1-4.

[32] Minfan Fu, Tong Zang, Chengbin Ma, Xinene Zhu. "Efficiency and optimal load analysis or multiple receiver wireless power transfer systems" IEEE Trans. on Microwave Theory and Techniques, vol. 63, no. 3, pp.801-812, March 2015.

[33] Huy H., Seunggyu L., Youngsu K., Yunho C.and Franklin B., “An adaptive technique to improve wireless power transfer for consumer electronics," IEEE Transaction on Consumer Electron., vol. 58, no. 2, pp.327-32, June 2012.

[34] Thuc Phi Duong and Jong-Wook Lee, "Experimental results of high-efficiency resonant coupling wireless power transfer using a variable coupling method" IEEE Microwave and Wireless Components Letters, vol. 21, no. 8, pp.442-444, Aug. 2011.

[35] HatefDabbaghian M., Sina A.D., Ali P. and AsIan N., "Wireless energy transfer efficiency enhancement for mobile receiver devices," IEEE Telecommunications Energy Conference, Oct. 2011. 
[36] Kim J, Choi WS, Jeong J. "Loop switching technique for wireless power transfer using magnetic resonance coupling”. Progr. Electromagn. Res., vol. 138, pp. 197209, 2013.

[37] Mizuno T, Yachi S, Kamiya A, Yamamoto D. "Improvement in efficiency of wireless power transfer of magnetic resonant coupling using magneto plated wire. IEEE Trans. Magn., Vol. 47, No. 10, pp. 4445-8, Oct. 2011.

[38] S. H. Lee and R. D. Lorenz, "Development and validation of model for 95\% efficiency $220 \mathrm{~W}$ wireless power transfer over a 30-cm air gap," IEEE Trans. Ind. Appl., vol. 47, no. 6, pp. 2495-2504, Nov./Dec. 2011.

[39] Kiani M, Jow UM, Ghovanloo M. "Design and optimization of a 3-coil inductive link for efficient wireless power transmission," IEEE Transaction Biomedical Circuits Systems. vol. 58, no.6, pp. 579-91, Dec. 2011.

[40] Zhang F, Hackworth SA, Fu W, Li C, Mao Z, Sun M. "Relay effect of wireless power transfer using strongly coupled magnetic resonances," IEEE Transaction on Magnetic vol. 47, no.5, pp. 1478-81, May 2011.

[41] Kim J, Son HC, Kim KH, Park YJ. "Efficiency analysis of magnetic resonance wireless power transfer with intermediate resonant coil," IEEE Antennas and Wireless Propagation Letters. vol. 10, pp. 389-92, 2011.

[42] Kittisak P., Titipong L., Chuwong P. "Study of a repeater transmitting antenna concept of a portable device wireless battery charging system," In: IEEE AsiaPacific Conference on Communications (APCC). pp.442-5, October 2014.

[43] Kutkut NH, Klontz KW. "Design considerations for power converters supplying the SAE J-1773 electric vehicle inductive coupler," In: Proceedings of the twelfth 
annual Applied Power Electronics Conference and Exposition (APEC), vol. 2;1997. pp.841-7.

[44] N. Oodachi, K. Ogawa, H. Kudo, H. Shoki, S. Obayashi, and T. Morooka, "Efficiency improvement of wireless power transfer via magnetic resonance using transmission coil array,” in Proc. IEEE APSURSI, 2011, pp. 1707-1710.

[45] S. A. Mirbozorgi, M. Sawan, and B. Gosselin, "Multicoil resonance-based parallel array for smart wireless power delivery,” in Proc. IEEE EMBC, Jul. 2013, pp. 751754.

[46] Farid J., Yi-qiang Y. and Zhizhang C., "Electromagnetic modeling and optimization of magnetic resonant coupling wireless power transfer using coil array," In: Proceedings of the 2015 IEEE MTT-S International Conference on Numerical Electromagnetic and Multiphysics Modelling and Optimization (NEMO), Aug. 2015, pp. 1-3.

[47] S.Y.R.Hui, Wenxing Zhang, C.K.Lee, "A critical review of recent progress in mid-range wireless power transfer", IEEE Transactions On Power Electronics, vol. 24, no. 9, pp.4500-4511, Sept. 2014.

[48] L. Olvitz, D. Vinko and T. Švedek."Wireless power transfer for mobile phone charging device" in Proc. $35^{\text {th }}$ MIPRO International convention, pp.141-45, May 2012.

[49] J. A. Taylor, Z. N. Low, J. Casanova, and J. Lin, “A wireless power station for laptop computers,” in Proc. IEEE Radio Wireless Symp., 2010, pp. 625-628. 